Portland State University

PDXScholar

Summer 8-5-2015

\title{
The Influence of Surface Chemistry on the Photoelectrochemical Properties of FeS(2) Photoanodes
}

Qi Tong

Portland State University

Follow this and additional works at: https://pdxscholar.library.pdx.edu/open_access_etds

Part of the Chemistry Commons

Let us know how access to this document benefits you.

Recommended Citation

Tong, Qi, "The Influence of Surface Chemistry on the Photoelectrochemical Properties of FeS(2)

Photoanodes" (2015). Dissertations and Theses. Paper 2482.

https://doi.org/10.15760/etd.2479

This Dissertation is brought to you for free and open access. It has been accepted for inclusion in Dissertations and Theses by an authorized administrator of PDXScholar. Please contact us if we can make this document more accessible: pdxscholar@pdx.edu. 
The Influence of Surface Chemistry on the Photoelectrochemical Properties of $\mathrm{FeS}_{2}$

\title{
Photoanodes
}

\author{
by \\ Qi Tong
}

A dissertation submitted in partial fulfillment of the

Requirements for the degree of

\author{
Doctor of Philosophy \\ in \\ Chemistry
}
Dissertation Committee:
Erik Johansson, Chair
Andrea Goforth
Dean Atkinson
Erik Sanchez

\section{Portland State University}

2015 
C 2015 Qi Tong 


\begin{abstract}
The recurring theme of this dissertation is the correlation between $\mathrm{FeS}_{2}$ surface chemistry and key electrical and electronic properties of $\mathrm{FeS}_{2}$. Efforts have been made to identify and characterize the $\mathrm{FeS}_{2}$ surface, investigate the photoelectrochemistry of $\mathrm{FeS}_{2}$ photoanodes under anhydrous and anoxic conditions, and investigate the influence of deliberate surface chemistry on $\mathrm{FeS}_{2}$ photoelectrochemistry.

Infrared reflection-absorption spectroscopy (IRRAS) was used to investigate a thin adsorbate layer on pyrite. The results showed that the combination of angledependent studies and computational efforts are a powerful tool for characterizing the pyrite surface.

The photoelectrochemistry of $\mathrm{FeS}_{2}$ photoanodes was investigated in an $\mathrm{I}^{-} / \mathrm{I}_{3}^{-}$ acetonitrile electrolyte. The results revealed that the non-aqueous system was suitable for strictly anhydrous and anoxic photoelectrochemical studies. A model was proposed to explain the observed influence of concentration of dissolved $I_{2}$ on the photovoltage. A central component of the proposed model was that shunting was assumed to take place at physically distinct regions of the electrode and that mass-transport to and from these regions could be treated separately from mass-transport to the regions responsible for the rectifying behavior of the $\mathrm{FeS}_{2}$ /liquid junction. The implication of the agreement between experimental and calculated $J-E$ curves is that macroscopic photoelectrochemical investigations may underestimate the quality of $\mathrm{FeS}_{2}$ photoanodes due to the presence of defects.
\end{abstract}


The influence of surface treatments on $\mathrm{FeS}_{2}$ photoelectrochemistry was further studied using non-coordinating redox species. A statistically significant increase of photovoltage was observed after treating $\mathrm{FeS}_{2}$ surfaces with $\mathrm{KCN}$. X-ray photoelectron spectroscopy was used to study chemical bond formation between the electron donating ligands and iron(II) centers on the pyrite surface. The results were discussed in terms of charge recombination models and surface coordination chemistry.

Unfinished work is also presented. Cathodic polarization in acidic media is a prerequisite for any detectable photoresponse. The exact function of the electrochemical activations was further investigated by electropolishing pyrite electrode under different experimental conditions including etchant identity and applied bias. The results suggested that the electrochemical treatment removes the damaged surface layer caused by mechanical polishing, and might also stabilize the surface states. Further experiments can be focus on anhydrous etching of pyrite photoanode.

The research presented in this dissertation guides future studies of thin film $\mathrm{FeS}_{2}$ photovoltaics. 


\section{Dedication}

This dissertation is dedicated to my family. 


\section{Acknowledgments}

I wish to express my sincere gratitude to my advisor Prof. Erik Johansson. His broad knowledge and logical way of thinking have been of great value for me. The present dissertation would not have been possible without his encouragement and supervision. I would like to thank Prof. Andrea Goforth, Prof. Dean Atkinson, and Prof. Erik Sanchez for serving on my committee. I appreciate their perspective on my research and valuable feedback to my dissertation.

I want to thank all my fellow graduate students: Chase Reinhart, Eric Young, and Vitalii Dereviankin. It is a great pleasure to work with them. They offered me lots of help and precious suggestions to my research.

I also want to express my thanks to my former advisor Prof. Mingdi Yan for teaching me vast amounts of topics ranging from organic synthesis to nanoscience. I want to thank my past lab memebers: Dr. Lihong Liu, Dr. Hui Wang, Dr. Ke Jiang, Dr. Anuradha Tyagi, Dr. Xin Wang, Liling Li, Surangi Jayawardena, Jing Yuwen and Xuan Chen. The discussion with them benefits me a lot.

I wish to express special thanks to my parents, Guiqin Chen and Peiqing Tong for their great supports and encouragement. Last but not least, I owe my loving thanks to my husband, Li Lei. He helped me get through all the hard time during my Ph.D. study. Without my family, I could never have achieved this. 


\section{Table of Contents}

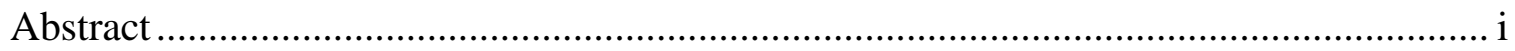

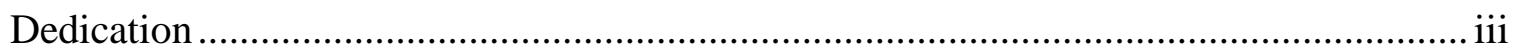

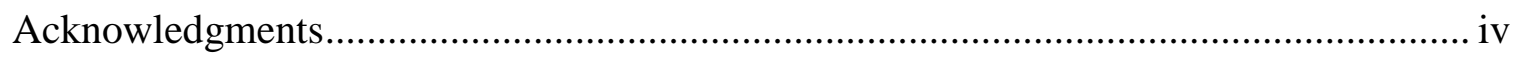

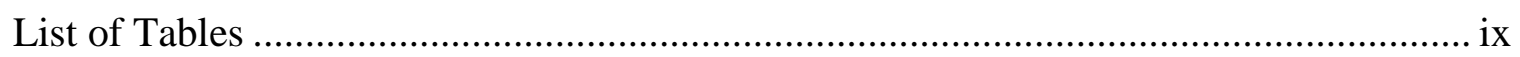

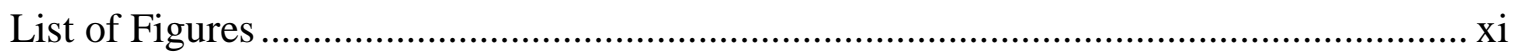

Glossary or List of Abbreviations/Symbols ...................................................... XV

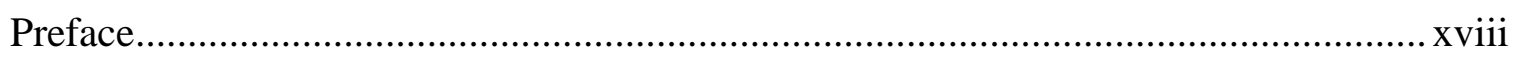

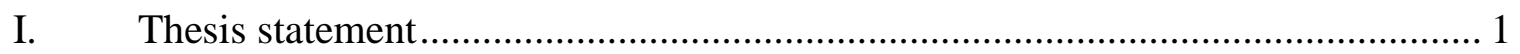

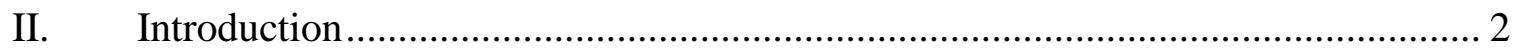

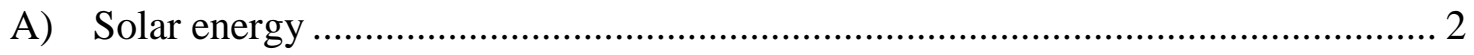

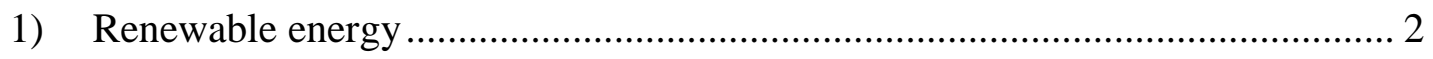

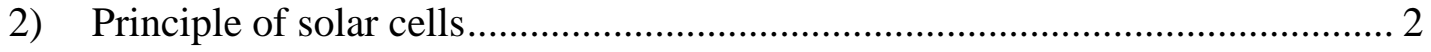

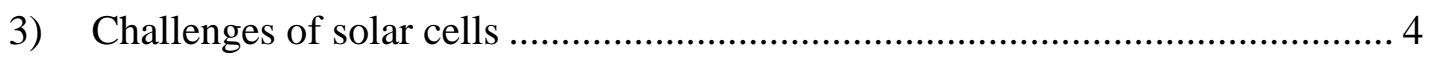

B) Iron pyrite as a potential material for solar energy conversion ......................... 7

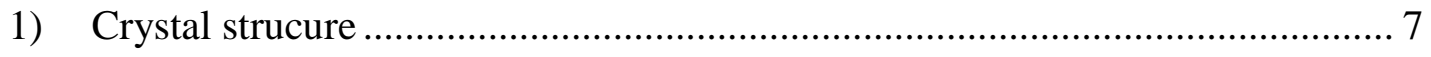

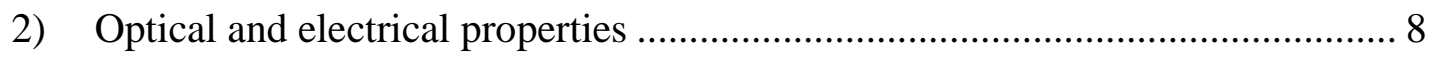

3) Main challenge of pyrite based solar devices ............................................ 9

III. Infrared reflection-absorption spectroscopy as a promising technique to

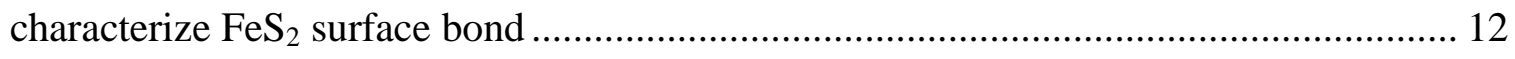

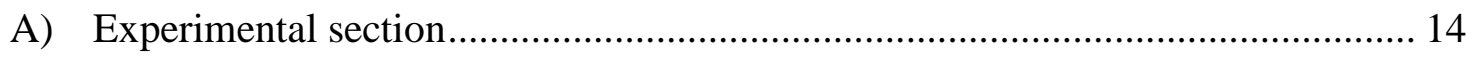




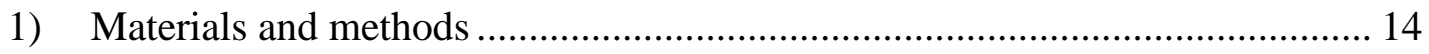

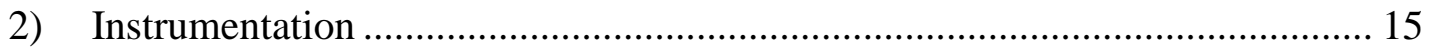

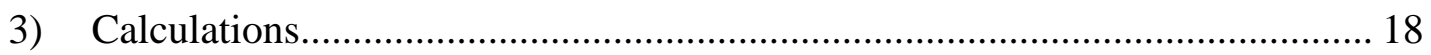

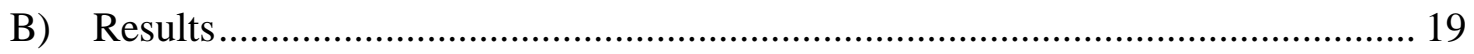

1) Experimentally obtained angle-dependent external reflectance spectra........... 19

2) Calculated angle-dependent external reflectance spectra ............................ 23

3) Surface - properties of the substrate....................................................... 24

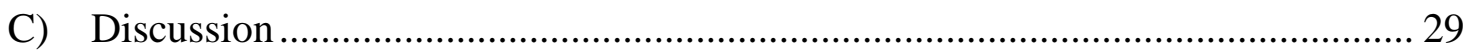

1) Experimentally obtained angle-dependent external reflectance spectra.......... 29

2) Calculated angle-dependent external reflectance spectra ........................... 31

3) The combination of angle-dependent IRRAS spectroscopy and computational

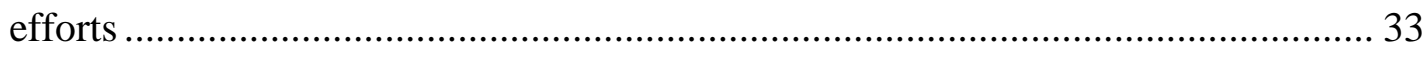

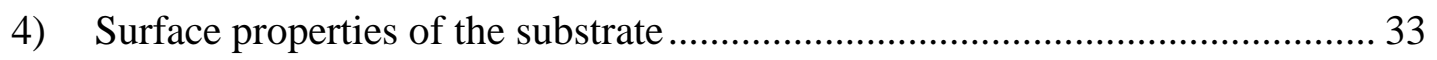

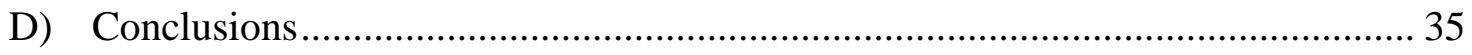

IV. Photoelectrochemical behavior of single-crystal $\mathrm{FeS}_{2}$ under anhydrous and anoxic

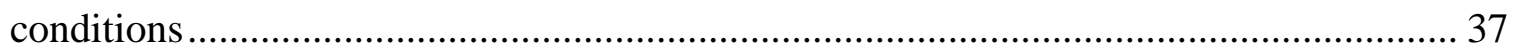

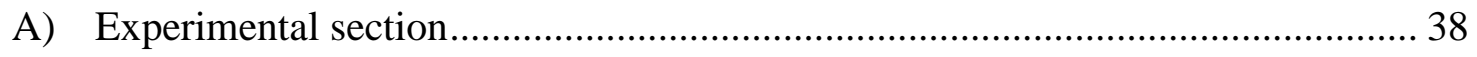

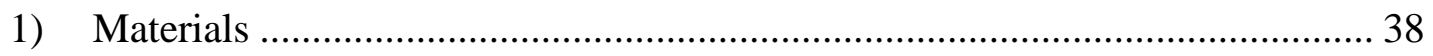

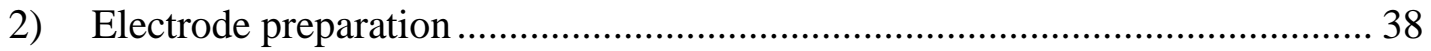

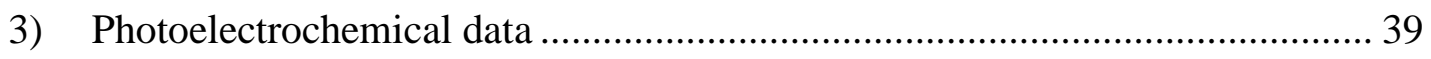

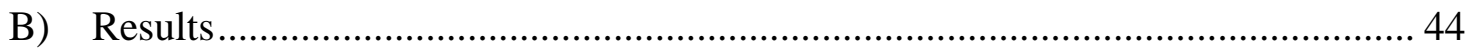

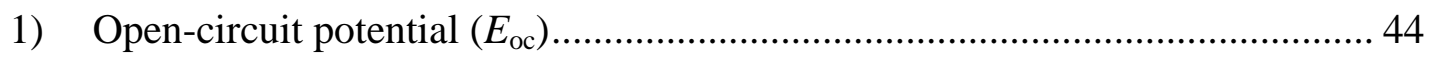




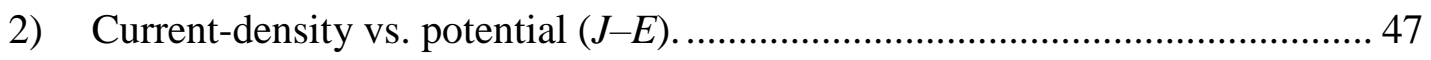

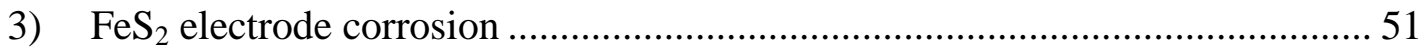

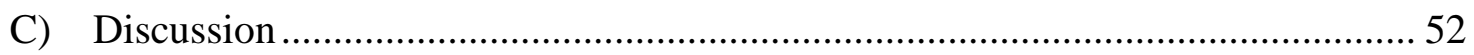

1) Influence of $I_{2}$ concentration on the current-voltage characteristics of single-

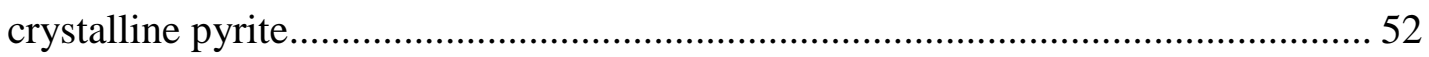

2) Influence of electrolyte-identity on the current-voltage characteristics of single-

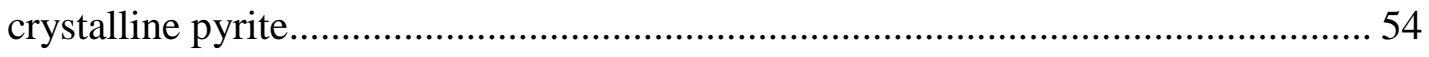

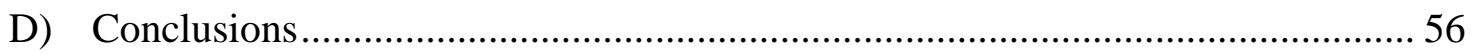

V. The influence of chemical treatment on the photoelectrochemical properties of Pyrite investigated using non-coordinating redox species ...................................... 57

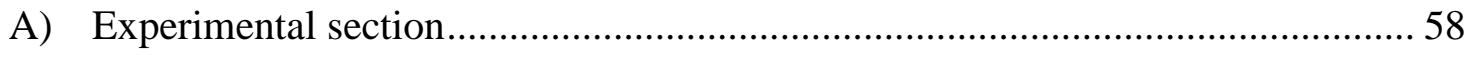

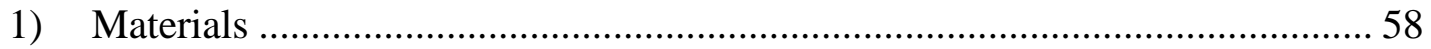

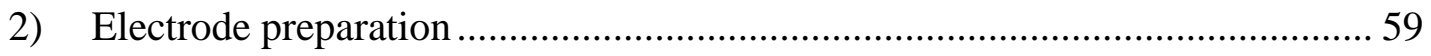

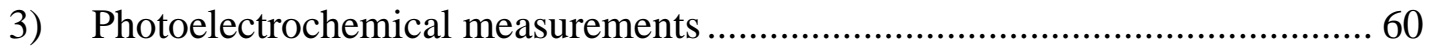

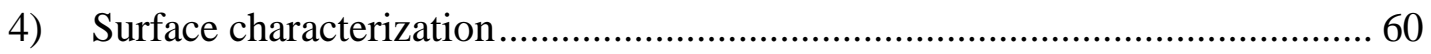

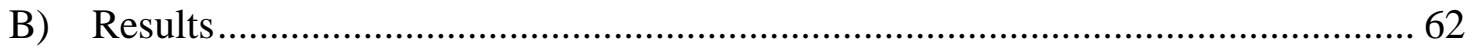

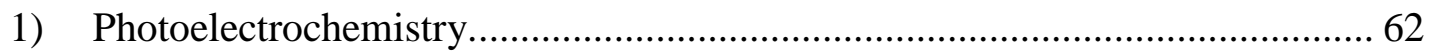

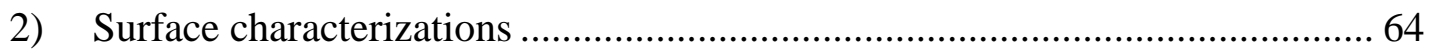

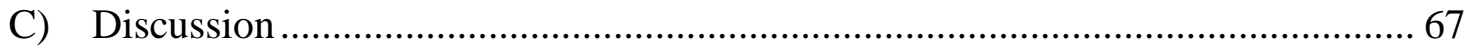

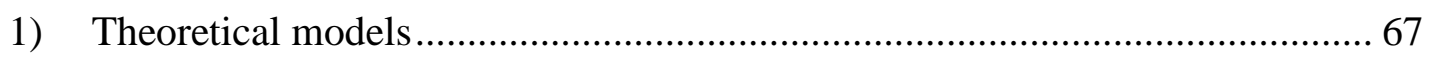

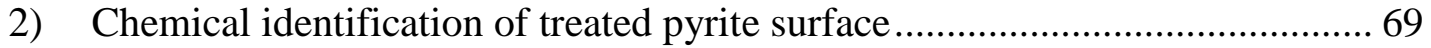

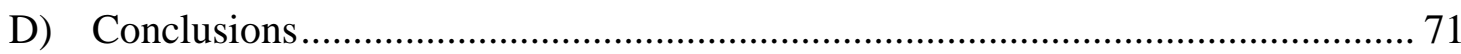


VI. Possible future studies on the influence of electrochemical etching on $\mathrm{FeS}_{2}$ photoelectrochemistry using aqueous and nonaqueous etchants ................................. 72

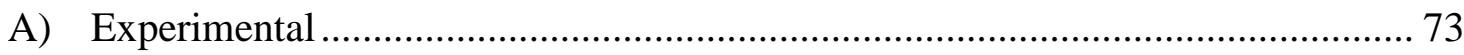

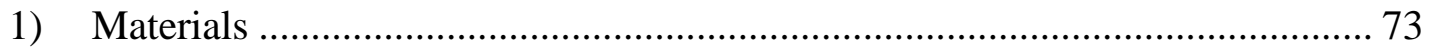

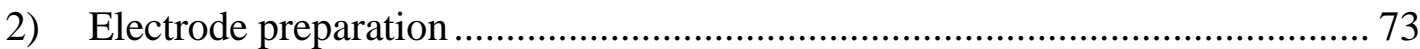

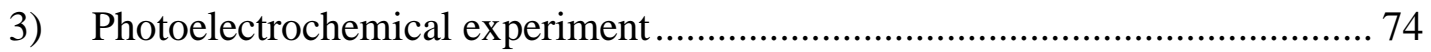

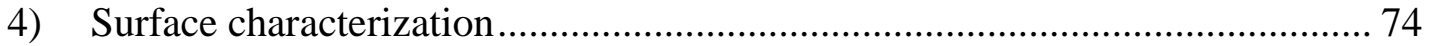

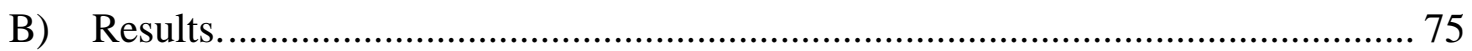

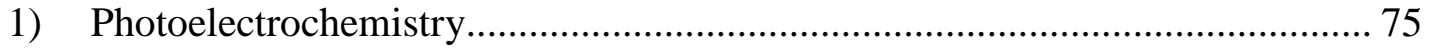

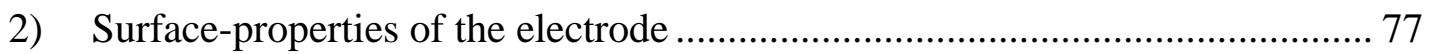

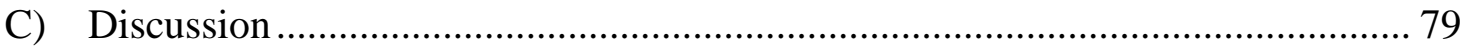

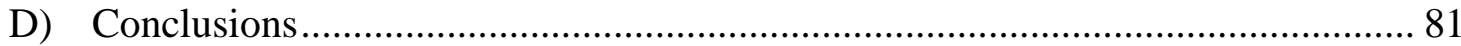

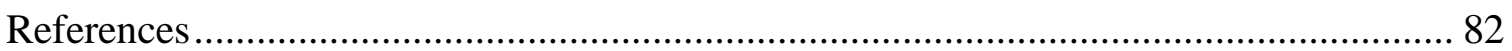

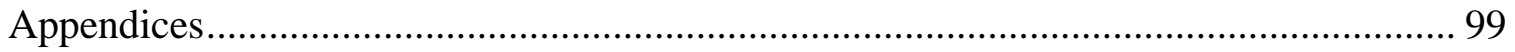

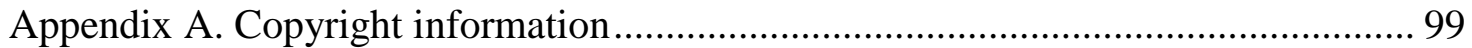

Appendix B. List of publications and presentations ......................................... 101 


\section{List of Tables}

Table 1. Assignment of IR peaks

Table 2. The dielectric functions of pyrite slides before and after annealing in a $S$ atmosphere (each data was an average of five spots on the same slide)....................... 25

Table 3. Binding energies and FWHM of representative pyrite slides ......................... 26

Table 4. Open-circuit potentials under high $\left(0.5 \mathrm{~W} \mathrm{~cm} \mathrm{~cm}^{-2}\right)$ and low $\left(0.1 \mathrm{~W} \mathrm{~cm}^{-2}\right)$ illumination intensities in aqueous and nonaqueous electrolytes prepared to $0.5 \mathrm{M} \mathrm{I}^{-}$and $0.004 \mathrm{M} \mathrm{I}_{2}$. The data is presented as the mean \pm 1 standard deviation. 46

Table 5. Open-circuit potentials under illumination $\left(0.1 \mathrm{~W} \mathrm{~cm}^{-2}\right)$ in aqueous electrolytes prepared to $0.5 \mathrm{M} \mathrm{I}^{-}$and different concentrations of $\mathrm{I}_{2}\left(\left[\mathrm{I}_{2}\right]\right)$. The data is presented as the mean \pm 1 standard deviation. 46

Table 6. Normalized open-circuit potential data under illumination $\left(0.1 \mathrm{~W} \mathrm{~cm}^{-2}\right)$ in aqueous electrolytes prepared to $0.5 \mathrm{M} \mathrm{I}^{-}$and different concentrations of $\mathrm{I}_{2}\left(\left[\mathrm{I}_{2}\right]\right)$. The data is presented as the mean \pm 1 standard deviation (second column). Calculated opencircuit potential data are a function of limiting cathodic current (two rightmost columns).

Table 7. Dissolved Fe-ion concentration after $30 \mathrm{~min}$. Each data is an average of three trials and is presented as the mean \pm 1 standard deviation. 52

Table 8 . The changes in $E_{\mathrm{oc}}$ and $J_{\mathrm{sc}}$ after surface treatment. The data is presented as the mean \pm 1 standard deviation. Each experiment was reproduced at least three times. ...... 64 
Table 9. Peak fitting results of $\mathrm{N} 1 \mathrm{~s}$ spectra. The intensity of each peak is normalized to the intensity of $\mathrm{Fe} 2 \mathrm{p}_{3 / 2}$ peak. Each data was presented as an average of three trials \pm 1

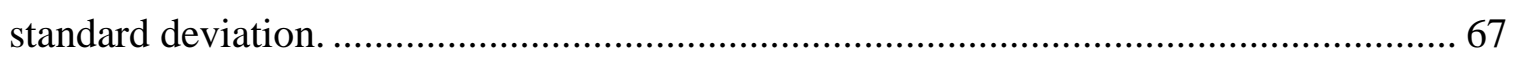

Table 10. Photovoltage and short-circuit current under illumination $\left(0.5 \mathrm{~W} \mathrm{~cm}^{-2}\right)$ after

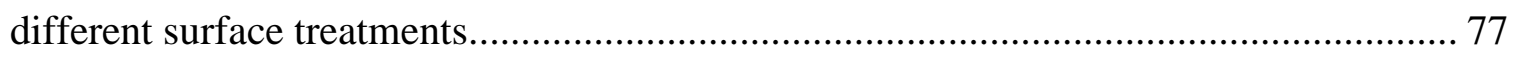




\section{List of Figures}

Figure II-1. Typical $I-V$ characteristics of an ideal solar cell. MPP stands for the maximum power point.

Figure II-2. Schematic representation of a three-junction solar cell. SC stands for semiconductor. The bandgap energy, $\mathbf{E}_{\mathrm{g}}$ of each absorber is $\mathrm{q} E_{\mathrm{g}} . V_{\mathrm{x}}$ and $J_{\mathrm{x}}$ are photovoltage and photocurrent densities generated by the $\mathrm{x}^{\text {th }}$ layer, respectively. $V_{\text {total }}$ and $J_{\text {total }}$ are the output photovoltage and photocurrent for the whole device. ....................... 6

Figure II-3. Crystal structure of iron pyrite. ....................................................... 8 Figure II-4. Schematic of $\mathrm{FeS}_{2} / \mathrm{I}_{3}{ }^{-}, \mathrm{I}^{-}$junction. The dashed line represents the pyrite/liquid

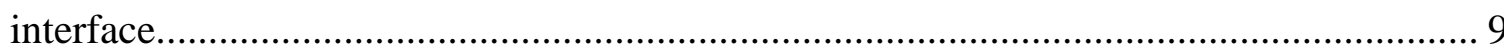

Figure III-1. Schematic diagram for light incident at an angle $\theta$ on a thin film of thickness $d$ on a substrate. $\varepsilon_{0}$ and $\varepsilon_{\mathrm{s}}$ are the complex dielectric functions of the substrate and the film, respectively. $n_{0}$ and $n_{\mathrm{s}}$ are the refractive indices of the substrate and the film, respectively. $k_{0}$ and $k_{\mathrm{s}}$ are the absorption coefficients of the substrate and the film, respectively. 17

Figure III-2. Experimental (Exp) and calculated (Cal) IR reflection spectra of a thin alkane-layer on $\mathrm{FeS}_{2}$

Figure III-3. Reflectivities of clean pyrite as a function of the incidence angle for spolarized and p-polarized radiation. Each data point was an average of 3 samples........ 22 Figure III-4. (a) Calculated absorbance at $3000 \mathrm{~cm}^{-1}$ of a hypothetical adsorbate on pyrite. (b) Zoomed in view of (a). 23 
Figure III-5. (a), (b) and (c) are SEM images of the clean $\mathrm{FeS}_{2}$ substrate. (d) shows an AFM image of the clean substrate. 26

Figure III-6. Normalized Fe $2 \mathrm{p}$ and S $2 \mathrm{p}$ spectra of pre- and post-anneal pyrite slides... 27 Figure III-7. EBSP (kikuchi patterns) of a pyrite slide (a) pre- and (b) post-sulfur anneal. (c) and (d) are auto index results of two different spots on the annealed slide. 28

Figure III-8. Representative EBSD map scans of (1) pre-annealed slide and (2) post annealed slide. The colored spots are the area that can be indexed as pyrite, while the black areas could not be indexed. More than one database entry for pyrite was used to ensure that both perfectly cubic and weakly distorted pyrite could be indexed. 28 Figure IV-1. Two models for calculating I- $V$ curves. Both models are composed of a current source $\left(I_{\mathrm{sc}}\right)$, a diode, a shunt resistance $\left(R_{\mathrm{sh}}\right)$, and current limitations by mass transfer as two independent components (a) or one single component (b). If the rectifying and shunting parts of the semiconductor electrode are physically distinct, then chemically distinct regions in the near-surface stagnant layer can be established (c) while a uniform electrode surface contacts only one, chemically homogenous, stagnant layer (d).

Figure IV-2. Representative $J-E$ data for $\mathrm{FeS}_{2}$ electrodes in contact with aqueous (a) and nonaqueous (b) $\mathrm{I}^{-}, \mathrm{I}_{3}{ }^{-}$electrolytes. The three traces in each graph were collected in the dark, under intense illumination $\left(0.5 \mathrm{~W} \mathrm{~cm}^{-2}\right)$ and under approximately 1 sun illumination intensity $\left(0.1 \mathrm{~W} \mathrm{~cm}^{-2}\right)$. The scan rate was $100 \mathrm{mV} \mathrm{s}^{-1}$.

Figure IV-3. $J-E$ curves for $\mathrm{FeS}_{2}$ and $\mathrm{Pt}$ electrodes in aqueous and nonaqueous electrolytes without illumination. (Scan rate: $100 \mathrm{mV} \mathrm{s}^{-1}$ ). 
Figure IV-4. Representative experimental $J-E$ data for a $\mathrm{FeS}_{2}$ electrode in contact with a solution containing $0.5 \mathrm{M} \mathrm{I}^{-}$and $0.004 \mathrm{M} \mathrm{I}_{2}$ (a), or $0.5 \mathrm{M} \mathrm{I}^{-}$and $0.05 \mathrm{M} \mathrm{I}_{2}$ (b). The three traces of experimental data in panels (a) and (b) were collected in the dark, under illumination $\left(0.1 \mathrm{~W} \mathrm{~cm}^{-2}\right)$ and directly again in the dark. The scan rate was $20 \mathrm{mV} \mathrm{s}^{-1}$. Dark and light curves of calculated data in panels (c) and (d) were calculated using the parameters mentioned earlier. 50 Figure V-1. Representative $J-E$ data for $\mathrm{FeS}_{2}$ electrodes before and after treatment in (a) $0.5 \mathrm{M} \mathrm{KCN}$ solution in formamide, and (b) neat formamide. $J-E$ data were collected in the dark or under $0.1 \mathrm{~W} \mathrm{~cm}^{-2}$ illumination at a scan rate of $20 \mathrm{mV} \mathrm{s}^{-1}$. 64 Figure V-2. (1) N 1s spectra for iron pyrite surface right after cathodic polarization (blue line), further immersed in $0.5 \mathrm{M} \mathrm{KCN}$ solution in formamide (orange line) or neat formamide (red line) for $1 \mathrm{~h}$. (2) Peak fitting results for the top two $\mathrm{N} 1 \mathrm{~s}$ spectra in (1)..... 66

Figure V-3. N 1s spectra of samples after $\mathrm{KCN}$ solution treatment (top three) and neat formamide treatment (bottom three). The KCN used in trail (a) and (b) was unpurified. The $\mathrm{KCN}$ used in trail (c) was purified by recrystallization from a $\mathrm{H}_{2} \mathrm{O}$-ethanol mixture $(1: 3)$ 70

Figure VI-1. Representative $J-E$ data for $\mathrm{FeS}_{2} / \mathrm{I}^{-}, \mathrm{I}_{3}{ }^{-}$half cell after: (1) cathodically polarized in acidic media; (2) anodically polarized in acidic media; (3) cathodically polarized in alkaline media; (4) anodically polarized in alkaline media; and (5) no pretreatment. (Light intensity: $0.5 \mathrm{~W} \mathrm{~cm}^{-2}$ ) 76 
Figure VI-2. SEM images of pyrite electrodes after: (1) cathodically polarized in acidic media; (2) anodically polarized in acidic media; (3) cathodically polarized in alkaline

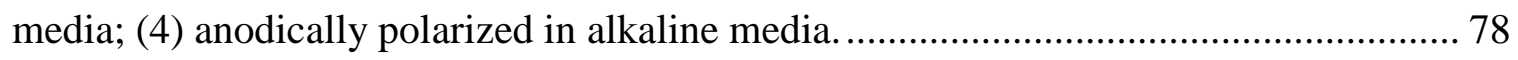
Figure VI-3. Kikuchi patterns of pyrite slide after (1) polishing; and (2) cathodic polarization in acidic media. (2) was automatically solved by software as shown in (3). (4) is the EDX spectrum for (2). 79 


\section{Glossary or List of Abbreviations/Symbols}

AES: Auger electron spectroscopy

AFM: atomic force microscopy

$\alpha:$ transfer coefficient

$\alpha_{\mathrm{ov}}$ : diameter of the overlayer species

ATR: attenuated total reflection

$c_{\mathrm{ox}}:$ concentration of oxidized species

$d$ : film thickness

$E$ : potential

EBSD: electron backscatter diffraction

EBSP: electron backscatter diffraction patterns

EDX: energy dispersive spectroscopy

$\mathbf{E}_{\mathrm{g}}$ : bandgap

$E_{\mathrm{k}}$ : electron kinetic energy

$E_{\mathrm{oc}}$ : open-circuit potential

$E_{\text {solution}}:$ solution potential

$\eta$ : overpotential

$\varepsilon_{0}$ : complex dielectric functions of the substrate

$\varepsilon_{\mathrm{s}}:$ complex dielectric functions of the adsorbate layer

F: Faraday constant

$\Phi_{\mathrm{ov}}$ : surface coverage of adsorbed layer

$\phi_{\mathrm{b}}$ : barrier height 
FWHM: full width at half maximum

GATR: grazing angle attenuated total reflectance

GIXD: grazing incidence X-ray diffraction

I: current

$i_{0}$ : exchange current

$i_{1, \mathrm{a}}:$ limiting anodic current

$i_{1, \mathrm{c}}$ : limiting cathodic current

IR: infrared spectroscopy

IRRAS: infrared reflection-absorption spectroscopy

$I_{\mathrm{sc}}:$ short-circuit current

$I_{\mathrm{x}}$ : raw signal intensity of species $\mathrm{x}$

$J$ : current density

$J_{\mathrm{ph}}$ : photocurrent density

$k$ : Boltzmann's constant

$k_{0}$ : extinction coefficient of substrate

$k_{\mathrm{s}}$ : extinction coefficient of adsorbate layer

$\lambda$ : escape depth of photoelectrons through the adsorbate layer

LO: longitudinal optical

MPP: maximum power point

$\mathrm{n}$ : diode quality factor

$n_{0}$ : refractive index of substrate

$N_{\mathrm{c}}$ : effective density of states of the semiconductor conduction band 
$n_{\mathrm{s}}$ : refractive index of adsorbate layer

PV: photovoltaic

$q$ : charge of an electron

$\rho_{\mathrm{x}}$ : density of species $\mathrm{X}$

$R_{0}$ : reflectivity of unfunctionalized substrate

$R_{\mathrm{s}}$ : reflectivity of functionalized surface

SEM: scanning electron microscopy

$S F$ : modified Scofield sensitive factor

$S_{r}:$ surface recombination velocity

$\mathrm{t}$ : reaction time

T: Temperature

$\theta$ : (1) incident angle (IRRAS tests in chapter III); (2) take off angle (XPS tests in chapter V)

$\theta_{\mathrm{B}}$ : Brewster angle

TO: transverse optical

$\mathrm{V}$ : volume

$V_{\text {oc }}$ open-circuit voltage

$V_{\text {ph}}:$ photovoltage

z: number of electrons involved in a reaction 


\section{Preface}

This thesis is based on the work contained in the following papers:

I Tong, Q.; Young, R. E.; Johansson, E. Infrared Reflection-Absorption Spectroscopy of an Isotropic Adsorbate Layer on Pyrite J. Phys. Chem. C. 2013, 117, 25982-25990

II Tong, Q.; Johansson, E. Photoelectrochemical Behavior of $\mathrm{FeS}_{2}$ in Aqueous and Nonaqueous $\mathrm{I}^{-} / \mathrm{I}_{3}{ }^{-}$electrolytes, J. Electrochem. Soc. 2014, 161, H950-H954

III Tong, Q.; Young, R. E.; Johansson, E. Influence of Surface Passivation on the Photoresponse of Iron Pyrite in a Non-aqueous Electrolyte with Non-coordinating Redox Couple. (manuscript in preparation)

Papers I-II are reproduced with the permission of the publishers.

The contribution of the author to the papers included in this thesis was as follows:

I. Participated in planning the study. Performed the majority of the laboratory work. Main writer of the manuscript.

II. Participated in planning the study. Performed all the laboratory work. Main writer of the manuscript.

III. Participated in planning the study. Performed the majority of the laboratory work. Main writer of the manuscript.

In addition the dissertation contains preliminary work presented in chapter VI. 


\section{THESIS STATEMENT}

Single crystalline $\mathrm{FeS}_{2}$ surface chemistry can be correlated with $\mathrm{FeS}_{2}$ photoelectrochemistry.

Specifically:

1. Infrared reflection-absorption spectroscopy holds promise as a technique to identify and fully characterize $\mathrm{FeS}_{2}$ surface bonds.

2. Photoelectrochemistry of $\mathrm{FeS}_{2}$ can be investigated under anhydrous and anoxic conditions.

3. The influence of surface chemistry on $\mathrm{FeS}_{2}$ photoelectrochemistry can be further understood using non-coordinating redox species. 


\section{INTRODUCTION}

\section{A) Solar energy}

\section{1) Renewable energy}

Global energy consumption increases rapidly year by year due to the fast growth of the world's population and the development of its inhabitants. It has been predicted that by 2050 , more than 30 terawatts new power will be needed. ${ }^{1}$ The carbon emissions and other environmental pollutions associated with current fossil-fuel-based energy supply therefore constitute a serious problem today. ${ }^{2,3}$ As a result, renewable energies have attracted more and more attention in recent decades. Solar energy is one of the most promising renewable energy resources due to its abundance and environmental friendliness. The sun provides more than enough energy and utilizing solar energy is already competitive from the perspective of $\mathrm{CO}_{2}$ emission per $\mathrm{kWh}$. The sun provides approximately 6,000 times the current annual energy needs to the Earth's surface. A currently commercially available solar cell has a $\mathrm{CO}_{2}$ emission lifecycle of less than 200 $\mathrm{g} / \mathrm{kWh}$, which is significantly lower than coal ( 910 g/ kWh). ${ }^{4}$

\section{2) Principle of solar cells}

A solar cell, or a photovoltaic (PV), is a device that harvests photons, converting solar energy into electrical energy. The process for solar to electrical energy conversion can be roughly divided into two steps: (1) photogeneration and (2) charge separation. ${ }^{5}$ 
In the photogeneration step, the incoming photons are absorbed by semiconductor materials and electron-hole pairs are generated. The key parameter of this step is the bandgap energy $\left(\mathbf{E}_{\mathrm{g}}\right)$ of the semiconductor material. ${ }^{5}$ In an ideal case, all photons with energy equal or greater than the bandgap will each generate an electron-hole pair; the photons with energy less than the bandgap will not contribute to any photogeneration. The excess energy ( $h v-\mathbf{E}_{\mathrm{g}}$ ) of those absorbed photons, however, cannot be converted to electricity. Instead, it will be lost rapidly as heat. As a result, the open-circuit voltage, $V_{\mathrm{oc}}$, (which is the maximum attainable voltage) cannot exceed $\mathbf{E}_{\mathrm{g}} / q$ ( $q$ is the elementary charge). The short circuit current $I_{\mathrm{sc}}$, on the other hand, is determined by the number of photons that have an energy $h v \geq \mathbf{E}_{\mathrm{g}}$. Therefore, the greater $\mathbf{E}_{\mathrm{g}}$ is, the smaller $I_{\mathrm{sc}}$ is. Since the power output of a PV device is the product of photovoltage and photocurrent, there is no energy production at either open-circuit or short-circuit point and the maximum power point is somewhere in between on an $I-V$ curve as shown in Figure II-1 (c).$^{2}$

The band gap of a semiconductor material can be obtained using optical or electronic measurements. Qualitatively speaking, the optical bandgap represents the minimum energy absorbed photons; the electronic bandgap is correlated to the maximum expected photovoltage. For most inorganic semiconductor materials, the electronic bandgap is approximately the same as the optical bandgap. However, low-densities of near band-edge states may not contribute significantly to the absorption profile of a material but can significantly affect its electronic properties. In this case, the electronic bandgap may be lower than the measured optical bandgap. 


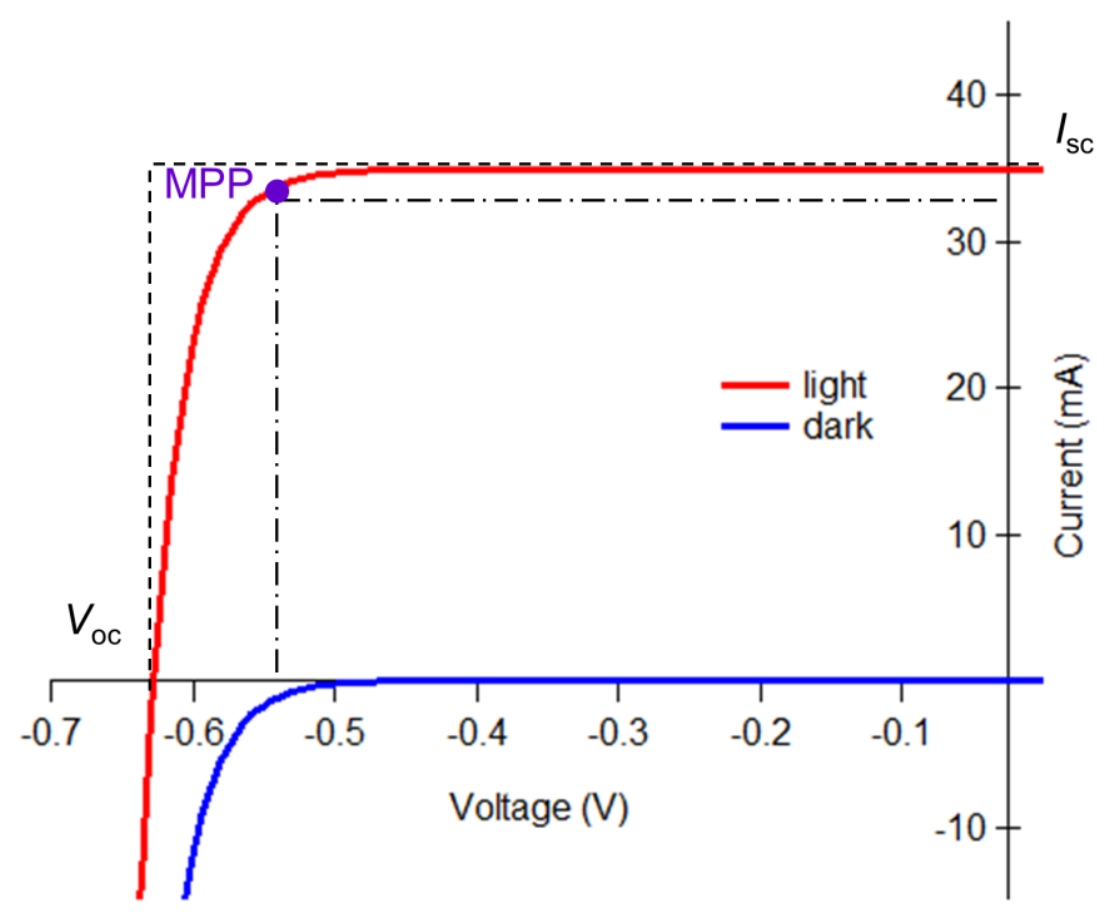

Figure II-1. Typical $I-V$ characteristics of an ideal solar cell. MPP stands for the maximum power point.

\section{3) Challenges of solar cells}

Providing large-scale energy supply with competitive pricing by photovoltaics remains a challenge. One problem with solar energy usage is that the power density of solar radiation is low. On average, the Earth receives approximately 1,300-1,400 W per square meter. The direct available solar power, however, varies depending on locations due to the latitude, status of atmosphere, and the season of the year and the time of day. In the U.S., the national average is dramatically lower at $100-150 \mathrm{~W} \mathrm{~m}^{-2}{ }^{6}$ Therefore, solar devices with very large areas are required to meet our energy needs. This might be 
a serious problem especially for indirect bandgap semiconductors, which require more material to absorb all incoming radiation. Take crystalline silicon, the dominating material in the PV market, as an example. Due to its low absorption coefficient, a relatively thick $(\sim 100 \mu \mathrm{m})$ layer is required to absorb all useful incident photons. ${ }^{5,7}$ This not only requires a lot of raw material, but also makes the manufacturing process more difficult and expensive.

To address these issues, many efforts have focused on thin film technologies. The basic concept is to use a thin layer $(<100 \mathrm{~nm})$ of a highly absorbing semiconductor material to absorb light and to inject the photo-generated electron into another conducting material to generate a photopotential. The advantages of this technology are: (1) less material consumption; (2) rapid charge extraction from the absorber material allowing lower charge recombination rates.

Another opportunity to improve the performance of solar devices is to raise the theoretical efficiency by replacing single-junction devices with multiple absorber cells. ${ }^{8,9}$ A typical schematic representation of a multiple-absorber cell is shown in Figure II-2. In general, it consists of several photovoltaic cells of progressively smaller $\mathbf{E}_{\mathrm{g}}$. The incident irradiation first reaches the largest bandgap $\left(\mathbf{E}_{\mathrm{g}, 1}\right)$ material and high energy photons with $h v \geq \mathbf{E}_{\mathrm{g}, 1}$ are absorbed. The photons with lower energy are then transmitted through to a lower bandgap absorbing layer and absorbed there. Since the photovoltaic cells are connected in series, the total $V_{\mathrm{ph}}$ is limited by the sum of photovoltage of each cell, and the total current flow is limited by the least photocurrent among all cells. A maximum 
efficiency of $56 \%$ has been predicted for an ideal three-junction solar cells under intense illumination. ${ }^{10}$

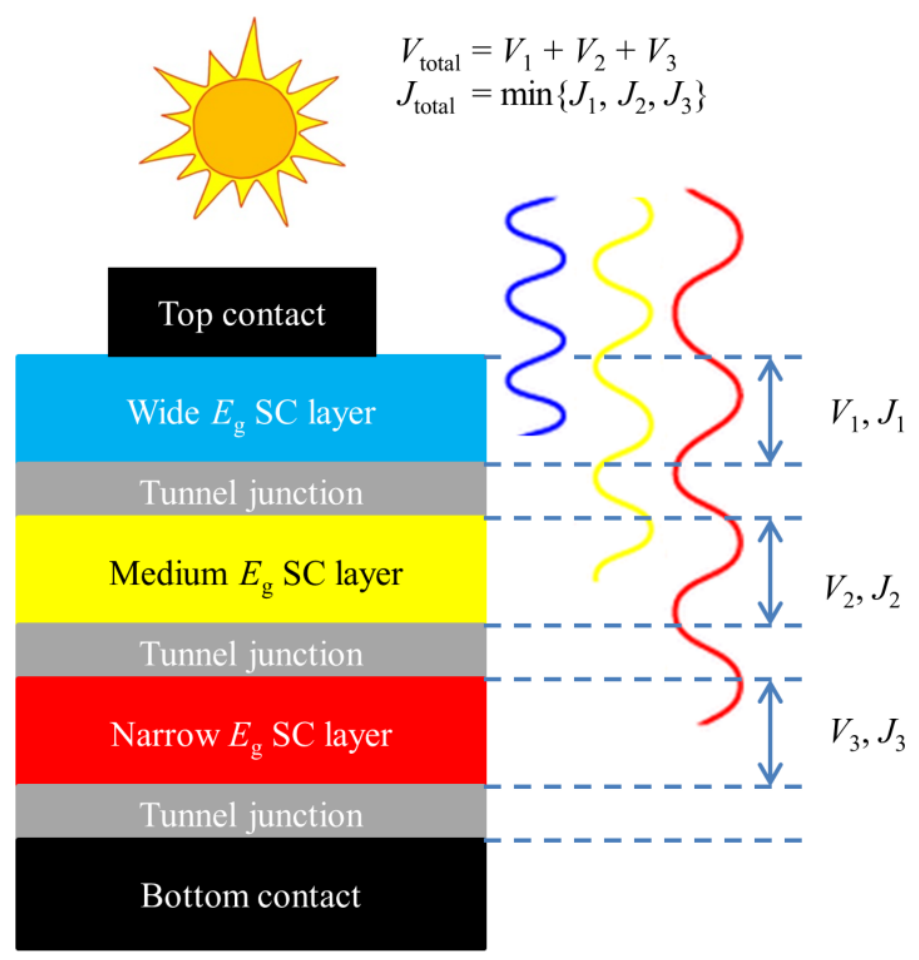

Figure II-2. Schematic representation of a three-junction solar cell. SC stands for semiconductor. The bandgap energy, $\mathbf{E}_{\mathrm{g}}$ of each absorber is $\mathrm{q} E_{\mathrm{g}} . V_{\mathrm{x}}$ and $J_{\mathrm{x}}$ are photovoltage and photocurrent densities generated by the $\mathrm{x}^{\text {th }}$ layer, respectively. $V_{\text {total }}$ and $J_{\text {total }}$ are the output photovoltage and photocurrent for the whole device.

Recently, researchers have made significant progress on thin-film solar cells using non-silicon materials as an absorbing layer. ${ }^{11}$ The main drawbacks of several leading thin-film materials (e.g. CdTe, GaAs) are the high cost and potential environmental 
hazards. ${ }^{9,} 12$ Thus, materials that are abundant, highly absorbing, and have low toxicity are obviously more desirable. A promising alternative material is iron pyrite $\left(\mathrm{FeS}_{2}\right)$.

\section{B) Iron pyrite as a potential material for solar energy conversion}

$\mathrm{FeS}_{2}$ has attracted considerable attention over the past decades as an energyconversion material, as a common by-product of mining, and as a factor in some originof-life theories. Pyrite is commonly encountered during mining operations and it is found in both gold and coal among many other materials. The extraction cost of its constituent metallic element, iron, is only $\$ 0.03 / \mathrm{kg}$, which is significantly lower than the extraction cost of $\sim \$ 1.70$ for silicon. ${ }^{12}$ Pyrite also has low toxicity. ${ }^{7}$ Thus, pyrite is very attractive for economic and environmental reasons.

\section{1) Crystal strucure}

Pyrite has a cubic structure in which Fe ions are located at the corners and face centers of the cube and S-S divalent anions are at the cube centers and the midpoints of cube edges as shown in Figure II-3. As a transition metal compound, the semiconducting properties of $\mathrm{FeS}_{2}$ can be understood by considering $\mathrm{FeS}_{2}$ as a coordination compound with Fe centers in octahedral coordination by six sulfur dimers. ${ }^{13}$ The iron center in pyrite is in a low-spin $\mathrm{d}^{6}$ configuration and the d-orbitals are split into $\mathrm{e}_{\mathrm{g}}$ and $\mathrm{t}_{2 \mathrm{~g}}$ energy levels. According to the ligand field theory, pyrite can be anticipated as a semiconductor with a band gap of $0.9 \mathrm{eV} .{ }^{14}$ By way of contrast, the other crystal form of iron disulfide, namely marcasite, has an orthorhombic structure. As a result, the 
splitting of the $t_{2 \mathrm{~g}}$ orbitals increases, resulting in a decrease in the semiconducting band gap to $0.4 \mathrm{eV} .{ }^{15}$ Therefore marcasite is less interesting than pyrite as a solar-energy conversion material. In addition, pyrite is more thermodynamically favorable than marcasite across all temperatures. ${ }^{16}$

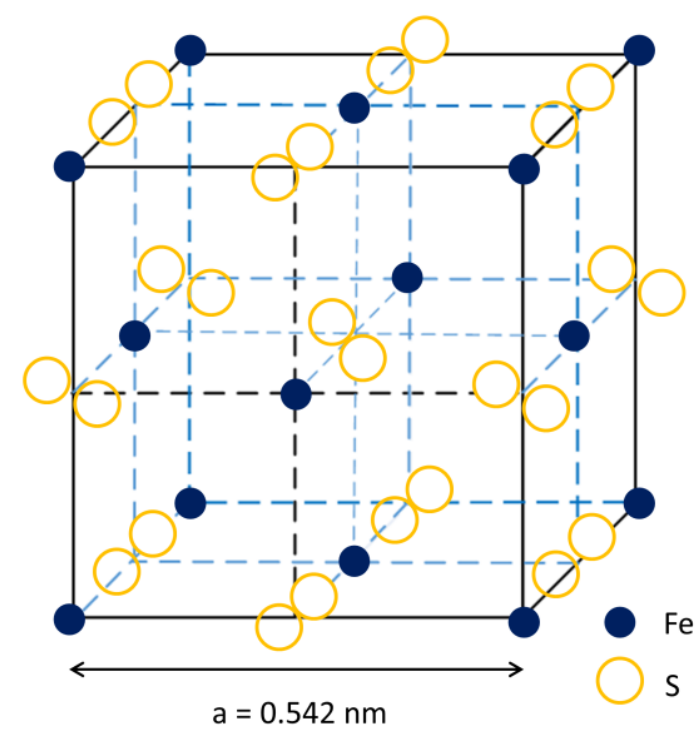

Figure II-3. Crystal structure of iron pyrite. ${ }^{17}$

\section{2) Optical and electrical properties}

Pyrite is a promising material for solar-energy conversion due to its suitable band gap (optical bandgap of $0.95 \mathrm{eV}$ and electronic bandgap of $0.8 \mathrm{eV}$ ), and strong absorption coefficient, $\alpha$, which is greater than $10^{5} \mathrm{~cm}^{-1}$ for $\mathrm{h} v>1.3 \mathrm{eV} \cdot{ }^{18-20}$ Furthermore, near unity (0.923) photon-to-electron conversion efficiency under intense illumination $\left(4-5 \mathrm{~W} \mathrm{~cm}^{-2}\right)$ has been reported for monocrystalline n-type $\mathrm{FeS}_{2}$ in contact with an aqueous solution 
containing an $\mathrm{I}_{3}{ }^{-} / \mathrm{I}^{-}$redox couple. ${ }^{20}$ (The schematic of such a pyrite photodiode/liquid junction is shown in Figure II-4.) Reported charge-carrier diffusion lengths $(0.1-1 \mu \mathrm{m})$ match the materials thickness required based on the extinction coefficient of $\mathrm{FeS}_{2}{ }^{21-26}$ There is also some evidence that polycrystalline $\mathrm{FeS}_{2}$ may be relevant for solar-toelectrical energy conversion. ${ }^{27}$

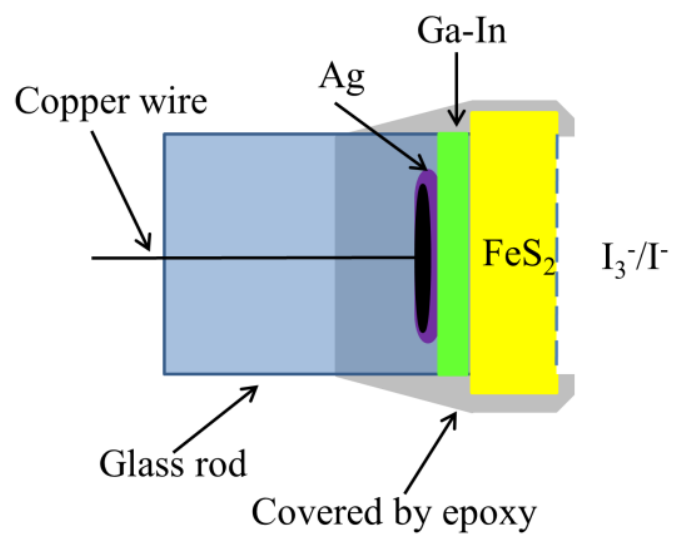

Figure II-4. Schematic of $\mathrm{FeS}_{2} / \mathrm{I}_{3}{ }^{-}, \mathrm{I}^{-}$junction. The dashed line represents the pyrite/liquid interface.

\section{3) Main challenge of pyrite based solar devices}

By evaluating the theoretical maximum power conversion efficiency and raw material cost, it has been predicted that pyrite has the potential to offer electricity at $<2 \times$ $10^{-6} \phi / \mathrm{W}^{12}$ However, $\mathrm{FeS}_{2}$ is not presently a viable solar-energy-conversion material. While pyrite-based photoelectrodes have shown large currents under intense illumination, the reported photovoltages of approximately $200 \mathrm{mV}$ were considerably lower than what 
is expected to be theoretically achievable $(\sim 500 \mathrm{mV})$ under normal operating conditions and accounting for thermodynamic losses..$^{2028-31}$ The low photovoltage was likely a result of one or more of the following, previously identified, ${ }^{32-34}$ causes: (1) Bulk, and interfacial defects including bulk sulfur vacancies, ${ }^{13,21,35-37}$ surface and interfacial defects, ${ }^{38-40}$ line defects, ${ }^{41}$ and point defects, ${ }^{33}$ (2) Intrinsic surface states, owing to termination of the crystal lattice, ${ }^{26,38}$ and (3) The presence of $\mathrm{FeS}$ and $\mathrm{FeS}_{2}$ in phases other than the pyrite phase. Concerning the latter, several studies have suggested that marcasite, pyrrhotite, and amorphous iron sulfides affect the photovoltaic performance of pyrite. ${ }^{21,42}$ These causes can all result in electronic states that facilitate electron-hole pair recombination and Fermi-level pinning. Fermi-level pinning refers to a phenomenon that the band bending in a semiconductor is fixed to a constant value because of the presence of surface states. In a semiconductor/liquid junction device, when Fermi-level pinning occurs, the junction properties are independent of the solution potential. In practice, Fermi-level pinning has the disadvantage of limiting photovoltage. Since surface states can play a crucial role in Fermi-level pinning, surface reactions that changes the nature of the surface states might improve the photovoltage. ${ }^{43}$

The photoactivity of pyrite has been shown to be improved by specific pretreatment protocols in acidic media. ${ }^{44}$ The electrochemical dissolution of pyrite in an aqueous solution has been shown to depend on $\mathrm{pH}^{45}$ The presence of some chemicals, including silanes and humic acids, have been shown to decrease electrochemical corrosion rate by forming an insulating passivation layer. ${ }^{46}$ Furthermore, corrosion has been shown to be inhibited by the presence of halogens and coordinating groups, 
including $\mathrm{CO}$, in solution. ${ }^{47-49}$ It was suggested that facilitating inner-sphere electron transfer processes (possibly through kinetically shutting down the corrosion pathways) inhibited corrosion. Some organic ligands, for instance pyrazine and 4,4'-bipyridine, were shown to decrease the anodic dark current of an n-pyrite/electrolyte junction; and treatment with pyrazine was also shown to increase the difference between currentvoltage curves obtained under illumination and in the dark. ${ }^{50}$ It was suggested that the organic ligands passivated the surface by coordinating $\mathrm{Fe}^{2+}$ to form $\mathrm{Fe}(\mathrm{II})$-ligand complexes, and that charge transfer proceeded via the ligand bridge. However, the chemical identity of the surface was never determined experimentally.

The experimental aim of my doctoral research was to explore the relationship between $\mathrm{FeS}_{2}$ surface chemistry and photoelectrochemistry. The studies presented in this dissertation provided a fundamental understanding of $\mathrm{FeS}_{2}$ surface identity, and illustrated their influences on energy-conversion performance of $\mathrm{FeS}_{2}$. The methodologies established should benefit the future study of $\mathrm{FeS}_{2}$ solar devices. 


\section{INFRARED REFLECTION-ABSORPTION SPECTROSCOPY AS A PROMISING TECHNIQUE TO CHARACTERIZE FES 2 SURFACE BOND}

A number of techniques, all having specific strengths, have been used for pyrite surface characterization including Auger electron spectroscopy (AES), ${ }^{51,}{ }^{52}$ grazing incidence X-ray diffraction (GIXD), ${ }^{53-55}$ Raman spectroscopy, ${ }^{56,57}$ electron energy loss spectroscopy (EELS), ${ }^{58}$ scanning electron microscopy (SEM), ${ }^{59,} 60$ and X-ray photoelectron spectroscopy (XPS). ${ }^{37,61}$ Infrared (IR) spectroscopy is an important tool in the characterization of surfaces due to its non-destructive sampling, ability to identify chemical compounds, high sensitivity, and compatibility with a range of environmental conditions. ${ }^{62}$

Transmission and attenuated total reflection (ATR) IR spectroscopy are frequently employed with great success for studying monolayers on surfaces. ATR-IR spectroscopy has been employed to study polycrystalline films and powder samples of $\mathrm{FeS}_{2}$ where the sample was deposited onto an ATR crystal. ${ }^{63-65}$ However, neither transmission- nor ATR-IR spectroscopy is ideal for studying single-crystal $\mathrm{FeS}_{2}$ surface chemistry. Transmission IR spectroscopy is not ideal for characterizing overlayers on $\mathrm{FeS}_{2}$ single crystals because of the relatively high intrinsic absorption in the mid-IR (greater than $\left.10 \mathrm{~cm}^{-1}\right) .{ }^{66}$ This results in an almost threefold attenuation of the probing light even at a thickness of only $1 \mathrm{~mm}$, making background subtraction when comparing two different samples, or comparing the same sample at different stages of a chemical process, difficult. The same physical property, a high extinction coefficient in the mid-IR, 
also makes using a $\mathrm{FeS}_{2}$ crystal as an ATR substrate a poor choice. Grazing angle attenuated total reflectance (GATR), commonly achieved by close contact between a Ge hemisphere and the sample, has successfully been used to increase the signal by enhancing the local electric-field strength to probe sub-monolayer chemistry on $\mathrm{Si}^{67,68}$ However, this technique is not suitable either because of the high refractive index of pyrite. ${ }^{69}$ The interest in studying single-crystal pyrite surface chemistry as opposed to that of polycrystalline films or (nano) particles, both of which are easier to prepare and have higher surface area and have been studied extensively using IR spectroscopy, ${ }^{22,63-65,70,71}$ arises from the fact that good photovoltaic performance has only been demonstrated using single-crystal pyrite. ${ }^{20}$ Angle-dependent IRRAS provides an opportunity to study not only the chemical information relating to the surface and thin adsorbate layer, but also the surface orientation of adsorbate molecules. ${ }^{72}$

A unique feature of IRRAS spectra is that the directions and the intensities of absorbance bands varies with the incident angle, polarization of incident radiations and optical properties of both adsorbate and substrate. The complicated spectral behavior can help confidently interpret the spectrum, especially weak absorption bands, since signals arising from the spectrometer would not show the same complex dependency on angle of incidence. To understand the optical behavior of thin films on metallic and non-metallic substrates, several theoretical approaches have been developed for the general case of adsorbate films of variable symmetry. In extension of older treatments for isotropic media, ${ }^{73}$ a rigorous $4 \times 4$ transfer matrix method was established to simulate adsorbate reflection spectra on a variety of substrates (e.g., $\mathrm{Au}, \mathrm{Cu}, \mathrm{CuS}_{2}, \mathrm{Si}$, and $\mathrm{H}_{2} \mathrm{O}$ ) as a 
function of molecular orientation..$^{74-76} \mathrm{~A}$ treatment based on the longitudinal and transverse optical (LO and TO, respectively) modes was also developed to simulate the infrared spectra of isotropic polymeric thin films on Si and Au. ${ }^{62}$ However, pyrite has not benefitted from angle-dependent IRRAS investigations coupled to computational efforts, which could provide chemical information to understand effects of surface chemistry on photovoltage.

In this chapter a thin isotropic surface layer on $\mathrm{FeS}_{2}$ was studied by combining angle-dependent IRRAS spectroscopic and computational efforts. 1-dodecanethiol was chosen as a model adsorbate because: (1) the extinction coefficient spectrum of alkyl chain has been previously reported in the literature; and (2) it is easily reacted with the $\mathrm{FeS}_{2}$ surface. Comparisons are made between theoretical predictions and experimental results and the two are discussed in terms of the general utility of IRRAS for studying oligo-, and monolayer-chemistry of $\mathrm{FeS}_{2}$ surfaces.

\section{A) Experimental section}

1) Materials and methods

All chemicals were used as received. Pyrite samples were purchased from Ward's Natural Science (Rochester, NY).

Sample preparation. Natural pyrite cubes (Spain, $\sim 15 \times 15 \times 15 \mathrm{~mm}^{3}$ ) were polished using a progression of diamond lapping films $(9 \mu \mathrm{m}, 3 \mu \mathrm{m}, 1 \mu \mathrm{m}$ and $0.25 \mu \mathrm{m})$ with a TechPrep ${ }^{\mathrm{TM}}$ polishing system (Allied High Tech Products, Inc.) at a rotational speed of $60 \mathrm{rpm}$. The cubes were polished with each diamond lapping film until any 
scratches from polishing with the previous, coarser, lapping film had been removed completely. Each cube was cut using an IsoMet ${ }^{\circledR}$ Low Speed Saw (Buehler) to give a 2 mm thick slide having the polished face as one of its sides. The slides were then etched for 15 minutes in $\mathrm{NH}_{4} \mathrm{~F}(\mathrm{aq})$ (Transene Company, Inc., 40\%, $10.9 \mathrm{M}$ ) that had previously been sparged with $\mathrm{N}_{2}$ for 30 min to remove $\mathrm{O}_{2}$. The etched pyrite slides were annealed in a vacuum sealed $\left(5 \times 10^{-7}\right.$ Torr $)$ ampoule in the presence of $50 \mathrm{mg}$ elemental sulfur (Aldrich, 99.999\%) at $600{ }^{\circ} \mathrm{C}$ for 12 hours (Linderg/Blue $\mathrm{M}^{*}$ Tube Furnace, Thermo Scientific). Adsorption of 1-dodecanethiol onto the $\mathrm{FeS}_{2}$ was carried out by immersing the $\mathrm{FeS}_{2}$ slides in 1-dodecanethiol for 2 hours under inert atmosphere followed by quickly rinsing with $1 \mathrm{~mL}$ of absolute ethanol three times to remove loosely bound alkylthiol. Finally, the pyrite slides were dried under $\mathrm{N}_{2}$.

\section{2) Instrumentation}

IRRAS spectra were collected using a Nicolet 6700 FT-IR spectrometer equipped with a variable-angle reflectance unit (Seagull, Harrick Scientific) and a liquid-nitrogen cooled MCT/A detector. The sample-chamber was purged with purified air (Parker Balston FT-IR purge gas generator, Model 75-52 equipped with additional hydrocarbon filters) to minimize levels of $\mathrm{CO}_{2}$, moisture, and hydrocarbons. A wire grid polarizer (Model PWG-SEA, Harrick Scientific) was used for selecting p-polarized or s-polarized radiation. Interferograms were collected with an optical velocity of $0.6329 \mathrm{~cm} \mathrm{~s}^{-1}$, and 4 $\mathrm{cm}^{-1}$ spectral resolution. For both clean and functionalized surfaces 2000 consecutive scans were collected and averaged to ensure adequate signal-to-noise ratio. A $2^{\text {nd }}$ order 
baseline correction was applied to all the spectra presented in this paper. Collection was started 30 minutes after sample insertion to allow time for purging the sample chamber.

The thickness of the adsorbed 1-dodecanethiol layer was measured using a Gaertner Model L116A ellipsometer (Gaertner Scientific Co.) with a He/Ne laser (632.8 $\mathrm{nm}, 2 \mathrm{~mW}$, Melles Griot) at an incidence angle of $70^{\circ}$. The refractive index $n_{0}$ and extinction coefficient $k_{0}$ values of each clean substrate were measured right before immersing the slide into 1-dodecanethiol. A value of 1.46 was used as the refractive index of 1-dodecanethiol, $n_{\mathrm{s}}{ }^{77,78}$

The surface roughness of the clean $\mathrm{FeS}_{2}$ substrate was evaluated using an atomic force microscope (Nanoscope II, Veeco) in tapping mode with a scan rate of $1 \mathrm{~Hz}$. SEM imaging employed a Zeiss Sigma VP FEG SEM operating at $1 \mathrm{kV}$ and a chamber pressure of $10^{-5} \mathrm{~Pa}$.

X-ray photoelectron spectra were collected using a ThermoScientifc ESCALAB 250 instrument equipped with a monochromatized Al X-ray source and at a chamber pressure less than $10^{-7} \mathrm{~Pa}$. The spot size was $500 \mu \mathrm{m}$, the pass energy $20 \mathrm{eV}$ for composition scans, and all binding energies were referenced using $284.8 \mathrm{eV}$ as the binding energy for the $\mathrm{C}$ 1s peak associated with aliphatic hydrocarbons.

Surface crystal structure was studied using SEM-based electron backscatter diffraction analysis (EBSD). No carbon coating was applied prior to EBSD. All crystallographic data was collected using a Zeiss Sigma VP FEG SEM operating at accelerating voltage of $20 \mathrm{kV}$ and a chamber pressure of $10^{-5} \mathrm{~Pa}$. The sample was tilted 70 degrees and electron backscatter patterns were collected on a phosphor screen. Point 
scans were collected with a binning mode of $1 \times 1$ and a frame averaging of 16. Map scans were collected with a binning mode of $4 \times 4$ and a frame averaging of 8 . The step size of map scans was $0.66 \mu \mathrm{m}$. The number of 'Kikuchi' bands required for pyrite indexing was 8. All EBSD data were processed using the AZtecHKL software package (Oxford Instruments, UK).

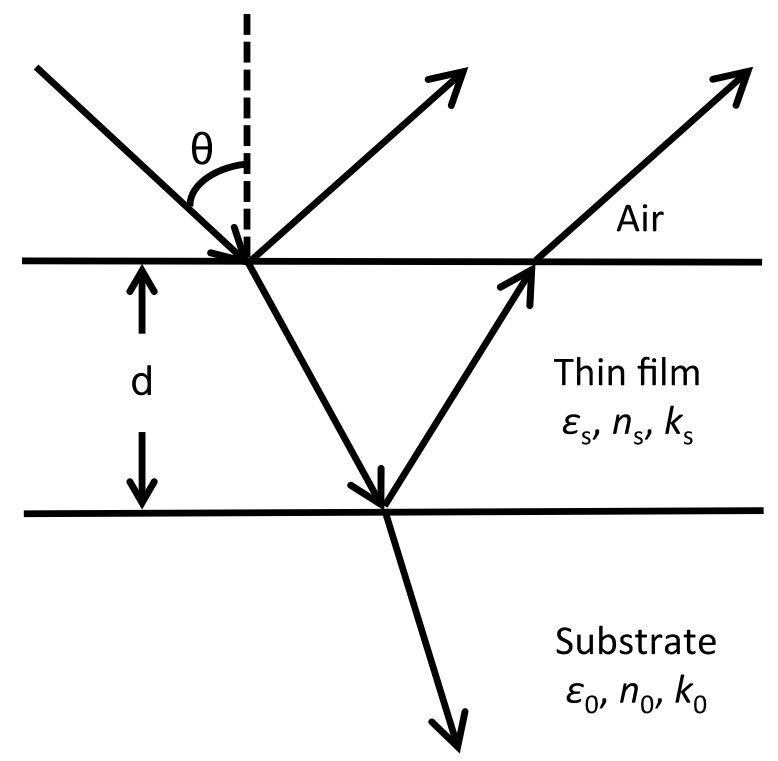

Figure III-1. Schematic diagram for light incident at an angle $\theta$ on a thin film of thickness $d$ on a substrate. $\varepsilon_{0}$ and $\varepsilon_{\mathrm{s}}$ are the complex dielectric functions of the substrate and the film, respectively. $n_{0}$ and $n_{\mathrm{s}}$ are the refractive indices of the substrate and the film, respectively. $k_{0}$ and $k_{\mathrm{s}}$ are the absorption coefficients of the substrate and the film, respectively. 


\section{3) Calculations}

Calculations were carried out using an existing three-phase model. ${ }^{62}$ In brief, the system was modeled as a thin layer (the 1-dodecanethiol) sandwiched between air and $\mathrm{FeS}_{2}$ (Figure III-1). Furthermore: the clean pyrite slide was treated as an ideal dielectric substrate, meaning that it was assumed to be non-absorbing in the region of interest. The influence of the adsorbate layer was characterized by the ratio of the reflectivities of a functionalized surface vs. an unfunctionalized surface $\left(R_{\mathbb{s}} / R_{0}\right)$. For the two polarizations, the reflectivities of the substrate $\left(R_{0}\right)$, and substrate + sample $\left(R_{\mathrm{S}}\right)$, were calculated using equations III-1-4 (below) where $\operatorname{Im}(\varepsilon)$ and $\operatorname{Im}(-1 / \varepsilon)$ are the energy-loss functions for the TO and LO modes, respectively. ${ }^{62}$

For s-polarization: $\quad R_{0}=\left(\frac{\sqrt{\varepsilon_{0}-\sin ^{2} \theta}-\cos \theta}{\sqrt{\varepsilon_{0}-\sin ^{2} \theta}+\cos \theta}\right)^{2}$

$$
R_{\mathrm{S}}=\left(\frac{\sqrt{\varepsilon_{0}-\sin ^{2} \theta}-\cos \theta}{\sqrt{\varepsilon_{0}-\sin ^{2} \theta}+\cos \theta}\right)^{2}\left[1+\frac{8 \pi v d \cos \theta}{\varepsilon_{0}-1} \operatorname{Im}\left(\varepsilon_{S}\right)\right]
$$

For p-polarization: $\quad R_{0}=\left(\frac{\sqrt{\varepsilon_{0}-\sin ^{2} \theta}-\varepsilon_{0} \cos \theta}{\sqrt{\varepsilon_{0}-\sin ^{2} \theta}+\varepsilon_{0} \cos \theta}\right)^{2}$

$$
R_{\mathrm{S}}=\left(\frac{\sqrt{\varepsilon_{0}-\sin ^{2} \theta}-\varepsilon_{0} \cos \theta}{\sqrt{\varepsilon_{0}-\sin ^{2} \theta}+\varepsilon_{0} \cos \theta}\right)^{2}\left[1+\frac{8 \pi v d}{\cos \theta} \frac{\left(\varepsilon_{0}-\sin ^{2} \theta\right) \operatorname{Im}\left(\varepsilon_{S}\right)-\varepsilon_{0}^{2} \sin ^{2} \theta \operatorname{Im}\left(\frac{-1}{\varepsilon_{S}}\right)}{\left(\varepsilon_{0}-1\right)\left(\varepsilon_{0}-\tan ^{2} \theta\right)}\right]
$$

Here, $d$ is the film thickness, $v$ is the wavenumber of interest, $\theta$ is the incidence angle with respect to the surface normal, and $\varepsilon_{0}$ and $\varepsilon_{\mathrm{s}}$ are the complex dielectric functions of the substrate and the film, respectively. In general, the dielectric function $\varepsilon$ can be expressed in terms of the optical constants as $\varepsilon=(n+i k)^{2}$, where $n$ is the real refractive index, and $k$ is the extinction coefficient. It has been reported that over the 
wavenumber range of interest, the refractive index of pyrite $\left(n_{0}\right)$ is 4.60 while the adsorption coefficient of pyrite $\left(k_{0}\right)$ is $0 .{ }^{79}$ Hence $\varepsilon_{0}=n_{0}{ }^{2}=(4.60)^{2}=21.16$. A literature $k$ spectrum for a long-chain alkyl salt (polycrystalline $\mathrm{C}_{19} \mathrm{H}_{39} \mathrm{CO}_{2} \mathrm{Na}$ ) in $3000-2800 \mathrm{~cm}^{-2}$ region was used to calculate the $n$ spectrum based on Kramers-Kronig relations, and from which the dielectric function $\varepsilon(v)$ of the $\mathrm{C}-\mathrm{H}$ vibration modes was derived. ${ }^{75}$ The energyloss function for TO mode of the adsorbate, $\operatorname{Im}\left(\varepsilon_{\mathrm{s}}\right)$, is the imagination part of the optical constant $\varepsilon_{\mathrm{s}}$ and thus equals to $2 n_{\mathrm{s}} k_{\mathrm{s}}$. Likewise, the energy-loss function for LO mode of the adsorbate, $\operatorname{Im}\left(-1 / \varepsilon_{\mathrm{s}}\right)$ was calculated as $2 n_{\mathrm{s}} k_{\mathrm{s}} /\left(n_{\mathrm{s}}^{4}+2 n_{\mathrm{s}}^{2} k_{\mathrm{s}}^{2}+k_{\mathrm{s}}{ }^{4}\right)$.

\section{B) Results}

1) Experimentally obtained angle-dependent external reflectance spectra Figures III-2 a and c show the angle-dependent external reflection-absorption spectra for functionalized $\mathrm{FeS}_{2}$ surfaces referenced to unfunctionalized surfaces. Peaks were observed at $2854 \mathrm{~cm}^{-1}, 2925 \mathrm{~cm}^{-1}$, and $2954 \mathrm{~cm}^{-1}$ with p-polarized light, and were most easily observed at higher degrees of incidence angle. Peaks were observed at 2854 $\mathrm{cm}^{-1}$ and $2925 \mathrm{~cm}^{-1}$, with a weak band at around $2954 \mathrm{~cm}^{-1}$, with s-polarized light. All spolarized bands were "negative", and the absolute value of band intensities decreased with increasing incidence angle. The peak assignments from IRRAS results are summarized in Table 1. 
Table 1. Assignment of IR peaks

\begin{tabular}{cc}
\hline Peak frequency $\left(\mathrm{cm}^{-1}\right)$ & Vibration \\
\hline 2854 & $\mathrm{CH}_{2}$, sym. str. \\
2925 & $\mathrm{CH}_{2}$, asym. str. \\
2954 & $\mathrm{CH}_{3}$, asym. str. \\
\hline
\end{tabular}



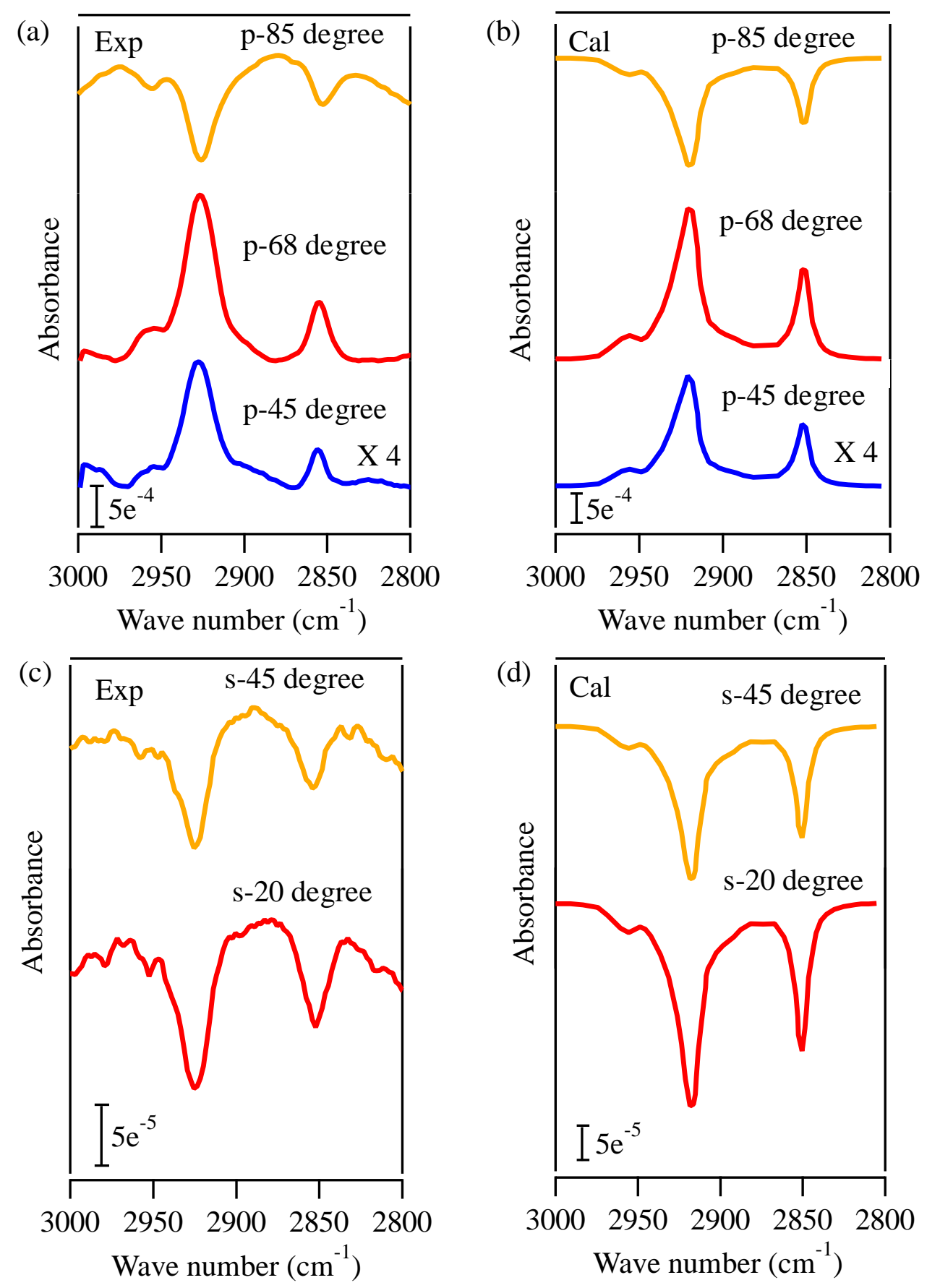

Figure III-2. Experimental (Exp) and calculated (Cal) IR reflection spectra of a thin alkane-layer on $\mathrm{FeS}_{2}$. 
The $\mathrm{FeS}_{2}$ substrate's Brewster angle was determined by plotting the intensity of reflected light as a function of incident angle for s-polarized and p-polarized light (See Figure III-3). A Brewster angle is an incident angle at which the p-polarized radiation perfectly transmits through the substrate and thus the reflected radiation is only spolarized. At an incidence angle of $76 \pm 2$ degrees, the reflectivity of p-polarized radiation is close to 0 . This is consistent with the calculated Brewster angle of pyrite $\left(\theta_{\mathrm{B}}\right.$ $=\tan ^{-1} n_{0}=78$ degrees). In theory, the reflectivity of a clean substrate should increase monotonically with increasing incidence angle for s-polarized radiation. However, the experimental results show a decrease in the intensity of the reflected s-polarized light due to experimental conditions; the beam is partially clipped by the experimental setup at high angles.

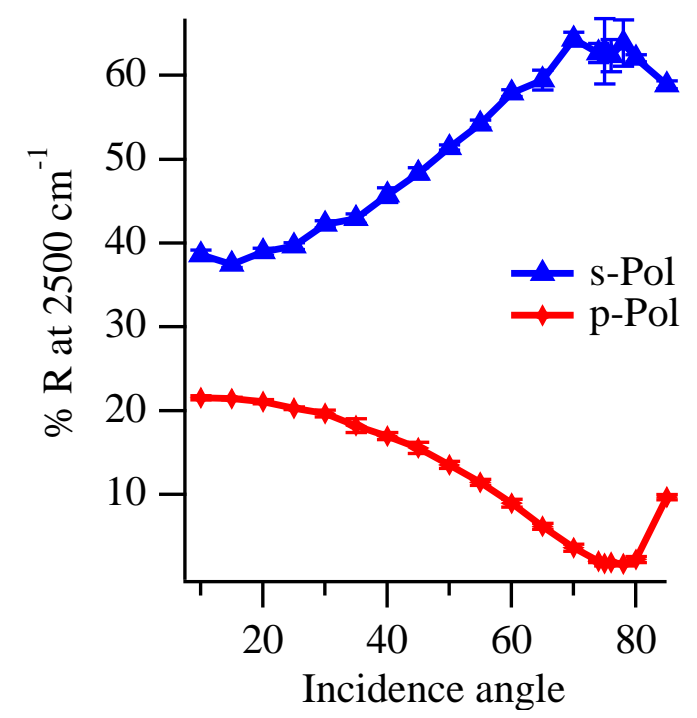

Figure III-3. Reflectivities of clean pyrite as a function of the incidence angle for spolarized and p-polarized radiation. Each data point was an average of 3 samples. 


\section{2) Calculated angle-dependent external reflectance spectra}
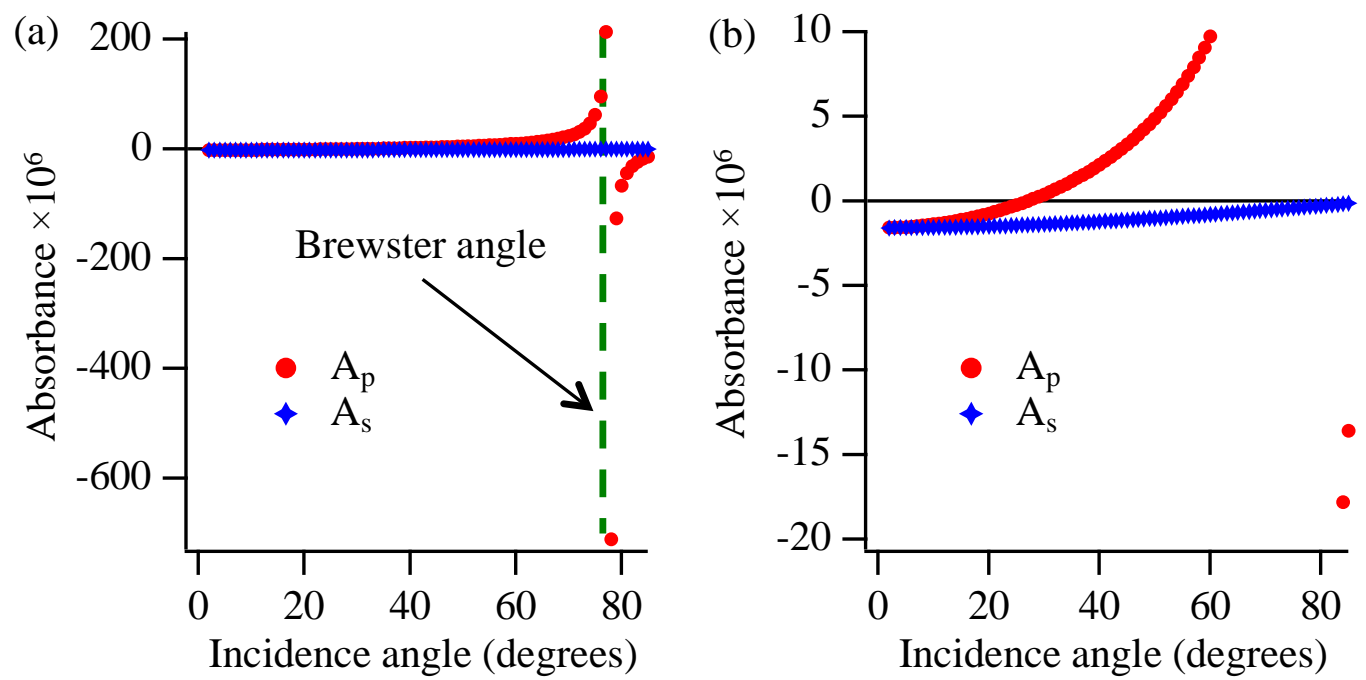

Figure III-4. (a) Calculated absorbance at $3000 \mathrm{~cm}^{-1}$ of a hypothetical adsorbate on pyrite. (b) Zoomed in view of (a).

Figures III-2 $\mathrm{b}$ and $\mathrm{d}$ show the angle-dependent external reflection-absorption spectra of the functionalized $\mathrm{FeS}_{2}$ calculated using equations III-1-4. In general, good agreement was found between the measured and calculated spectra. The spectral features were further investigated by calculating the absorbance at a single wavelength as a function of angle of incidence.

Figure III-4 shows calculated changes in "Absorbance" $\left(-\log R_{\S} / R_{0}\right)$ as a function of incidence angle at a single wavelength $\left(3000 \mathrm{~cm}^{-1}\right)$ for both p-polarized and spolarized light. The adsorbate layer was modeled as $n_{\mathrm{s}}=1.45, k_{\mathrm{s}}=0.001$ and a thickness of $30 \AA$, and the pyrite surface was modeled as a dielectric with $n_{0}=4.60, k_{0}=0 .{ }^{79}$ The following can be seen: 
(1) Absorption of s-polarized light always lead to inverted ("negative") absorption bands with relatively low intensity that increased with decreasing incidence angle.

(2) Absorption of p-polarized light results in both positive and negative absorption bands depending on incidence angle with an inversion at the Brewster angle of the substrate. A second band inversion is predicted for p-polarized light according to equation III-5. ${ }^{62}$

$$
\sin ^{2} \theta_{2 i}=\left(\frac{\varepsilon_{0}}{\left|\varepsilon_{s}\right|^{2}}+\frac{1}{\varepsilon_{0}}\right)^{-1}
$$

In our cases $\theta_{2 i}$ is approximately 27 degrees. Thus, there are three regimes (a) $\theta>\theta_{\mathrm{B}}$; (b) $\theta_{\mathrm{B}}>\theta>\theta_{2 i}$; (c) $\theta<\theta_{2 i}$ that should be discussed separately. For (a), absorption bands are "negative", and the absolute value of band intensities decrease with increasing incidence angle. For (b), absorption bands are positive, and their intensities increase with increasing incidence angle. For (c), absorption bands are inverted ("negative"), and the absolute value of their intensities decrease with increasing incidence angle.

3) Surface - properties of the substrate.

Alkane overlayer thickness. The thickness of the adsorbed dodecane thiol layer was $30 \pm 2 \AA$ as measured by elipsometry.

Surface preparation by polishing, etching and annealing in a sulfur atmosphere. Slides that were polished and etched using the procedure outlined in the experimental section went from having a dull face, with an inhomogeneous color, to mirror-like finish 
and metallic luster, the color of the sample now silver. The final step before the alkane overlayer adsorption, the sulfur anneal, resulted in observable changes to the optical properties of the clean $\mathrm{FeS}_{2}$ substrate (Table 2); the refractive index, $n_{0}$, increased and became more consistent from sample to sample. There was no color change observed after sulfur anneal. The surface morphology of as-prepared pyrite slides was studied using SEM and AFM imaging (Figure III-5). The surfaces contained two types of irregularities: scratches and point-like defects. The scratches were $100 \mathrm{~nm}$ or less wide. The point-like defects were also on the $100 \mathrm{~nm}$ scale. A 10 by $10 \mu \mathrm{m}^{2}$ AFM image of the surface provided a root mean square roughness of $1.56 \mathrm{~nm}$ and the total $\mathrm{Z}$ (height) range of the image was $20.46 \mathrm{~nm}$.

Table 2. The dielectric functions of pyrite slides before and after annealing in a $S$ atmosphere (each data was an average of five spots on the same slide).

\begin{tabular}{|c|c|c|c|c|}
\hline & \multicolumn{2}{|c|}{ Pre annealing } & \multicolumn{2}{|c|}{ Post annealing } \\
\hline & $n_{0}$ & $k_{0}$ & $n_{0}$ & $k_{0}$ \\
\hline Slide 1 & $3.98 \pm 0.18$ & $-3.10 \pm 0.02$ & $4.05 \pm 0.16$ & $-2.86 \pm 0.04$ \\
\hline Slide 2 & $3.25 \pm 0.03$ & $-3.03 \pm 0.01$ & $4.43 \pm 0.12$ & $-3.02 \pm 0.03$ \\
\hline Slide 3 & $1.79 \pm 0.04$ & $-3.29 \pm 0.02$ & $4.54 \pm 0.02$ & $-2.96 \pm 0.02$ \\
\hline
\end{tabular}




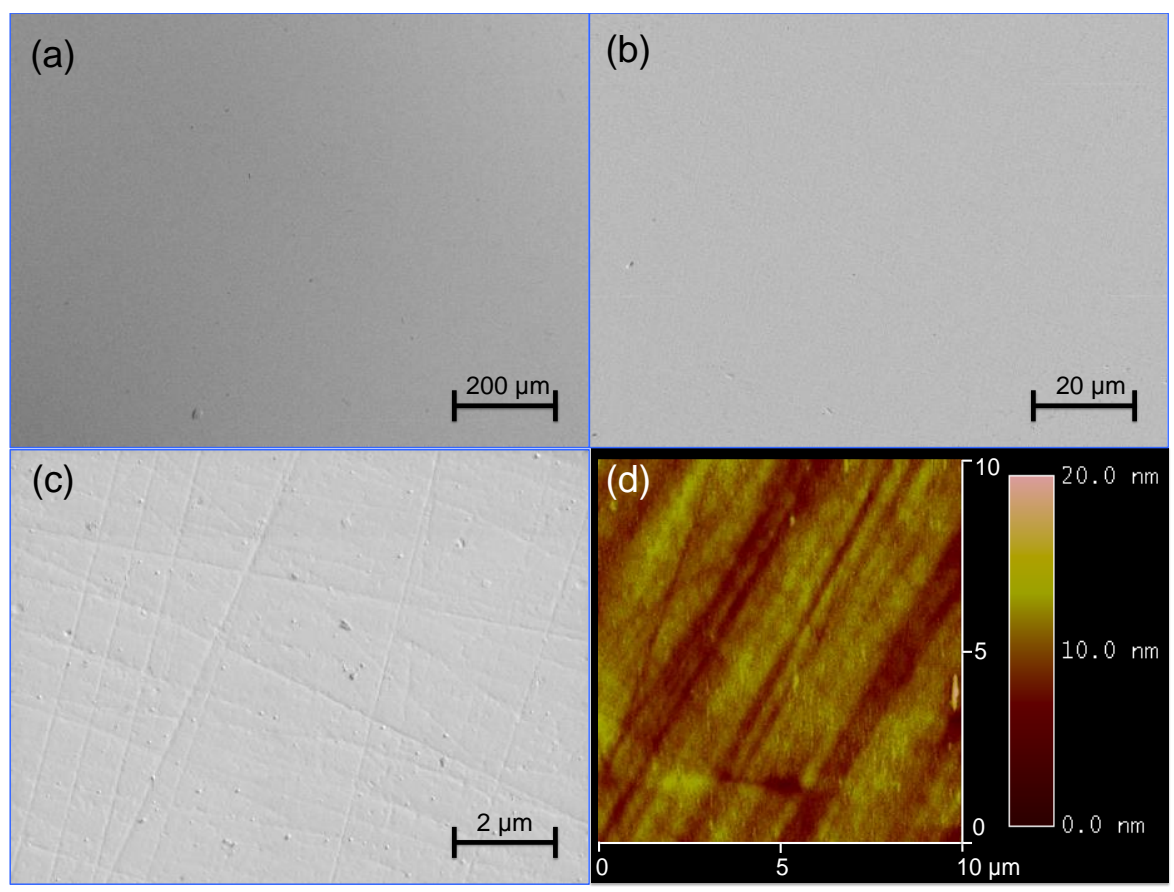

Figure III-5. (a), (b) and (c) are SEM images of the clean $\mathrm{FeS}_{2}$ substrate. (d) shows an AFM image of the clean substrate.

The surface of the pyrite slides before and after sulfur-anneal was also studied by XPS. Figure III-6 displays representative Fe $2 p$ and $S$ 2p spectra. The binding energies and full width at half magnitude (FWHM) were summarized in Table 3, which are consistent with literature values. ${ }^{26,80-83}$

Table 3. Binding energies and FWHM of representative pyrite slides

\begin{tabular}{ccccc}
\hline & \multicolumn{2}{c}{ Pre annealing } & \multicolumn{2}{c}{ Post annealing } \\
\cline { 2 - 5 } & Binding energy & FWHM & Binding energy & FWHM \\
\hline $\mathrm{Fe} \mathrm{2} \mathrm{p}_{3 / 2}$ & 707.47 & 0.83 & 707.69 & 0.77 \\
$\mathrm{~S} 2 \mathrm{p}_{3 / 2}$ & 162.78 & 0.77 & 162.96 & 0.72 \\
\hline
\end{tabular}



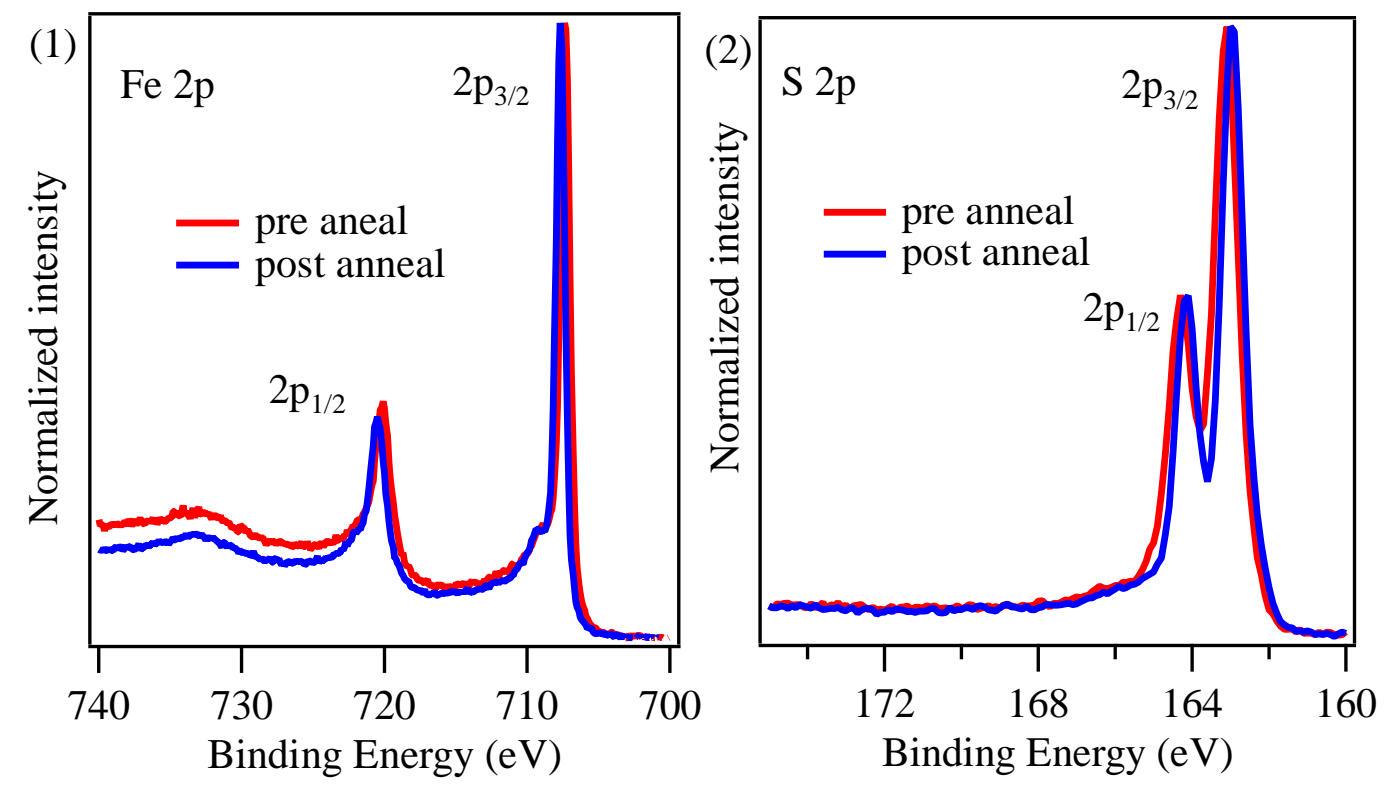

Figure III-6. Normalized $\mathrm{Fe} 2 \mathrm{p}$ and $\mathrm{S} 2 \mathrm{p}$ spectra of pre- and post-anneal pyrite slides.

The near-surface crystal structure before and after the sulfur-anneal step was studied using EBSD. The clarity of the measured Kikuchi patterns were affected by the sulfur anneal; after sulfur-annealing, electron backscatter diffraction patterns (EBSP) could be clearly captured and indexed as shown in Figure III-7. The near-surface crystal structure of the annealed slide was determined to be pyrite. The hit rate, known as the percentage of area which could be automatically indexed as pyrite by the software, of a 100 by $100 \mu \mathrm{m}^{2}$ area for pre- and post-anneal slides were $12.70 \pm 8.93 \%$ and $93.12 \pm$ 5.28\% (Figure III-8), respectively (both values are an average of three slides). 
(a)

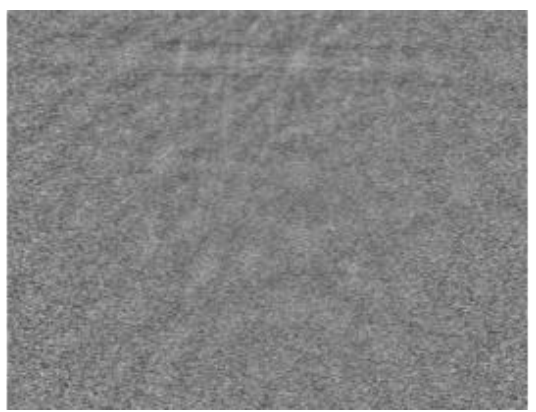

(c)

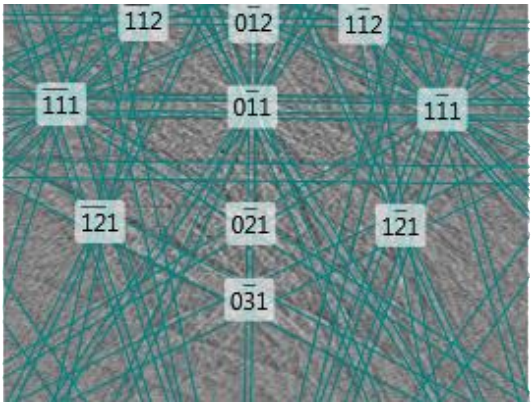

(b)

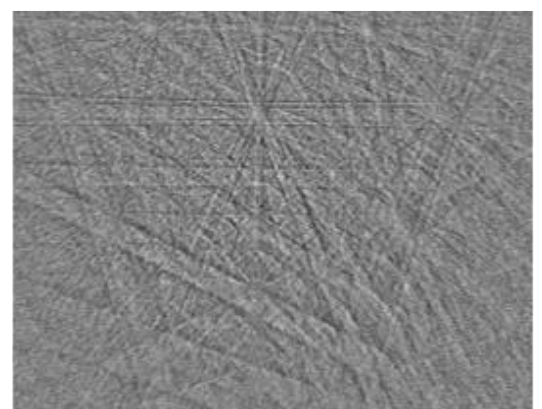

(d)

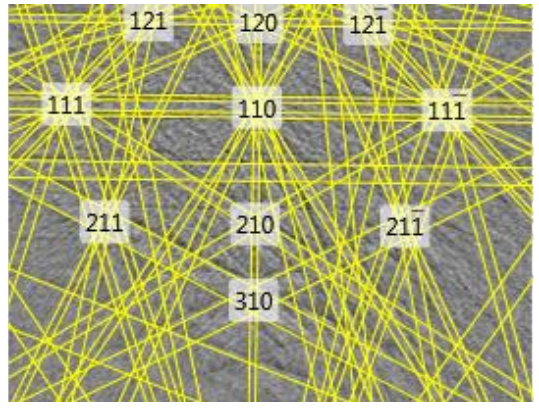

Figure III-7. EBSP (kikuchi patterns) of a pyrite slide (a) pre- and (b) post-sulfur anneal.

(c) and (d) are auto index results of two different spots on the annealed slide.
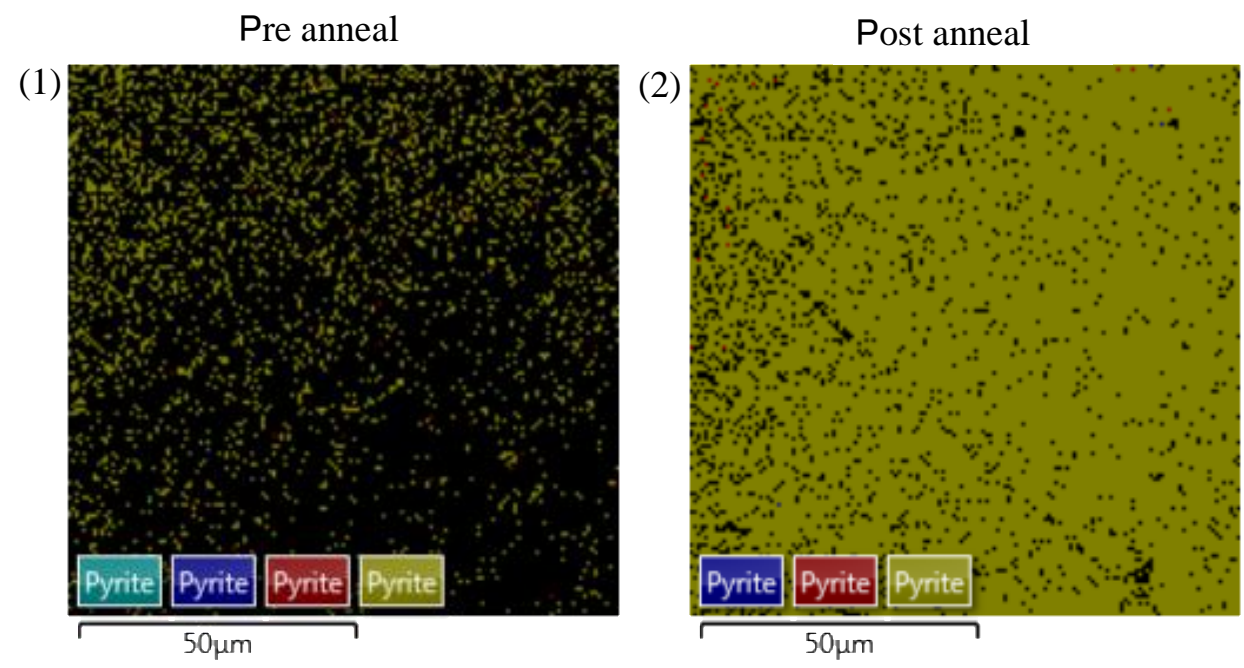

Figure III-8. Representative EBSD map scans of (1) pre-annealed slide and (2) post annealed slide. The colored spots are the area that can be indexed as pyrite, while the 
black areas could not be indexed. More than one database entry for pyrite was used to ensure that both perfectly cubic and weakly distorted pyrite could be indexed.

\section{C) Discussion}

Previously a number of experimental techniques including XPS, ${ }^{81,84,85}$ EELS, ${ }^{86}$ and infrared spectroscopy to a lesser degree, ${ }^{87}$ have been used to investigate singlecrystal $\mathrm{FeS}_{2}$ surfaces; infrared spectroscopy has been used more frequently when investigating $\mathrm{FeS}_{2}$ powders. ${ }^{39,64,65,88}$ The present work has evaluated the utility of angledependent infrared reflection absorption spectroscopy for investigating thin alkane layers on single-crystal $\mathrm{FeS}_{2}$. The utility of angle-dependent reflectance absorption spectroscopy studies coupled to computational efforts has been demonstrated for other materials including $\mathrm{Si}, \mathrm{SiO}_{2}$, and $\mathrm{CuS}_{2},{ }^{62,72,76,89}$ but has not been demonstrated for $\mathrm{FeS}_{2}$ previously.

1) Experimentally obtained angle-dependent external reflectance spectra The experimentally obtained external reflectance spectra are in qualitative agreement with what has been reported before at a single angle of incidence. However, these studies show that previously used angles of incidence (e.g. $45^{\circ}$ ) might not have been optimal from a signal-to-noise consideration. ${ }^{87}$ Furthermore, we have demonstrated that the direction and intensity of the absorption bands reported show a complex relationship with incidence angle. For an incidence angle greater than the Brewster angle (i.e. 85 degrees), all bands for p-polarized light pointed in the negative direction. For an incidence angle of 68 degrees p-polarized absorption bands were positive. For an incidence angle of 45 degrees absorption bands pointed in the positive direction for $\mathrm{p}$ - 
polarized light and in the negative direction for s-polarized light for which bands were only observable at or below an incidence angle of $45^{\circ}$. The intensity of the absorption bands was higher at 68 degrees than at 45 degrees for p-polarized light, but no experiments aimed at experimentally determining the angle of maximum signal-to-noise were undertaken. Unfortunately we were not able to reliably distinguish bands at incidence angles below 45 degrees for p-polarized light while absorption peaks were reliably detectable only at 45 degrees or less for s-polarized light. The relatively low absorbance of s-polarized absorption bands makes them difficult to detect. According to literature, ${ }^{75}$ a relatively good estimation for the absorption strength in transmission mode can be obtained from a Beer-Lambert type relationship (equation III-6):

$$
-\log \left(R_{\mathrm{S}} / R_{0}\right)=4 \pi k v d / 2.303
$$

At $2925 \mathrm{~cm}^{-1}, k \sim 0.2$, and $\mathrm{d} \sim 30 \AA$, the absorbance is approximately $1 \times 10^{-3}$, while the intensity for s-polarized light is only $2 \times 10^{-4}$, smaller by a factor of 5 compared to a transmission spectrum.

The biggest advantage of angle-dependent infrared reflection-absorption spectroscopy is in the complicated behavior of the observed absorption peaks as a function of angle. It is well known and often encountered by infrared spectroscopists trying to detect and characterize monolayers on flat surfaces (i.e. in the absence of signalenhancement due to a large surface area) that adventitious carbon present at varying concentrations at varying times makes it hard to confidently assign peaks in the $\mathrm{C}-\mathrm{H}$ stretching region. A series of spectra that must exhibit a certain dependence on angle of incidence gives an additional means to determine the origin of observed peaks. If, as in 
this case, the absorbance spectra are in good agreement with theoretical predictions then one can have confidence that the spectra are related to the overlayer since carbon contaminations in any other part of the spectrometer or sample chamber should not give rise to the same complicated spectral dependence on incidence angle.

\section{2) Calculated angle-dependent external reflectance spectra}

According to previous studies, ${ }^{62,90}$ there are in general two types of vibrations that have to be considered in order to understand the behavior of an anisotropic film on a dielectric substrate. These two vibrations are longitudinal (LO) and transverse optical (TO) modes. For $s$-polarization only TO bands can be observed. Based on equation III-2,

it is easy to find out that the TO term $\left[\frac{8 \pi \bar{v} d \cos \theta}{\varepsilon_{0}-1} \operatorname{Im}\left(\varepsilon_{s}\right)\right]$ is always positive over the whole incidence angle range (theoretically 0-90 degree), that is, absorption of s-polarized light by the adsorbate leads to an increase in reflectivity $\left(R_{\mathrm{S}}>R_{0}\right)$. Hence, the adsorption bands of s-polarization spectra are negative regardless of $\theta$. Since this TO term decreases with the increasing incidence angle, the absolute intensities of TO bands should be largest at normal incidence ( 0 degree) and then decrease with increasing $\theta$. It is worthwhile to note that the absolute band intensities of s-polarized spectra are on the order of $10^{-4}$. We were unsuccessful in obtaining reproducible and resolvable spectra at lower (i.e. 2 degree) or higher (i.e. 68 and 85 degree) incidence angles due to the low signal-to-noise ratio but expect that theory accurately predicts future experimental spectra at these angles as well. 
P-polarized light, on the other hand, has components of the electric vector both parallel and perpendicular to the surface. As a result, both the TO and LO modes make contributions to the final spectra, and their relative intensities are $\theta$-dependent. For $\theta>$ $\theta_{\mathrm{B}}$, the TO term contributes negatively to the calculated absorption band, while the LO term contributes positively to the absorption band. Since the TO term dominates the LO term, the spectra display negative absorption bands. At the Brewster angle the intensity of reflected p-polarized light approaches zero and even though Figure III-4 predicts an infinitely large absorption band at the Brewster angle this is not observed as the total amount of reflected light, and thus the signal-to-noise ratio, approaches zero. ${ }^{72}$ For $\theta<$ $\theta_{\mathrm{B}}$, the situation is the opposite: TO term shows positive absorbance, while LO term shows negative absorbance. However, the TO and LO terms compete in intensity over this incidence angle range and a second inversion will occur when the LO term is once again able to dominate the TO term at an angle $\theta$ as determined by equation III-5. The second inversion angle $\theta_{2 i}$ depends on the value of $\varepsilon_{\mathrm{s}}$ relative to $\varepsilon_{0}$. Since the dielectric function of natural pyrite is dependent on its inherent characteristics (e.g. level of impurities, surface defects, etc.) (Table 2), the angle of the second inversion is expected to vary from sample to sample. As mentioned in the experimental section, a value of 21.16 was used as the $\varepsilon_{0}$ for all the calculations, and thus $\theta_{2 i}$ was calculated as 27 degrees. For $\theta_{\mathrm{B}}>\theta>\theta_{2 i}$, the overall spectra show positive absorption bands, since the TO term plays a leading role in this case. For $\theta<\theta_{2 i}$, the absorption bands are calculated to be "negative" but, as mentioned above, we failed to obtain reproducible spectra at this range due to the low signal-to-noise ratio. 


\section{3) The combination of angle-dependent IRRAS spectroscopy and computational}

efforts

The good agreement between experimental and calculated reflection spectra of a thin adsorbate layer on pyrite indicates that angle-dependent IRRAS is a sensitive method appropriate for investigating pyrite surface chemistry. It has previously been shown that pyrazine and $4,4^{\prime}$ 'bipyridine affected charge transfer and corrosion rates for pyrite in contact with an aqueous electrolyte. It was assumed that light-induced charge transfer was facilitated by pyrazine and 4,4'-bipyridine acting as a bridge between pyrite $\mathrm{Fe}$ (II) centers and the electrolyte. However, though infrared spectroscopy was identified as a suitable candidate for understanding the resulting interface this was not possible due to an insufficient signal-to-noise ratio. ${ }^{50}$ The combination of angle-dependent IRRAS spectroscopic and computational efforts provides a tool to study these important surfaces, and therefore gaining a better understanding of the relationship between surface chemistry and the photoresponse of single crystalline pyrite/electrolyte junctions.

\section{4) Surface properties of the substrate}

The polishing, etching and annealing procedure produced mirror-like surfaces. A number of methods have been reported in literature for producing flat $\mathrm{FeS}_{2}(100)$ surfaces including electropolishing, ${ }^{91}$ polishing with $0.5 \mu \mathrm{m}$ alumina,${ }^{92}$ and polishing with 0.25

$\mu \mathrm{m}$ diamond paste. ${ }^{93}$ Only a few examples exist of studies focusing explicitly on the effects of varying polishing procedures on surface quality, ${ }^{94}$ so the full identity is not 
generally known for any reported polishing procedure. The procedure reported herein produces a mirror-like surface well suited for external reflectance infrared spectroscopy.

The goal of the polishing and etching step was to produce a macroscopically flat pyrite surface. However, these treatments left some scratches and point-like defects, the latter ones appear randomly on the substrate surface. Those defects might be caused by preferential etching of impurity inclusions or the removal of small $\mathrm{FeS}_{2}$ particles from the surface. The XPS spectra of polished and etched slides are consistent with literature. ${ }^{26,80-}$ ${ }^{82}$ Peaks at $161.3 \mathrm{eV}$ and $167.5-169.5 \mathrm{eV}$ were not detected indicating the absence of $\mathrm{S}^{2-}$ and $\mathrm{SO}_{4}{ }^{2-}$; however, a shoulder at approximately 708.9-711.3 eV indicated that small amounts of Fe-O species were present. ${ }^{26,80,82}$

The sulfur-anneal step was important for obtaining consistent reflectance spectra. The vapor pressure of $S$ in the ampoule can be estimated at approximately 6080 torr by extrapolating from existing data. ${ }^{95}$ The vapor pressure of $\mathrm{S}$ was thus much higher than the equilibrium pressure of $\mathrm{S}$ over $\mathrm{FeS}_{2}$ which has been reported as approximately 15 Torr at a temperature of $600{ }^{\circ} \mathrm{C}$. As the temperature was lowered after annealing, the end of the ampoule opposite the $\mathrm{FeS}_{2}$ slide was kept slightly cooler by positioning the ampoule at the edge of the tube furnace. This prevented $\mathrm{S}$ deposition onto the $\mathrm{FeS}_{2}$ slide.

After annealing, the XPS spectra of Fe $2 p$ and $S 2 p$ were very similar to those of pre-anneal slides. However, the sulfur-anneal step did affect the surface crystal structure. In contrast to the blurred Kikuchi patterns of pre-annealed slides, consistent with an amorphous top layer, much clearer Kikuchi patterns were obtained after annealing, and thus the hit rate of map scans increased significantly. The EBSD map scan data were 
collected and processed using an automated procedure without further manual treatment. The significantly improved detectability of surface crystal structure suggests that the $S$ anneal resulted in improved near-surface crystal structure. Furthermore, the complex refractive index after sulfur annealing matched literature values well, ${ }^{79}$ in contrast to values obtained for slides that had not been annealed. This is consistent with a non-pyrite top layer on the surface after polishing and etching; and recovered surface crystallinity after the sulfur anneal.

\section{D) Conclusions}

Mirror-like $\mathrm{FeS}_{2}$ (100) surfaces were prepared with an alkane thiol overlayer. In accordance with previous results a simple polish and etch procedure produced a mirrorlike surface, but sulfur annealing improved near-surface crystallinity. Angle-dependent infrared reflection absorption spectroscopy was used to investigate the alkane overlayer and very good agreement was found between experimental and calculated spectra. We demonstrated that external reflection infrared spectroscopy is a powerful tool for studying thin films on pyrite. The complex relationship between band intensities, band directions, incidence angle and dielectric properties of a substrate allows even weak absorption bands to be confidently assigned to surface species since adventitious carbon on other parts of the spectrometer, including the $\mathrm{KBr}$ windows and beam splitter, would not show the same complex dependency on incidence angle. However, there is still room for improvement. As we discussed in chapter II, some organic and inorganic ligands have been reported to passivate $\mathrm{FeS}_{2}$ surface. Take cyanide as an example, the expected 
absorbance of a monolayer of $-\mathrm{CN}$ on $\mathrm{FeS}_{2}$ surface was calculated to be on the order of $10^{-5}$, which is one order of magnitude lower than the detection limit for our current setup. The technique presented in this chapter holds promise to fully characterize monolayer species on $\mathrm{FeS}_{2}$ surface if the signal to noise ratio were to be increased. 


\section{PHOTOELECTROCHEMICAL BEHAVIOR OF SINGLE-CRYSTAL FES $_{2}$ UNDER ANHYDROUS AND ANOXIC CONDITIONS}

The most promising results indicating the potential of $\mathrm{FeS}_{2}$ as an energyconversion material have been obtained through photoelectrochemical studies. However, it was shown that $\mathrm{FeS}_{2}$ photoelectrochemistry was critically dependent on experimental conditions including redox-couple identity and electrochemical pre-treatment of the $\mathrm{FeS}_{2}$ electrode ${ }^{44,} 48,96,97$ the choice of redox couple affected both photon-to-electron conversion efficiency and the extent of $\mathrm{FeS}_{2}$ corrosion, ${ }^{48,98}$ and electrochemical pretreatment by cathodic polarization in $\mathrm{H}_{2} \mathrm{SO}_{4}(\mathrm{aq})$ of the $\mathrm{FeS}_{2}$ photoanode was consistently necessary to realize any significant photoresponse. ${ }^{20,44}$

It has been shown that aqueous $\mathrm{FeS}_{2}$ corrosion was not responsible for the observed photocurrent of $\mathrm{FeS}_{2}$ electrodes in contact with an aqueous $\mathrm{I}^{-} / \mathrm{I}_{3}{ }^{-}$electrolyte. ${ }^{20,98}$ Monocrystalline n-type $\mathrm{FeS}_{2}$ electrodes maintained $77 \%$ of initial current densities after passing $6.23 \times 10^{5} \mathrm{C} \mathrm{cm}^{-2}$ (at $1 \mathrm{~V}$ vs. a carbon reference) without microscopic evidence of corrosion damage. However, it is generally known that surface chemistry is often linked to photoelectrochemical performance, and it has been shown that aqueous chemistry involving the $\mathrm{FeS}_{2}$ surface can take place even in the potential range where continuous corrosion of $\mathrm{FeS}_{2}$ is not observed. ${ }^{99}$ It is not known what effect surfacelimited aqueous $\mathrm{FeS}_{2}$ chemistry has on the photoresponse of $\mathrm{FeS}_{2}$ electrodes in contact with an $\mathrm{I}^{-} / \mathrm{I}_{3}{ }^{-}$electrolyte. Therefore, it is desirable to test the photoelectrochemistry of $\mathrm{FeS}_{2}$ in a nonaqueous system where a minimum of undesired chemical reactions are expected. 
In this chapter, we compare the photoelectrochemistry of $\mathrm{FeS}_{2}$ in contact with aqueous and nonaqueous $\mathrm{I}^{-} / \mathrm{I}_{3}{ }^{-}$electrolytes and propose an explanation for the observed relationship between photovoltage and the concentration of oxidized species using a simple model. We highlight some important aspects of the system that warrant further investigation.

\section{A) Experimental section}

\section{1) Materials}

All chemicals were used as received unless mentioned specifically. Concentrated sulfuric acid (Certified ACS Plus) was obtained from Sigma-Aldrich. Acetonitrile (anhydrous, 99.8\%) was obtained from Sigma-Aldrich, and was further purified using a MB-SPS Manual Solvent Purification System to remove oxygen and moisture. The dried acetonitrile was transported in a Schlenk flask into a LABstar glovebox (MBRAUN) having a $\mathrm{N}_{2}$ atmosphere containing less than $0.5 \mathrm{ppm} \mathrm{O}_{2}$ and $0.5 \mathrm{ppm} \mathrm{H}_{2} \mathrm{O}$. KI (99\%) and LiI (99\%) were purchased from VWR and $\mathrm{I}_{2}(>99.8 \%)$ was purchased from SigmaAldrich. Single-crystalline pyrite samples were natural, originating from Turkey.

\section{2) Electrode preparation}

Electrode fabrication. $3 \mathrm{~mm}$ thick pyrite slides exposing the (100) surface were cut into several smaller pieces $\left(\sim 6 \times 6 \times 3 \mathrm{~mm}^{3}\right)$ using a diamond pen. Each piece was attached to a tinned copper wire using $\mathrm{Ga} / \mathrm{In}$ eutectic and silver paint. The electrically 
contacted pyrite pieces were sealed to a glass rod (Pyrex ${ }^{\circledR} 7740$ glass, $6 \mathrm{~mm}$ outer diameter, Corning Inc., NY) using epoxy (Loctite Hysol 1C Epoxi-Patch Adhesive) to form an electrode. The electrode was polished using a progression of diamond lapping films from $9 \mu \mathrm{m}$ down to $0.25 \mu \mathrm{m}$ and epoxy was re-applied to mask the edges of the sample leaving a flat surface of $0.1-0.3 \mathrm{~cm}^{2}$ exposed. The area of the exposed surface was determined for each electrode (Cannon scanner and ImageJ software) to convert measured currents to current densities.

Electrochemical pretreatment. Pyrite electrodes were cathodically polarized in $0.5 \mathrm{M} \mathrm{H}_{2} \mathrm{SO}_{4}(\mathrm{aq})$ that had been sparged with $\mathrm{N}_{2}$ for 30 min prior to any experiments to remove $\mathrm{O}_{2}$. A constant current density of $-15 \mathrm{~mA} \mathrm{~cm}{ }^{-2}$ was maintained to pass a total of $2.7 \mathrm{C} \mathrm{cm}^{-2}$ prior to photoelectrochemical measurements. ${ }^{44}$ A standard three-electrode cell configuration was used with a Pt mesh counter electrode and a Pt wire reference electrode.

\section{3) Photoelectrochemical data}

Solutions. Aqueous solutions were prepared from a base electrolyte $(0.5 \mathrm{M}$ $\mathrm{H}_{2} \mathrm{SO}_{4}(\mathrm{aq})$ ) that had been sparged with $\mathrm{N}_{2}(\mathrm{~g})$ for $30 \mathrm{~min}$. They were prepared to $0.5 \mathrm{M}$ $\mathrm{KI}(\mathrm{aq})$ and $0.004,0.01,0.02,0.03$, or $0.05 \mathrm{M} \mathrm{I}_{2}(\mathrm{aq})$. Nonaqueous solutions were prepared in the glovebox. LiI was dissolved in acetonitrile to a concentration of $0.5 \mathrm{M}$ in a sealed electrochemical cell. The cell was removed from the glove box and connected to a $\mathrm{N}_{2}(\mathrm{~g})$ purge. $\mathrm{I}_{2}$ was added to the solution to a final concentration of $0.004 \mathrm{M}$.

Open-Circuit Potential ( $\left.\mathbf{E}_{\mathrm{oc}}\right)$ and Current Density versus Potential (J-E) Measurements. A three-electrode setup was used for all photoelectrochemical 
experiments. A Pt mesh counter electrode and a Pt wire reference electrode were used in all cases with a Gamry Reference 600 potentiostat. All potentials were measured with respect to the solution potential and an inert Pt-disc working electrode was used to characterize the system before and after experiments. For both $E_{\mathrm{oc}}$ and $J-E$ measurements the $\mathrm{FeS}_{2}$ working electrode was left in the electrolyte for at least $10 \mathrm{~min}$ before any measurement, until the rest potential of the $\mathrm{FeS}_{2}$ electrode had stabilized from at most $\pm 1 \mathrm{mV}$ to within $\pm 0.5 \mathrm{mV}$ of the solution potential. $E_{\mathrm{oc}}$ and $J-E$ data were collected in the dark and under illumination (ABET solar simulator, model 10500) under vigorous stirring. Light intensities were either 0.1 or $0.5 \mathrm{~W} \mathrm{~cm}^{-2}$, as determined using a UV005 photodiode (OSI optoelectronics) electrode that was placed at the same position as the $\mathrm{FeS}_{2}$ electrodes. The UV500 photodiode electrode had been calibrated using a Melles-Griot 13PEM001 broadband power meter equipped with a water filter. For each electrode and experimental condition, $J-E$ data were collected without illumination before and after collection under illumination. The statistical significance of the differences of measured open-circuit potentials for the aqueous and nonaqueous electrolytes was determined using the standard $t$-test. ${ }^{100}$ The level of significance was set as 0.05 .

Current-Voltage (I-V) calculations. $I-V$ curves were calculated using two simple models (Scheme 1) both incorporating a current source $\left(I_{\mathrm{sc}}\right)$, diode characterized by a reverse saturation current, and shunt resistance $\left(R_{\mathrm{sh}}\right)$. The model in Scheme 1a assumed shunting to occur at distinct locations of the electrode surface and therefore the kinetic and mass-transfer limitations on the current $(I=\mathrm{f}(\mathrm{\eta}))$ were evaluated 
independently for the current arising from the rectifying part (photocurrent source and diode) and from shunting. The net current was calculated as the sum of the two components. This model implies that chemically distinct regions can establish within the stagnant layer near the electrode surface (Figure IV-1), affecting charge-transfer to and from corresponding electrode regions to different degrees. For example: consider the case where the concentration of oxidized species is much lower than the concentration of reduced species in solution. At a small applied negative bias ( $v s$. the bulk solution potential) cathodic shunt currents may quickly become mass-transfer limited while an anodic photoinduced current from the rectifying region is not affected significantly by mass-transfer; the contribution of the shunt current to the net current is suppressed by mass-transfer limitations. The simpler model, Scheme 1b, evaluated the effects of masstransfer limitations on the net current only. In this case the stagnant layer near the electrode surface will be chemically constant across the electrode surface (Figure IV-1 b). In both cases, the dashed lines in Scheme 1a and $1 \mathrm{~b}$ represent the electrode/electrolyte interface. The effect of mass transfer on current as a function of applied potential was evaluated using Equation IV-1, which is based on the current-overpotential equation. ${ }^{101}$

$$
\frac{I}{i_{0}}=\left(1-\frac{I}{i_{l, a}}\right) e^{(1-\alpha) f \eta}-\left(1-\frac{I}{i_{l, c}}\right) e^{-\alpha f \eta}
$$

Here, $i_{0}, i_{1, \mathrm{a}}$, and $i_{1, \mathrm{c}}$ are the exchange current, limiting anodic current, and limiting cathodic current, respectively. $\alpha$ is a transfer coefficient that was assumed to be $0.5, \eta$ is overpotential, and $f=\mathrm{F} / \mathrm{RT}$ where $\mathrm{F}$ is the Faraday constant, $\mathrm{R}$ is the gas constant, and $\mathrm{T}$ is the temperature (assumed to be $298 \mathrm{~K}$ ). It should be noted that this equation does not 
technically describe mass-transfer in a complicated system like the one proposed in Scheme 1a but serves only as an approximation.

Practically, the calculations were performed as follows for each voltage point. The $I-V$ relationship for each circuit component was calculated for the entire voltage range of interest (e.g., the $I-V$ relationship for the diode was calculated using the ideal diode equation). The voltage drop across any branch had to be equal to the sum of the voltage drops across the components in that branch subject to the constraint that the current across these components were equal. Finally, the currents calculated for the two parallel branches were added together (Figure IV-1a) or used directly (Figure IV-1b). 

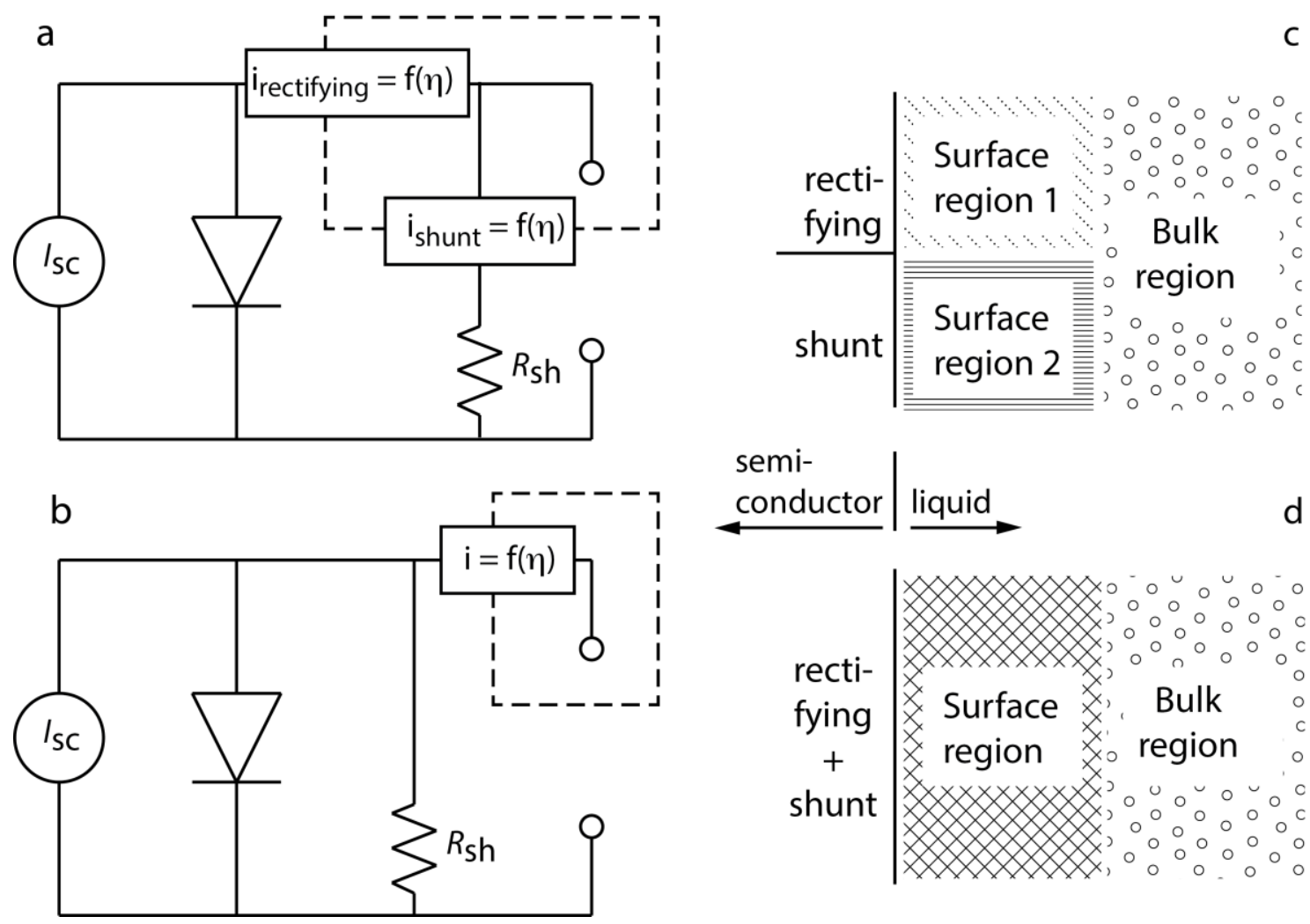

Figure IV-1. Two models for calculating I-V curves. Both models are composed of a current source $\left(I_{\mathrm{sc}}\right)$, a diode, a shunt resistance $\left(R_{\mathrm{sh}}\right)$, and current limitations by mass transfer as two independent components (a) or one single component (b). If the rectifying and shunting parts of the semiconductor electrode are physically distinct, then chemically distinct regions in the near-surface stagnant layer can be established (c) while a uniform electrode surface contacts only one, chemically homogenous, stagnant layer (d). 


\section{B) Results}

\section{1) Open-circuit potential $\left(E_{\mathrm{oc}}\right)$}

All open-circuit potentials were measured with respect to the solution potential for both the aqueous and nonaqueous systems. The recorded open-circuit potentials under illumination are summarized in Tables 4 and 5. The open-circuit potential in the dark, measured for both $\mathrm{FeS}_{2}$ and Pt-disc electrodes in the aqueous and nonaqueous electrolytes was within $0.5 \mathrm{mV}$ of the solution potential. The averages of the measured open-circuit potentials were slightly different for the aqueous vs. nonaqueous electrolytes but the differences were not statistically significant for low illumination intensities. For high illumination intensities, the open-circuit potentials in both cases were within one \pm standard deviation. A more detailed T-test was performed later; and the result indicated that the higher open-circuit potential using the aqueous electrolyte compared to the nonaqueous electrolyte under $0.5 \mathrm{~W} \mathrm{~cm}{ }^{-2}$ illuminations was statistically significant. Illumination intensity, as expected, affected the open-circuit potentials in both aqueous and nonaqueous electrolytes. Open-circuit potentials decreased by 59 and $53 \mathrm{mV}$ in the aqueous and nonaqueous electrolytes, respectively, when the illumination intensity was reduced from 0.5 to $0.1 \mathrm{~W} \mathrm{~cm}^{-2}$ (Table 4); the difference between the aqueous and nonaqueous case was again statistically insignificant. The open-circuit potentials under illumination were dependent on the concentration of dissolved $\mathrm{I}_{2}$ (Table 5). The overall trend was a negative correlation between the open-circuit potential and $\mathrm{I}_{2}$ concentration $\left(\left[\mathrm{I}_{2}\right]\right)$. The trend is emphasized if the open-circuit potential data for each individual electrode was normalized to the maximum open-circuit potential recorded with that 
electrode (Table 6). Two sets of calculated open-circuit potential data were normalized in the same way as the experimental data (Table 6). Different trends were observed depending on whether Scheme $1 \mathrm{a}$ or $\mathrm{b}$ were used. No dependence of calculated opencircuit potential $\left(E_{\mathrm{oc}}\right)$ on $i_{\mathrm{l}, \mathrm{c}}$ was observed if mass-transfer limitations were applied to the net current (Figure IV-1b). However, if mass-transfer limitations were considered to apply independently to the currents associated with the shunt resistance and photodiode (Figure IV-1a), calculated $E_{\text {oc }}$ were observed to depend on $i_{1, \mathrm{c}}$. The above values were calculated using $i_{\mathrm{l}, \mathrm{a}}=0.2 \mathrm{~A}, I_{\mathrm{sc}}=0.01 \mathrm{~A}, i_{0}=0.03 \mathrm{~A}$, a reverse saturation current $=5 \times$ $10^{-5} \mathrm{~A}$, and a shunt resistance $R_{\mathrm{sh}}=15 \mathrm{Ohm}$. The experimentally determined cathodic limiting current $\left(i_{1, \mathrm{c}}\right)$ was $0.0025,0.006,0.012,0.02$ and 0.03 A for $\left[I_{2}\right]$ of $0.004,0.01$, $0.02,0.03,0.05 \mathrm{M}$, respectively. The anodic and cathodic limiting currents were based on experimental data obtained with a $\mathrm{FeS}_{2}$ electrode in the dark. $I_{\mathrm{sc}}=0.01 \mathrm{~A}$ was chosen because it closely matches the short-circuit current density for a typical $\mathrm{FeS}_{2}$ electrode under 1 sun illumination. $i_{0}=0.03$ was chosen to match calculated $I-V$ data (equation IV-1) to that of experimental data. A reverse saturation current $=5 \times 10^{-5} \mathrm{~A}$ was chosen to produce a photovoltage of $\sim 200 \mathrm{mV}$ for $I_{\mathrm{sc}}=0.01 \mathrm{~A}$. The shunt resistance of $15 \mathrm{Ohm}$ was chosen by fitting a small region around $\mathrm{E}=0$ of the dark $J-E$ curves obtained with $\mathrm{FeS}_{2}$ electrodes; this provided an upper, most conservative, estimate of $R_{\mathrm{sh}}$ as it ascribes the entire effective resistance to the shunt resistance. The observed trend where calculated $E_{\mathrm{oc}}$ varied as a function of the cathodic limiting current was robust. It was not dependent on residing within some narrow range of anodic limiting current, photocurrents, exchange-currents, or shunt resistance. 
Table 4. Open-circuit potentials under high $\left(0.5 \mathrm{~W} \mathrm{~cm} \mathrm{~cm}^{-2}\right)$ and low $\left(0.1 \mathrm{~W} \mathrm{~cm}^{-2}\right)$ illumination intensities in aqueous and nonaqueous electrolytes prepared to $0.5 \mathrm{M} \mathrm{I}^{-}$and $0.004 \mathrm{M} \mathrm{I}_{2}$. The data is presented as the mean \pm 1 standard deviation.

\begin{tabular}{ccc}
\hline \multirow{2}{*}{ Intensity $\left(\mathrm{W} \mathrm{cm}^{-2}\right)$} & \multicolumn{2}{c}{$E_{\mathrm{oc}}(\mathrm{mV})$} \\
\cline { 2 - 3 } & $195 \pm 12$ & Nonaqueous electrolyte \\
\hline 0.5 & $136 \pm 12$ & $124 \pm 8$ \\
0.1 & & \\
\hline
\end{tabular}

Table 5. Open-circuit potentials under illumination $\left(0.1 \mathrm{~W} \mathrm{~cm}^{-2}\right)$ in aqueous electrolytes prepared to $0.5 \mathrm{M} \mathrm{I}^{-}$and different concentrations of $\mathrm{I}_{2}\left(\left[\mathrm{I}_{2}\right]\right)$. The data is presented as the mean \pm 1 standard deviation.

\begin{tabular}{cc}
\hline$\left[\mathrm{I}_{2}\right](\mathrm{M})$ & $E_{\mathrm{oc}}(\mathrm{mV})$ \\
\hline 0.004 & $115 \pm 7$ \\
0.01 & $113 \pm 14$ \\
0.02 & $99 \pm 12$ \\
0.03 & $90 \pm 6$ \\
0.05 & $81 \pm 3$ \\
\hline
\end{tabular}


Table 6. Normalized open-circuit potential data under illumination $\left(0.1 \mathrm{~W} \mathrm{~cm} \mathrm{~cm}^{-2}\right)$ in aqueous electrolytes prepared to $0.5 \mathrm{M} \mathrm{I}^{-}$and different concentrations of $\mathrm{I}_{2}\left(\left[\mathrm{I}_{2}\right]\right)$. The data is presented as the mean \pm 1 standard deviation (second column). Calculated opencircuit potential data are a function of limiting cathodic current (two rightmost columns).

Normalized open-circuit potentials

\begin{tabular}{cccc}
{$\left[\mathrm{I}_{2}\right](\mathrm{M})$} & Experimental data & $\begin{array}{c}\text { Calculated data } \\
(\text { Scheme 1a) }\end{array}$ & $\begin{array}{c}\text { Calculated data } \\
(\text { Scheme 1b) }\end{array}$ \\
\hline 0.004 & $0.98 \pm 0.03$ & 1.00 & 1.00 \\
0.01 & $0.96 \pm 0.05$ & 0.93 & 1.00 \\
0.02 & $0.84 \pm 0.03$ & 0.88 & 1.00 \\
0.03 & $0.77 \pm 0.02$ & 0.87 & 1.00 \\
0.05 & $0.69 \pm 0.04$ & 0.87 & 1.00 \\
\hline
\end{tabular}

2) Current-density vs. potential (J-E).

Representative $J-E$ data for $\mathrm{FeS}_{2}$ electrodes in contact with the aqueous and nonaqueous $\mathrm{I}_{3} \mathrm{I}_{3}^{-}$electrolytes are shown in Figure IV-2. The $J-E$ response for any individual electrode was unchanging over the course of any experiment. Data were collected in the dark, under illumination, and then again in the dark; the dark traces consistently overlapped well. The photoelectrochemical behavior was similar using the aqueous and nonaqueous electrolyte. Dark $J-E$ curves show no clear evidence of rectification and the cathodic current quickly becomes mass-transfer limited. As 
expected, both $E_{\mathrm{oc}}$ and short-circuit current density $\left(J_{\mathrm{sc}}\right)$ were affected by illumination and illumination intensity. However, the cathodic current was affected to a much greater degree using the nonaqueous electrolyte. Figure IV-3 shows $J-E$ data for $\mathrm{FeS}_{2}$ and $\mathrm{Pt}$ electrodes in the aqueous and nonaqueous electrolytes. The aqueous electrolyte data show a greater increase in both anodic and cathodic current density at low overpotentials for the Pt compared to the $\mathrm{FeS}_{2}$ electrode; the cathodic currents quickly became masstransfer limited in both cases. In the nonaqueous system a greater increase in both anodic and cathodic current density at low overpotentials was observed for $\mathrm{FeS}_{2}$ compared to $\mathrm{Pt}$ electrodes. However, at larger overpotentials the anodic current density quickly became greater for the Pt electrode than for the $\mathrm{FeS}_{2}$ electrode. In contrast to the aqueous system there is no easily identified potential region in the nonaqueous electrolyte where the current was mass-transfer limited.

The concentration of dissolved $\mathrm{I}_{2}$ in the aqueous electrolyte affected the $J-E$ response (Figure IV-4). As expected, greater limiting cathodic current densities were reached as larger amounts of oxidized species were present. Consistent with the direct $E_{\mathrm{oc}}$ measurements reported above, open-circuit potential decreased as $\mathrm{I}_{2}$ concentration was increased. $I-V$ curves calculated using the model in Figure IV-1a (Figure IV-4 (c) and (d)) showed the same qualitative shape as the experimental data. 
(a)

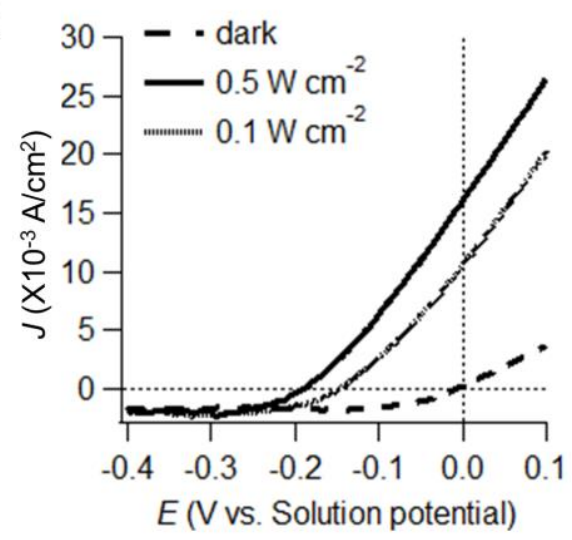

(b)

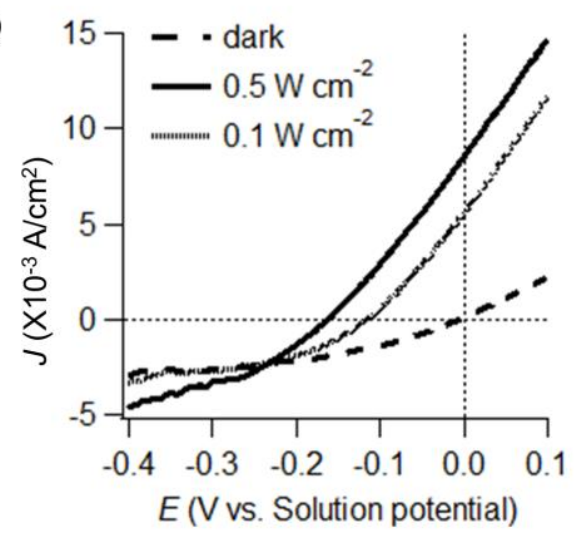

Figure IV-2. Representative $J-E$ data for $\mathrm{FeS}_{2}$ electrodes in contact with aqueous (a) and nonaqueous (b) $\mathrm{I}^{-}, \mathrm{I}_{3}{ }^{-}$electrolytes. The three traces in each graph were collected in the dark, under intense illumination $\left(0.5 \mathrm{~W} \mathrm{~cm}^{-2}\right)$ and under approximately 1 sun illumination intensity $\left(0.1 \mathrm{~W} \mathrm{~cm}^{-2}\right)$. The scan rate was $100 \mathrm{mV} \mathrm{s}^{-1}$.
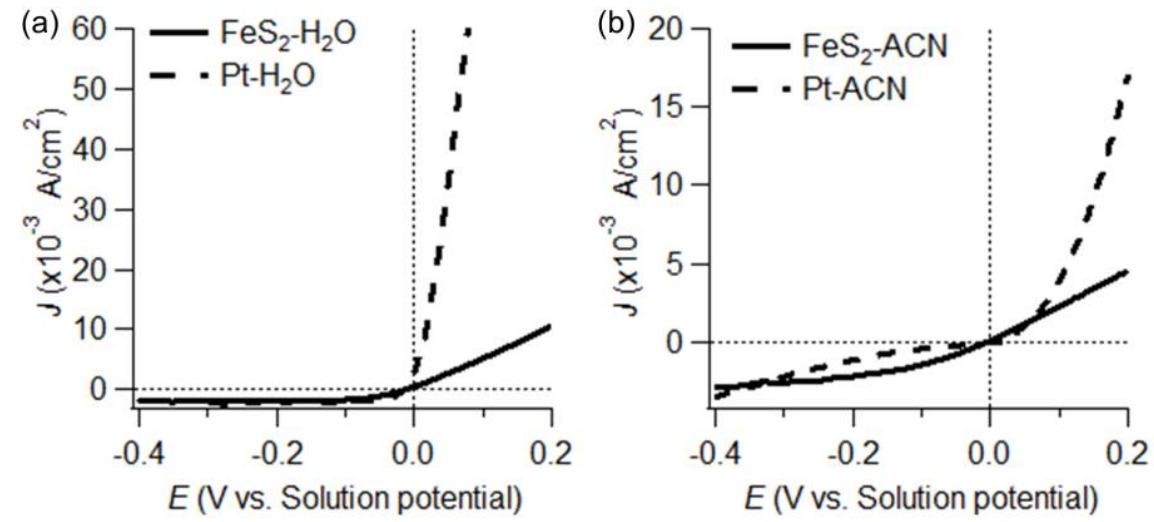

Figure IV-3. $J-E$ curves for $\mathrm{FeS}_{2}$ and $\mathrm{Pt}$ electrodes in aqueous and nonaqueous electrolytes without illumination. (Scan rate: $100 \mathrm{mV} \mathrm{s}^{-1}$ ) 

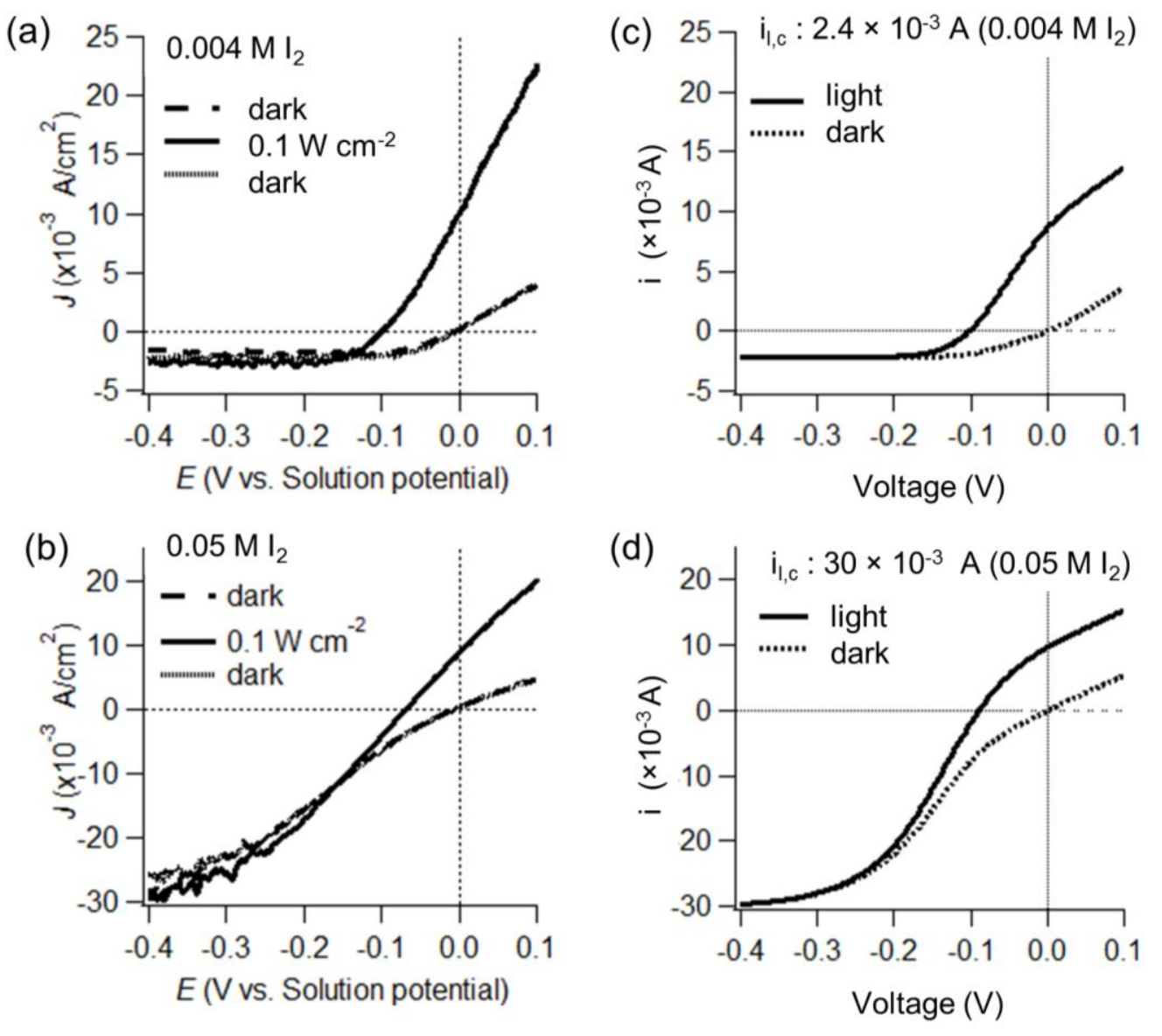

Figure IV-4. Representative experimental $J-E$ data for a $\mathrm{FeS}_{2}$ electrode in contact with a solution containing $0.5 \mathrm{M} \mathrm{I}^{-}$and $0.004 \mathrm{M} \mathrm{I}_{2}$ (a), or $0.5 \mathrm{M} \mathrm{I}^{-}$and $0.05 \mathrm{M} \mathrm{I}_{2}$ (b). The three traces of experimental data in panels (a) and (b) were collected in the dark, under illumination $\left(0.1 \mathrm{~W} \mathrm{~cm}^{-2}\right)$ and directly again in the dark. The scan rate was $20 \mathrm{mV} \mathrm{s}^{-1}$. Dark and light curves of calculated data in panels (c) and (d) were calculated using the parameters mentioned earlier. 


\section{3) $\mathrm{FeS}_{2}$ electrode corrosion}

$\mathrm{FeS}_{2}$ corrosion in the aqueous electrolyte was indirectly measured based on the concentration of dissolved Fe ions. The working electrode was kept at the solution potential or open-circuit potential under illumination or in the dark for 30 minutes. No precipitation was observed during any experiments. The amount of Fe ion dissolved into the electrolyte was measured at Oregon Health and Sciences University using an inductively coupled plasma mass spectrometer (ICP-MS). The amounts of dissolved Fe at the end of each experiment are given in Table 7. An upper limit on the faradaic efficiency of $\mathrm{FeS}_{2}$ corrosion can be calculated using the total number of electrons passed, combined with the assumption that the reaction proceeds according the most electronintensive chemical reaction:

$$
\mathrm{FeS}_{2}+8 \mathrm{H}_{2} \mathrm{O} \rightarrow \mathrm{Fe}^{2+}+2 \mathrm{HSO}_{4}^{-}+14 \mathrm{H}^{+}+14 e^{-}
$$

Therefore, the average cathodic current generated by corrosion of pyrite electrode from reaction IV-2 is given as

$$
\overline{\mathrm{l}}=\frac{\mathrm{Z} \cdot \mathrm{F} \cdot[\mathrm{Fe}] \cdot \mathrm{V}}{\mathrm{t}}
$$

where $\mathrm{z}$ is the number of electrons involved in the reaction; in this case, $\mathrm{z}$ equals 14 . F is the Faraday constant, $[\mathrm{Fe}]$ is the dissolved Fe concentration, $\mathrm{V}$ is the total volume, $\mathrm{t}$ is the total reaction time. Without illumination or external bias, an average of $37.2 \mathrm{nmol}$ pyrite was released into the $20 \mathrm{~mL}$ aqueous electrolyte after $30 \mathrm{~min}$. The calculated corrosion current is only $28 \mu \mathrm{A}$. Under intense illumination $\left(0.5 \mathrm{~W} \mathrm{~cm}^{-2}\right)$ with the electrode held at the solution potential, the corrosion current increased to $46 \mu \mathrm{A}$. Compared to short circuit 
current for $\mathrm{FeS}_{2} / \mathrm{I}^{-}, \mathrm{I}_{3}{ }^{-}$half cell, the current generated by photocorrosion and corrosion of the electrolyte was two orders of magnitude lower. Nonetheless, it seemed that illumination had a slight effect on rate of $\mathrm{FeS}_{2}$ corrosion.

Table 7. Dissolved Fe-ion concentration after $30 \mathrm{~min}$. Each data is an average of three trials and is presented as the mean \pm 1 standard deviation.

\section{$[\mathrm{Fe}](\mu \mathrm{M})$}

$\begin{array}{cc}\text { Illuminated at } \boldsymbol{E}_{\text {solution }} & 3.09 \pm 1.39 \\ \text { Illuminated at } \boldsymbol{E}_{\mathrm{oc}} & 3.18 \pm 0.84 \\ \text { Dark at } \boldsymbol{E}_{\text {solution }} & 1.86 \pm 0.47\end{array}$

\section{C) Discussion}

1) Influence of $I_{2}$ concentration on the current-voltage characteristics of singlecrystalline pyrite

The concentration of iodine affected the observed photovoltage through the cathodic limiting current $\left(i_{1, c}\right)$. The observed relationship between $E_{\mathrm{oc}}$ and iodine concentration, supported by calculated $I-V$ curves, suggests that shunting may have been a localized phenomenon in our system, in agreement with previous reports where photoactivity has been shown to vary across the $\mathrm{FeS}_{2}$ electrode surface. ${ }^{48,}$ 96, 102 Other models exist that explain how photovoltages are affected by electroactive-species concentration for ideal and non-ideal semiconductor/liquid junctions. For an ideal n-type 
semiconductor/liquid junction the photovoltage remains unaffected by a varying concentration of oxidized species (while maintaining the concentration of reduced species) even though the solution redox potential is affected. ${ }^{103}$ Current understanding of $\mathrm{FeS}_{2} /$ liquid junctions as non-ideal semiconductor/liquid junctions is supported by the fact that they do not behave as ideal semiconductor/liquid junctions. The model first derived to describe ideal semiconductor/liquid junctions ${ }^{103}$ has been applied towards Fermi-level pinned semiconductor/liquid junctions where the barrier height is invariant with the concentration of redox species and $E_{\mathrm{oc}}$ is limited by recombination via redox species in solution. ${ }^{104}$ In this case, $E_{\mathrm{oc}}$ is expected to decrease with increasing concentration of oxidized species which is the same result obtained with the model presented in this paper. However, the previous model connects $E_{\mathrm{oc}}$ and the concentration of oxidized species (when it is the limiting species) through the majority-carrier current from the semiconductor to the solution, which is dependent on the concentration of oxidized species. The model presented in this paper treats the rectifying junction as a buried junction, with strong Fermi-level pinning, which is likely the case for current $\mathrm{FeS}_{2} /$ liquid junctions. In this case, the concentration of oxidized species would not determine the forward majority-carrier current across the rectifying junction and, based on this alone, $E_{\mathrm{oc}}$ would not depend on the concentration of oxidized species.

The insights gained using the model presented in Scheme 1a are generally useful. They add more evidence in addition to the previous literature of the benefits with $J-E$ data obtained using an electrolyte having significant amounts of both reduced and oxidized species and $J-E$ data obtained using an electrolyte having low amounts of 
reduced or oxidized species. The former will generally give the best understanding of the system as a whole while the latter may suggest the extent to which ohmic shunt resistances are affecting $J-E$ data. In this study, the model presented in Scheme 1a suggests that the $E_{\mathrm{oc}}$ observed using low $\left[\mathrm{I}_{2}\right]$ provides a good estimate of the maximum achievable photovoltage using our present experimental system. However, the model does not address whether photovoltages in excess of $200 \mathrm{mV}$ are achievable using $\mathrm{FeS}_{2}$.

\section{2) Influence of electrolyte-identity on the current-voltage characteristics of single-} crystalline pyrite

It is well known that surface chemistry is frequently correlated to semiconductor photoelectrochemistry, and surface chemical treatments have, as mentioned in the introduction, consistently been reported as a prerequisite for $\mathrm{FeS}_{2}$ photoactivity though their exact influence on the surface remains undetermined. Furthermore, detailed studies have shown that the $\mathrm{FeS}_{2}$ surface interacts with aqueous solutions even when bulk decomposition is absent, ${ }^{105}$ and that applied potential determines what species are formed. ${ }^{107}$ We hypothesized that transitioning from an aqueous to a nonaqueous electrolyte would affect the photoelectrochemical response of a $\mathrm{FeS}_{2} / \mathrm{I}^{-}, \mathrm{I}_{3}{ }^{-}$liquid junction by virtue of greatly reducing the opportunities for surface-limited aqueous $\mathrm{FeS}_{2}$ chemistry (in contrast to aqueous corrosion chemistry which may not be surface-limited). The presented data show that transitioning from an aqueous electrolyte with a high concentration of $\mathrm{H}^{+}$to a nonaqueous electrolyte without $\mathrm{H}^{+}$was possible while preserving a significant photoresponse that remained qualitatively unchanged; the 
photoresponse was not dependent on a high activity of protons or bulk amounts of $\mathrm{H}_{2} \mathrm{O}$. However, it also showed that chemistry resulting from interactions with the aqueous electrolyte was not limiting the photoresponse of the $\mathrm{FeS}_{2} / \mathrm{I}^{-}, \mathrm{I}_{3}{ }^{-}$half-cell. A hypothesis of narrower scope can be proposed, and should be tested next: aqueous and oxic surface chemistry resulting from the cathodic pretreatment or transport of electrodes through an ambient environment chemically modifies the surface such that the photoelectrochemical performance is affected.

The results shown herein further support previous conclusions that $\mathrm{FeS}_{2}$ photocorrosion is not directly related to the observed photoresponse, but do not speak conclusively to the importance of surface-limited aqueous and oxic chemistry as the electrodes were all etched in $0.5 \mathrm{M} \mathrm{H}_{2} \mathrm{SO}_{4}(\mathrm{aq})$. Several studies have previously investigated aspects of the role of corrosion on $\mathrm{FeS}_{2}$ photoelectrochemistry. ${ }^{20,45,99}$ The photocorrosion of $\mathrm{FeS}_{2}$ was studied by polarizing pyrite electrode at a high anodic potential (1.0 V vs. a carbon reference electrode) for a prolonged time. No significant morphological signs of corrosion were detected after several days of continuous operation. ${ }^{20}$ Similar experiments were performed using $\mathrm{FeS}_{2}$ particles. ${ }^{106}$ It was proposed that water, or more specifically, $\mathrm{OH}^{-}$plays an essential role in photoelectrochemical dissolution of $\mathrm{FeS}_{2}$ by transferring the light-generated holes in the valence band of $\mathrm{FeS}_{2}$ to the $\mathrm{S}_{2}{ }^{2-}$ cites. ${ }^{106}$ The presented results add in addition to previous knowledge a quantitative measure of the faradaic corrosion yield near relevant operating conditions with the aqueous $\mathrm{I}^{-}, \mathrm{I}_{3}^{-}$electrolyte. 


\section{D) Conclusions}

In this chapter, we reported the photoelectrochemical behavior of a $\mathrm{FeS}_{2} / \mathrm{I}^{-}, \mathrm{I}_{3}^{-}$ half-cell as a function of $\mathrm{I}_{2}$ concentration and electrolyte identity $\left(\mathrm{H}_{2} \mathrm{SO}_{4}(\mathrm{aq})\right.$ or acetonitrile). We demonstrated that shunting may predominately occur only at distinct locations of the electrode surface; and that varying the relative concentrations of reduced and oxidized species can be used to provide insights into specific aspects of the photoelectrochemical system such as maximum attainable $E_{\mathrm{oc}}$. We report a simple model that explains the observed phenomena.

We also demonstrated that pyrite exhibited qualitatively similar photoresponses in the aqueous and nonaqueous system indicating that aqueous chemistry involving $\mathrm{FeS}_{2}$ and the electrolyte did not determine the junction properties. This was further supported by the quantitative studies of the faradaic corrosion yield, which showed that while some corrosion occurred the corrosion current density was low compared to observed photocurrents. 


\section{THE INFLUENCE OF CHEMICAL TREATMENT ON THE PHOTOELECTROCHEMICAL PROPERTIES OF PYRITE INVESTIGATED USING NON-COORDINATING REDOX SPECIES}

With the aim of improving the photo-conversion efficiency as well as photo stability, many efforts have been made to modify pyrite surfaces. For instance, electrochemical etching has been consistently reported as a prerequisite for any detectable photoresponse of $\mathrm{FeS}_{2}{ }^{20,}{ }^{44}$ Furthermore, it has been demonstrated that significant increases in photovoltage can be observed by treating pyrite electrode surface using inorganic (i.e. KCN) or organic ligands (i.e. pyrazine). ${ }^{48,97}$ However, those experiments were carried out in aqueous electrolyte with coordinating redox species (e.g. $\left.\mathrm{I}_{3}{ }^{-} / \mathrm{I}^{-}, \mathrm{Fe}^{3+/ 2+}\right)$. It has been shown that $\mathrm{FeS}_{2}$ surface can easily react with electrolyte under those conditions. ${ }^{37,}$ 99, 107 The possibility of undesired reactions makes it difficult to clearly understand the exact functions of the surface treatments on pyrite surface. In addition, even though infrared spectroscopy efforts have been made to study the structure of complexes forming on $\mathrm{FeS}_{2}$ surface, the chemical identity of the surface was not been determined experimentally due to the lack of instrumental sensitivity. ${ }^{97}$

Therefore, in order to gain a clearer picture about how surface adsorbate improves the solar performance of pyrite electrodes, we chose a non-aqueous system with noncoordinating redox species $\left(\mathrm{Fc}^{+/ 0}\right)$ for photoelectrochemical studies. Our previous work has shown that a significant photoresponse of pyrite can be retained when transitioning from an aqueous electrolyte with a high concentration of $\mathrm{H}^{+}$to a nonaqueous electrolyte 
without $\mathrm{H}^{+}$in the present of $\mathrm{I}_{3}{ }^{-} / \mathrm{I}^{-} \cdot{ }^{108}$ Similar results have also been performed using noncoordinating redox couple, $\mathrm{CoCp}_{2}{ }^{+/ 0}$, in acetonitrile. ${ }^{37}$

In this chapter, we studied the photoelectrochemical behavior of pyrite electrode after surface ligand $(-\mathrm{CN})$ treatments in contact with non-coordinating redox couple $\left(\mathrm{Fc}^{+/ 0}\right)$ in acetonitrile. The pyrite surface bonds were investigated using X-ray photoelectron spectroscopy. The improvement in photovoltage was discussed in terms of charge recombination models and coordinated surface chemistry.

\section{A) Experimental section}

\section{1) Materials}

Concentrated sulfuric acid (ACS grade), ferrocene (98\%), and ferrocenium tetraflouroborate (technical grade) were purchased from Sigma-Aldrich. Acetonitrile (>99.8\%, anhydrous) was purchased from EMD. Potassium cyanide (98\%) was purchased from J.T. Baker. Lithium perchlorate (99.99\%, anhydrous) was purchased from VWR. Hydranal ${ }^{\circledR}$-Formamide was purchased from Fluka. Chemicals were used as received unless otherwise specified. Ferrocene was purified by sublimation. Potassium

cyanide was purified by recrystallization from a mixture of $\mathrm{H}_{2} \mathrm{O}$ and $\mathrm{CH}_{3} \mathrm{CH}_{2} \mathrm{OH}(1: 3) .{ }^{109}$ All chemicals except sulfuric acid were stored in a nitrogen-filled glovebox (LABstar MBRAUN, less than 0.5 ppm $\mathrm{O}_{2}$ and $\mathrm{H}_{2} \mathrm{O}$ ). Natural single-crystal pyrite samples were originated from Turkey. 


\section{2) Electrode preparation}

Electrode fabrication. The electrode fabrication procedure has been reported

previously. ${ }^{108}$ In brief, a pyrite slide $(\sim 3 \mathrm{~mm}$ thick $)$ was cut into small pieces $(\sim 0.5 \times 0.5$ $\mathrm{cm}^{2}$ ) and connected to a tinned copper wire with $\mathrm{Ga} / \mathrm{In}$ eutectic and silver paint. The wire was threaded through a glass rod and sealed in place using epoxy (Loctite Hysol 1C Epoxi-Patch Adhesive); the epoxy also served to mask the sample to expose the (100) face only, masking any edges. The exposed face was progressively polished using diamond lapping films (particle size from $9 \mu \mathrm{m}$ to $0.25 \mu \mathrm{m}$ ). After polishing, the edge of polished pyrite electrode was again covered with epoxy. Electrode surface areas ranged from 0.15 to $0.30 \mathrm{~cm}^{2}$, determined with a Cannon scanner and ImageJ software. Prior to measurements, all pyrite electrodes were electrochemically etched in $0.5 \mathrm{M} \mathrm{H}_{2} \mathrm{SO}_{4}$ by passing a constant current density of $-15 \mathrm{~mA} / \mathrm{cm}^{2}$ for $3 \mathrm{~min}$. The $\mathrm{H}_{2} \mathrm{SO}_{4}(\mathrm{aq})$ electrolyte was deoxygenated prior to experiments by purging with $\mathrm{N}_{2}$ for at least 30 min. Following the cathodic etch, electrodes were quickly transferred into the glovebox to minimize air exposure.

Electrode-surface modification. Electrodes were chemically modified by immersion for $1 \mathrm{~h}$ in $0.5 \mathrm{M} \mathrm{KCN}$ solution in formamide. Electrodes were then in turn soaked in neat formamide to remove excess $\mathrm{KCN}$ and acetonitrile to remove traces of formamide. 


\section{3) Photoelectrochemical measurements}

Electrolyte and cell setup. The electrolyte was prepared by dissolving $20 \mathrm{mM}$ ferrocene, $2 \mathrm{mM}$ ferrocenium tetraflouroborate and $100 \mathrm{mM} \mathrm{LiClO}_{4}$ in $20 \mathrm{~mL}$ of acetonitrile inside the glovebox. A three-electrode configuration with a Pt wire as the reference electrode, poised at the solution potential, and a Pt flag as the counter electrode was used for all electrochemical experiments. The electrolyte was characterized using a glassy carbon electrode as the working electrode before and after experiments.

Open-Circuit Potential $\left(\mathrm{E}_{\mathrm{oc}}\right)$, and Current Density versus Potential (J-E) data. Open circuit potential $\left(E_{\mathrm{oc}}\right)$ and current density $v s$. potential $(J-E)$ data were collected before and after KCN treatment, with and without $0.1 \mathrm{~W} / \mathrm{cm}^{2}$ illuminations. Short circuit current $\left(J_{\text {sc }}\right)$ was obtained from the y-intercept of the $J-E$ curves under illuminations. Light intensities were determined by placing a calibrated UV005 photodiode (OSI optoelectronics) electrode at the same position as the pyrite electrode. All potentials were measured vs. the solution potential and reported as such. The statistical significance of the differences of $E_{\mathrm{oc}}$ and $J_{\mathrm{sc}}$ before and after surface treatments were evaluated by performing $t$-tests. ${ }^{100}$ A significance level of $5 \%$ was used for the calculation.

\section{4) Surface characterization}

Sample preparation. The pyrite samples for X-ray photoelectron spectroscopy

measurements are prepared in a slightly different way due to the difficulties of disassembling pyrite photodiodes. The thin pyrite slide was directly connected to a piece of copper wire using an alligator clip and then cathodically etched in $0.5 \mathrm{M} \mathrm{H}_{2} \mathrm{SO}_{4}$ right 
after polished. The etched slide was quickly transferred to a glovebox for further treatments. $\mathrm{KCN}$ treatment was carried out by immersing etched slide in $0.5 \mathrm{M} \mathrm{KCN}$ in formamide in a glovebox for $1 \mathrm{~h}$. Control experiments was carried out by immersing etched slide in neat formamide for the same amount of time. The treated slide was then rinsed with formamide and acetonitrile in order to the match the working condition of photoelectrochemical experiments. Before any XPS analysis, the slides were dried in a roughing-vacuum-pump chamber for at least 4 hours to get rid of any volatile species.

X-ray photoelectron spectroscopy. Spectra were collected using a PHI VersaProbe II Surface Analysis instrument equipped with an $\mathrm{Al} \mathrm{K}_{\alpha}$ X-ray source (1486.6 $\mathrm{eV}$ photo energy). The measurements were taken at $45^{\circ}$ take-off angle with a beam size of $200 \mu \mathrm{m}$. A neutralizer was operated at $1.0 \mathrm{~V}$ and $20.0 \mu \mathrm{A}$ through all experiments. The resolution of elemental scans was $0.05 \mathrm{eV}$. The pass energy was $187.5 \mathrm{eV}$ for survey scans and $23.5 \mathrm{eV}$ for detailed scans. All spectra were calibrated using the Fe $2 \mathrm{p}_{2 / 3}$ peak at $707 \mathrm{eV}$. Peak fitting was done using the MultiPak (version 9.5.0.8) software package.

Coverage calculations. The surface coverage of surficial $\mathrm{CN}^{-}$species was estimated using a previously reported "substrate-overlayer model” (Equation V-1). ${ }^{10}$

$$
\Phi_{\mathrm{ov}}=\left(\frac{\lambda \sin \theta}{a_{\mathrm{ov}}}\right)\left(\frac{S F_{\mathrm{sub}}}{S F_{\mathrm{ov}}}\right)\left(\frac{\rho_{\mathrm{sub}}}{\rho_{\mathrm{ov}}}\right)\left(\frac{I_{\mathrm{ov}}}{I_{\mathrm{sub}}}\right)
$$

$\lambda$ is the escape depth of photoelectrons through the cyanide absorbed layer, $\theta$ is the take-off angle, $a_{\mathrm{ov}}$ is the diameter of the overlayer species $(-\mathrm{CN}), S F_{\mathrm{x}}$ is the modified sensitivity factor, ${ }^{111} \rho_{\mathrm{x}}$ is the density of species $\mathrm{x}$, and $I_{\mathrm{x}}$ is the raw signal intensity. Here, $\theta$ was $45^{\circ}$ for all experiments. $a_{\mathrm{ov}}$ is approximately equal to the inverse cube root of the 
overlayer's atomic number density. We assumed that overlayer species were packed in such way that its density corresponded to the molar volume of $\mathrm{CN}^{-}$in $\mathrm{LiCN}\left(19.05 \mathrm{~cm}^{3}\right.$ $\mathrm{mol}^{-1}$ ). We neglected the effect of $\mathrm{Li}^{+}$on volume. $a_{\mathrm{ov}}$ was calculated as $\sim 0.32 \mathrm{~nm}$.

$\rho_{\text {sub }}$ and $\rho_{\mathrm{ov}}$ are the density of the atoms in the substrate and overlayer, respectively. In this study, the density of pyrite of $4.2 \times 10^{-2} \mathrm{~mol} \mathrm{~cm}^{-3}$ was used for $\rho_{\text {sub, }}$ and the density of LiCN of $5.2 \times 10^{-2} \mathrm{~mol} \mathrm{~cm}^{-3}$ was used for $\rho_{\mathrm{ov}} . I_{\mathrm{ov}}$ was the raw intensity of each component of $\mathrm{N} 1 \mathrm{~s}$ peak and $I_{\text {sub }}$ was the raw intensity of Fe $2 \mathrm{p}_{3 / 2}$ peak. The $I_{\mathrm{ov}} / I_{\text {sub }}$ values were summarized in Table 9.

The modified sensitivity factors were given by the MultiPak software. For detailed scan, $S F_{\mathrm{ov}}=S F_{\mathrm{N} 1 \mathrm{~s}}=11.029 ; S F_{\mathrm{sub}}=S F_{\mathrm{Fe} 2 \mathrm{p} 3}=48.646$.

The last unknown parameter in equation $\mathrm{V}-1, \lambda$, can be approximated using the equation $\mathrm{V}-2$ :

$$
\lambda=0.41 a^{1.5} E_{\mathrm{k}}^{0.5}
$$

where $E_{\mathrm{k}}$ is the electron kinetic energy of Fe. This gives the escape depths of Fe atom though overlayer of $2.1 \mathrm{~nm}$.

\section{B) Results}

1) Photoelectrochemistry.

$J-E$ and $E_{\mathrm{oc}}$ and $J_{\mathrm{sc}}$ characteristics of $\mathrm{FeS}_{2}$ photoanodes were determined as a function of two chemical treatment procedures: 1) immersion in $0.5 \mathrm{M} \mathrm{KCN}$ in FA, and 2) immersion in neat FA. Thus, $J-E$ and $E_{\mathrm{oc}}$ data were collected following three separate sample histories: 1) after electrochemical etching, 2) after electrochemical etching and 
immersion in 0.5 M KCN in FA, and 3) after electrochemical etching and immersion in FA. Representative $J-E$ data are shown in Figure V-1 and the results are summarized in Table 8. The improvement in $E_{\mathrm{oc}}$ and $J_{\mathrm{sc}}$ are emphasized if the data for each individual electrode was normalized to the open-circuit potential recorded with that electrode before chemical treatment (equations $\mathrm{V}-3-5) . \mathrm{KCN}$ treatment had a statistically significant effect on both $E_{\mathrm{oc}}$ and $J_{\mathrm{sc}}$, increasing both by over $25 \%$ on average. FA treatment correlated positively with a small, positive change in $E_{\text {oc }}$ by approximately $5 \%$. FA treatment did not significantly affect $J_{\text {sc }}$.

$$
\begin{array}{lc}
\Delta E_{\mathrm{oc}, \mathrm{n}}(\%)=\frac{\left(E_{\mathrm{oc}, \mathrm{n}-\text { post }}-E_{\mathrm{oc}, \mathrm{n}-\mathrm{pre})}\right.}{E_{\mathrm{oc}, \mathrm{n}-\mathrm{pre}}} \times 100 \% & \mathrm{~V}-3 \\
\overline{\Delta E_{o c(\%)}}=\frac{\sum_{i=1}^{n} \Delta E_{\mathrm{oc}, \mathrm{n}}(\%)}{n} & \mathrm{~V}-4 \\
\text { Standard deviation: SD }=\sqrt{\frac{\sum_{i=1}^{n}\left(\Delta E_{\mathrm{oc}, \mathrm{n}}(\%)-\overline{\Delta E_{o c(\%)}}\right)^{2}}{n-1}} & \mathrm{~V}-5
\end{array}
$$

$\Delta E_{\mathrm{oc}, \mathrm{n}}(\%)$ is the percentage increase in $E_{\mathrm{oc}}$ of the $\mathrm{n}^{\text {th }}$ trial. $E_{\mathrm{oc}, \mathrm{n}-\text { pre }}$ and $E_{\mathrm{oc}, \mathrm{n}-\text { post }}$ are the open-circuit potentials recorded before and after the chemical treatment. $\overline{\Delta E_{o c(\%)}}$ is the average of $\Delta E_{\mathrm{oc}, \mathrm{n}}(\%)$. 

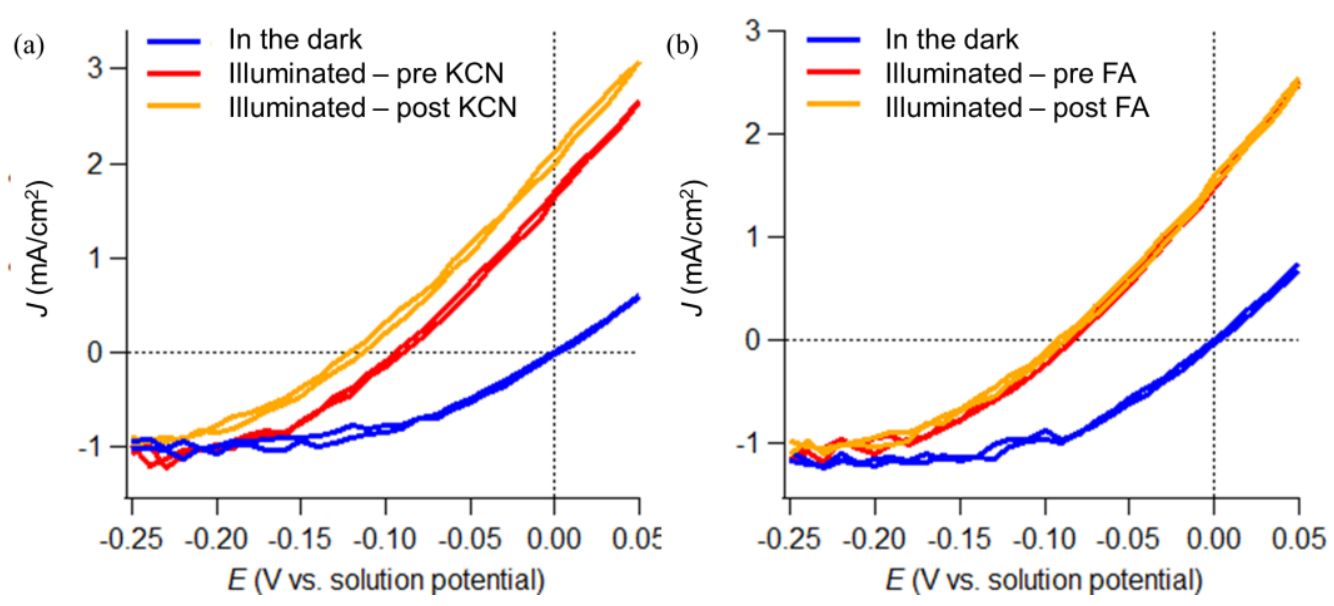

Figure V-1. Representative $J-E$ data for $\mathrm{FeS}_{2}$ electrodes before and after treatment in (a) $0.5 \mathrm{M} \mathrm{KCN}$ solution in formamide, and (b) neat formamide. $J-E$ data were collected in the dark or under $0.1 \mathrm{~W} \mathrm{~cm}^{-2}$ illumination at a scan rate of $20 \mathrm{mV} \mathrm{s}^{-1}$.

Table 8 . The changes in $E_{\mathrm{oc}}$ and $J_{\mathrm{sc}}$ after surface treatment. The data is presented as the mean \pm 1 standard deviation. Each experiment was reproduced at least three times.

$$
\Delta E_{\mathrm{oc}}(\mathrm{mV}) \quad \Delta E_{\mathrm{oc}}(\%) \quad \Delta J_{\mathrm{sc}}\left(\mathrm{mA} / \mathrm{cm}^{2}\right) \quad \Delta J_{\mathrm{sc}}(\%)
$$

After KCN treatment

$$
27.0 \pm 4.2 \quad 28.2 \pm 3.8 \quad 0.49 \pm 0.16 \quad 29.2 \pm 12.1
$$

After solvent (FA) treatment

$$
4.9 \pm 1.1
$$

$5.3 \pm 1.2$

$0.04 \pm 0.22$

$4.5 \pm 14.7$

\section{2) Surface characterizations}

The chemical identification of pyrite surfaces was investigated using X-ray photoelectron spectroscopy. Figure V-2(a) shows representative N 1s spectra for samples: 1) after electrochemical etching, 2) after electrochemical etching and immersion in $0.5 \mathrm{M}$ $\mathrm{KCN}$ in FA, and 3) after electrochemical etching and immersion in FA. In the cases of 
$\mathrm{KCN}$ treatment, three components can be resolved at $\sim 397.6 \mathrm{eV}, 399.3 \mathrm{eV}$ and $401.2 \mathrm{eV}$ (Figure V-2(b)). The relative intensities of each components compared to Fe 2p3 spectra are shown in Table 9. According to equation $\mathrm{V}-1$, the coverage of low binding energy nitrogen at $397.6 \mathrm{eV}$ on pyrite surface was calculated to be $\sim 0.55$ monolayer. The coverage of high binding energy nitrogen at $401.2 \mathrm{eV}$ was calculated to be $\sim 0.39$ monolayer. For the solvent treated samples, the majority spectral contribution is at $\sim 399.1 \mathrm{eV}$. Only a small contribution appeared at lower binding energy region $(\sim 397.4$ $\mathrm{eV}$ ), which gives $\sim 0.06$ monolayer coverage on pyrite surface.

For the etched only samples, although there seems to be a hump at $\sim 396-404 \mathrm{eV}$, it is very difficult to be resolved due to the low signal-to-noisy ratios. Therefore, this hump was not considered as an indicator of significant absorption of nitrogen on the etched $\mathrm{FeS}_{2}$ surface. 

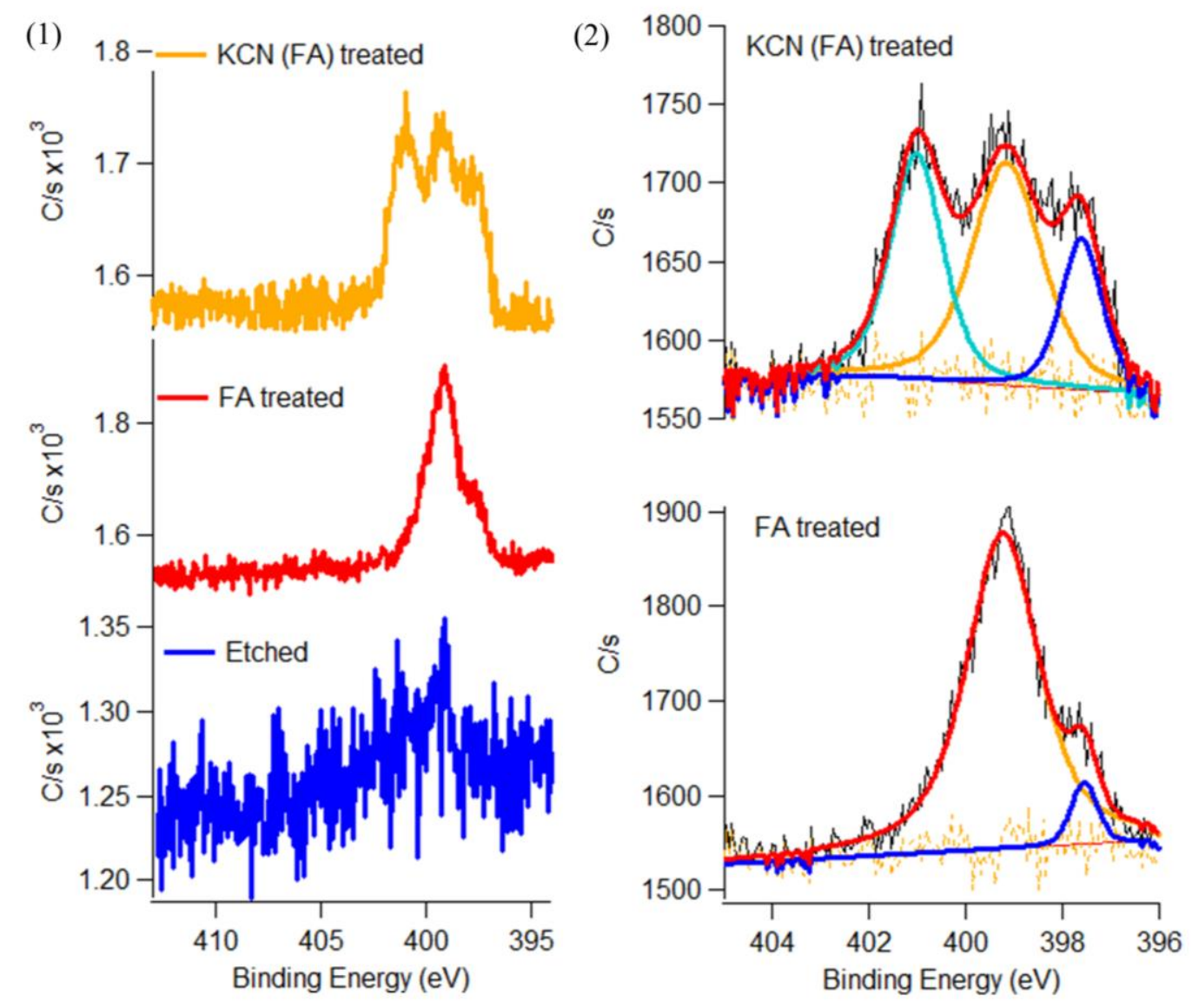

Figure V-2. (1) N 1s spectra for iron pyrite surface right after cathodic polarization (blue line), further immersed in $0.5 \mathrm{M} \mathrm{KCN}$ solution in formamide (orange line) or neat formamide (red line) for $1 \mathrm{~h}$. (2) Peak fitting results for the top two $\mathrm{N}$ 1s spectra in (1). 
Table 9. Peak fitting results of $\mathrm{N}$ 1s spectra. The intensity of each peak is normalized to the intensity of $\mathrm{Fe} 2 \mathrm{p}_{3 / 2}$ peak. Each data was presented as an average of three trials \pm 1 standard deviation.

\begin{tabular}{cccc}
\hline & FA & \multicolumn{2}{c}{ KCN/FA } \\
\hline Peak (eV) & Intensities (\%) & Peak (eV) & Intensities (\%) \\
\hline $397.39 \pm 0.18$ & $0.39 \pm 0.26$ & $397.57 \pm 0.13$ & $3.33 \pm 0.96$ \\
$399.14 \pm 0.07$ & $5.34 \pm 1.55$ & $399.26 \pm 0.22$ & $3.63 \pm 1.74$ \\
& & $401.18 \pm 0.59$ & $2.31 \pm 1.57$ \\
\hline
\end{tabular}

\section{C) Discussion}

\section{1) Theoretical models}

The photovoltage of semiconductor/liquid junction solar devices is critically controlled by recombination of photoexcited electrons and holes. Two major recombination pathways at interfaces between n-type semiconductors and electrolyte are: (1) recombination via redox species in solution; and (2) recombination at the interface via surface trapping levels.

Our previous studies have shown that the photovoltage decreases with increasing concentration of oxidized species. ${ }^{108}$ We proposed a model to explain this phenomenon. The model treated the rectifying junction as a buried junction, with strong Fermi-level pinning, which is likely the case for current $\mathrm{FeS}_{2}$ /liquid junction. When shunting only occurs in distinct regions, the photovoltage is affected by [1]: the concentration of oxidized species in electrolyte through the mass transport; [2] shunt resistance. However, 
in this study, the concentrations of redox species remain constant. Therefore one possible explanation for the observed increase in photocurrent and photovoltage is that $\mathrm{CN}^{-}$ reduced the dangling bonds on the $\mathrm{FeS}_{2}$ surface caused by mechanical polishing and electrochemical etching. As a result, the photovoltage was improved due to the larger shunt resistance.

Other models exist that explain charge recombination process at semiconductor/liquid interfaces. ${ }^{104}$ For non-ideal semiconductor/liquid junctions, when [1] the Fermi-level is pinned at semiconductor/liquid junctions where the barrier height is invariant with the concentration of redox species and [2] the interfacial charge transfer controls the recombination current, the open-circuit photovoltage can be described as equation V-6:

$$
V \mathrm{oc}=\mathrm{n}\left(\phi_{\mathrm{b}}-\frac{k T}{q} \ln \frac{q k_{\mathrm{c}} c_{\mathrm{ox}} N_{\mathrm{c}}}{J_{\mathrm{ph}}}\right)
$$

where $c_{\mathrm{ox}}$ is the concentration of oxidized species, $k_{\mathrm{c}}$ is the rate constant, $N_{\mathrm{c}}$ is the effective density of states of the semiconductor conduction band, $\mathrm{n}$ is diode quality factor, $\mathrm{q}$ is the electronic charge, $\mathrm{k}$ is Boltzmann's constant, $\mathrm{T}$ is temperature. $J_{\mathrm{ph}}$ is the photocurrent density. $\phi_{\mathrm{b}}$ is the barrier height. In this case, the most possible explanation for the improvement of the photovoltage is that electron donating groups $\left(\mathrm{CN}^{-}\right)$draw positive charges from the iron centers and push the sulfur deficient defect levels to the $\mathrm{FeS}_{2}$ valence band. Therefore, the available states in the conduction band of pyrite allowing for the electrons through the junction barrier decrease. ${ }^{13}$ As a result, the photovoltage increases due to a reduction of the recombination rate. 
It is also possible that surface recombination via trapping states plays a dominant role in recombination process. Then the surface-recombination-limited photovoltage can be expressed as:

$$
V \mathrm{oc}=\mathrm{n}\left(\phi_{\mathrm{b}}-\frac{k T}{q} \ln \frac{q S_{\mathrm{r}} N_{\mathrm{c}}}{J_{\mathrm{ph}}}\right)
$$

where $S_{\mathrm{r}}$ is the surface recombination velocity, which is dependent on the quality of the semiconductor surface. The ligand treatment would tend to stabilize the FeS-like defects. The decreasing of the recombination centers for electrons on $\mathrm{FeS}_{2}$ surface then results in an enhancement of photoactivity by decreasing $S_{\mathrm{r}}$ in equation $\mathrm{V}-7$.

\section{2) Chemical identification of treated pyrite surface}

The XPS results indicate the chemical absorption of $\mathrm{CN}^{-}$onto pyrite surface via both chemical treatments. The peak component at $\sim 397.6 \mathrm{eV}$ on $\mathrm{KCN}$ treated slides is in good agreement with the $\mathrm{N} 1 \mathrm{~s}$ spectrum of $\mathrm{K}_{4} \mathrm{Fe}(\mathrm{CN})_{6}{ }^{112,113}$ The tiny peak at $\sim 397.4 \mathrm{eV}$ on FA treated surfaces has been reported for nitrogen bonding to iron. ${ }^{114}$ The higher coverage of ligands on the $\mathrm{KCN}$ treated surfaces than the formamide treated ones is consistent with the trend of improvement in photovoltage due to those surface treatments. The peak at $\sim 399.1-399.3 \mathrm{eV}$ on both treated slides is from $\mathrm{N}$ of acetonitrile used in the final wash step. ${ }^{115}$ The peak at $\sim 401.2 \mathrm{eV}$ has been attributed to the nitrogen bounded to oxygen. ${ }^{116,117}$ However, it does not explain the absence of this peak on the formamide treated surfaces. The binding energy at $400-401 \mathrm{eV}$ was also reported for $\mathrm{CN}$ groups interacting with $\mathrm{Pt}$ and $\mathrm{Si}$, as well as $\mathrm{Fe}(\mathrm{CN})_{6}{ }^{3-}$ incorporated in polymer films. ${ }^{118-120}$ In this study, another possible explanation for this high binding energy peak is the 
physically absorbed $\mathrm{HCN}$, which might be the by-product of the purification process. ${ }^{121}$, 122 As a matter of fact, the surface coverage of the high binding energy $\mathrm{N}$ species on the surfaces which were treated using unpurified $\mathrm{KCN}$ was much diminished as shown in Figure V-3. However, the results do not speak conclusively to the possibility of decomposition of ferrocyanide. ${ }^{123}$

(a)
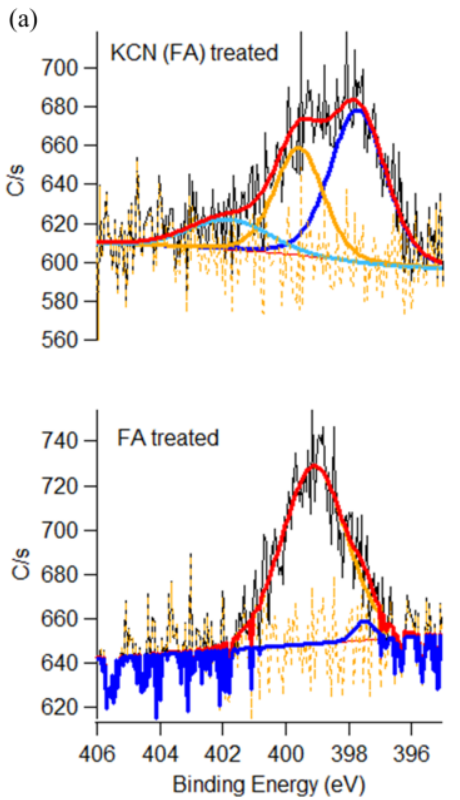

(b)
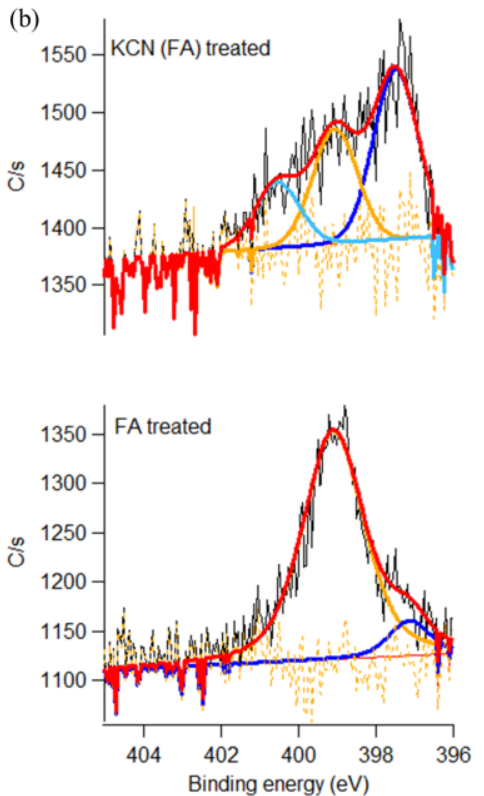

(c)
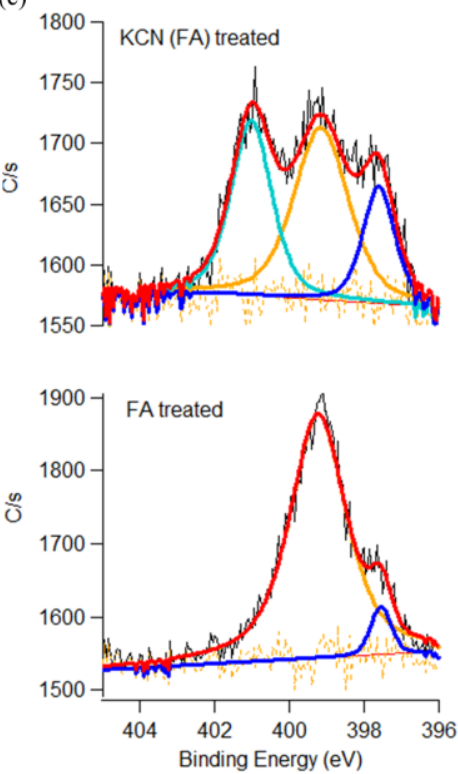

Figure V-3. N 1s spectra of samples after KCN solution treatment (top three) and neat formamide treatment (bottom three). The $\mathrm{KCN}$ used in trail (a) and (b) was unpurified. The $\mathrm{KCN}$ used in trail (c) was purified by recrystallization from a $\mathrm{H}_{2} \mathrm{O}$-ethanol mixture $(1: 3)$ 
It has to be mentioned that Sn was found on some of the slides. It is possible that $\mathrm{Sn}$ is an intrinsic impurity in those particular samples. Sn contamination might also occur during the transportation or degassing process in the roughing-vacuum-pump chamber. The presence of Sn was not correlated to improvement in photovoltage.

\section{D) Conclusions}

In this article, we reported the photocharacteristic of $\mathrm{FeS}_{2}$ with non-coordinating redox species as a function of surface chemical treatments. We demonstrated that the anhydrous and anoxic electrolyte with non-coordinating redox species is suitable for strict studies on photoelectrochemistry of $\mathrm{FeS}_{2}$. We also demonstrated that the surface chemical treatment improved the photoactivity of $\mathrm{FeS}_{2}$ photoanode. X-ray photoelectron spectroscopy data demonstrated the chemical bonding formation between the ligands and $\mathrm{FeS}_{2}$ surface. Three models have been discussed to explain the observed improvement of photovoltage after $\mathrm{KCN}$ treatment. 


\section{POSSIBLE FUTURE STUDIES ON THE INFLUENCE OF ELECTROCHEMICAL ETCHING ON FES2 PHOTOELECTROCHEMISTRY USING AQUEOUS AND NONAQUEOUS ETCHANTS}

Understanding the surface properties of $\mathrm{FeS}_{2}$ yields valuable information for improving its photovoltage. ${ }^{7}$ It has been consistently reported that surface chemical or electrochemical pre-treatments are prerequisites for $\mathrm{FeS}_{2}$ photoactivity. Chemical etching with strong oxidizing acids $\left(\mathrm{HF} / \mathrm{CH}_{3} \mathrm{COOH} / \mathrm{HNO}_{3}, 1: 1: 2\right.$ by volume) resulted in a photocurrent density of more than $40 \mathrm{~mA} \mathrm{~cm}{ }^{-2}$ at $1 \mathrm{~V}$ vs. $\mathrm{Hg}_{2} \mathrm{SO}_{4}{ }^{20}{ }^{20}$ However, a relatively high dark current density of about $10 \mathrm{~mA} \mathrm{~cm}{ }^{-2}$ was also observed. Later on, chlorine evolution under illumination during cyclic voltammetry tests was reported to enhance the photocurrent as well as decease the dark current. ${ }^{102}$ Up to now, the most common surface activation method is cathodic polarization in an aqueous media with a $\mathrm{pH}$ of $\sim 0.5$. The exact function of the electrochemical activation on pyrite surface, however, is still undetermined.

The present work in this chapter aims at the chemical origin for the improvement of photoactivity of pyrite photoanode after different electrochemical etching treatments and at the optimization of the surface pre-treatment process to further enhance the solar performance. 


\section{A) Experimental}

\section{1) Materials}

All chemicals were used as received. Concentrated sulfuric acid (Certified ACS Plus), potassium iodide (99\%) and iodine (>99.8\%) was purchase from Sigma-Aldrich. Potassium hydroxide pellet (Certified ACS grade, 88\%) and concentrated hydrochloride acid (Certified ACS grade, 36.9\%) were obtained from Fisher Scientific. Pyrite samples originated from Turkey.

\section{2) Electrode preparation}

Electrode fabrications. The preparation and the structure of the $\mathrm{FeS}_{2}$ photoanode have been described in earlier sections (Section II, IV and V) In brief, a pyrite slide $\left(\sim 6 \times 6 \times 3 \mathrm{~mm}^{3}\right)$ exposing the (100) surface was attached to a tinned copper wire using $\mathrm{Ga} / \mathrm{In}$ eutectic and silver paint. The wire was then sealed to a glass rod using epoxy to form an electrode. The electrode was then polished using a progression of diamond lapping films from $9 \mu \mathrm{m}$ down to 0.25 . Epoxy was again applied to cover the edges. The exposed surface area of each electrode (Cannon scanner and ImageJ software) was used to convert measured current $(I)$ to current densities $(J)$.

Electrochemical pretreatment. Pyrite electrodes underwent electrochemical etching under four different conditions listed below:

i. Cathodic/acidic: the electrode was polarized at a constant current of $-15 \mathrm{~mA} \mathrm{~cm} \mathrm{~cm}^{-2}$ for 3 min in deoxygenated $0.5 \mathrm{M} \mathrm{H}_{2} \mathrm{SO}_{4},{ }^{20}$ 
ii. Anodic/acidic: the electrode was polarized at a constant potential of $1.2 \mathrm{~V}$ (vs.

SCE) for 15 min in a 3: 1 mixture of $\mathrm{H}_{3} \mathrm{PO}_{4}$ with concentrated $\mathrm{HCl}$;

iii. Cathodic/alkaline: the electrode was polarized at a constant potential of $-1.2 \mathrm{~V}$ (vs. $\mathrm{Hg} / \mathrm{HgO}$ ) for $1 \mathrm{~h}$ in $4.24 \mathrm{M} \mathrm{KOH}$;

iv. Anodic/alkaline: the electrode was at a constant potential of $0.74 \mathrm{~V}$ (vs. $\mathrm{Hg} / \mathrm{HgO}$ ) for $5 \mathrm{~min}$ in $4.24 \mathrm{M} \mathrm{KOH}$.

\section{3) Photoelectrochemical experiment}

The electrolyte was prepared by dissolving $0.5 \mathrm{M} \mathrm{KI}$ and $0.004 \mathrm{M} \mathrm{I}_{2}$ in $0.5 \mathrm{M}$ $\mathrm{H}_{2} \mathrm{SO}_{4}(\mathrm{aq})$ that has been sparged with $\mathrm{N}_{2}$ for 30 min. A standard three-electrode setup was employed in all photoelectrochemical experiments. A Pt mesh electrode was used as the counter electrode and a Pt wire electrode was use as the reference electrode. All potentials were measured with respect to the solution potential. $E_{\mathrm{oc}}$ and $J-E$ data were collected in the dark and under illumination by an ABET solar simulator (model 10500) under vigorous stirring. Light intensities were $0.5 \mathrm{~W} \mathrm{~cm}^{-2}$.

\section{4) Surface characterization}

The surface morphology and surface chemical composition of etched $\mathrm{FeS}_{2}$ electrode was evaluated using a scanning electron microscope (SEM) alone with an energy dispersive spectrometer (EDX). All SEM and EDX data was collected using a Zeiss Sigma VP FEG SEM instrument operating at accelerating voltage of $20 \mathrm{kV}$ and a chamber pressure of $10^{-5} \mathrm{~Pa}$. Surface crystal structure was studied using SEM-based 
electron backscatter diffraction analysis (EBSD). The sample was tilted 70 degrees for all EBSD experiments. All EBSD data were processed using the AZtecHKL software package (Oxford Instruments, UK) with default settings.

\section{B) Results.}

\section{1) Photoelectrochemistry}

Representative $J-V$ data are shown in Figure VI-1. The open-circuit potentials and the short-circuit current densities under illumination are summarized in Table 10. Without electrochemical polarization, the polished $\mathrm{FeS}_{2}$ electrode can barely show any photoresponse. The cathodic polarization of $\mathrm{FeS}_{2}$ photoanode in acidic media significantly improved the photoactivity of $\mathrm{FeS}_{2} / \mathrm{I}^{-}, \mathrm{I}_{3}{ }^{-}$half-cells, which is in agreement with previous studies. ${ }^{20}$ Interestingly, the $\mathrm{FeS}_{2}$ electrode after anodic polarization in acidic media showed photoresponse though the electrode underwent very different surface reactions. The photocurrent density in this case, however, was significantly lower. Moreover, after electropolishing $\mathrm{FeS}_{2}$ electrode in a strong alkaline electrolyte which contains less than $10^{-14} \mathrm{~mol} / \mathrm{L}$ free protons, the photoactivity was also enhanced. 

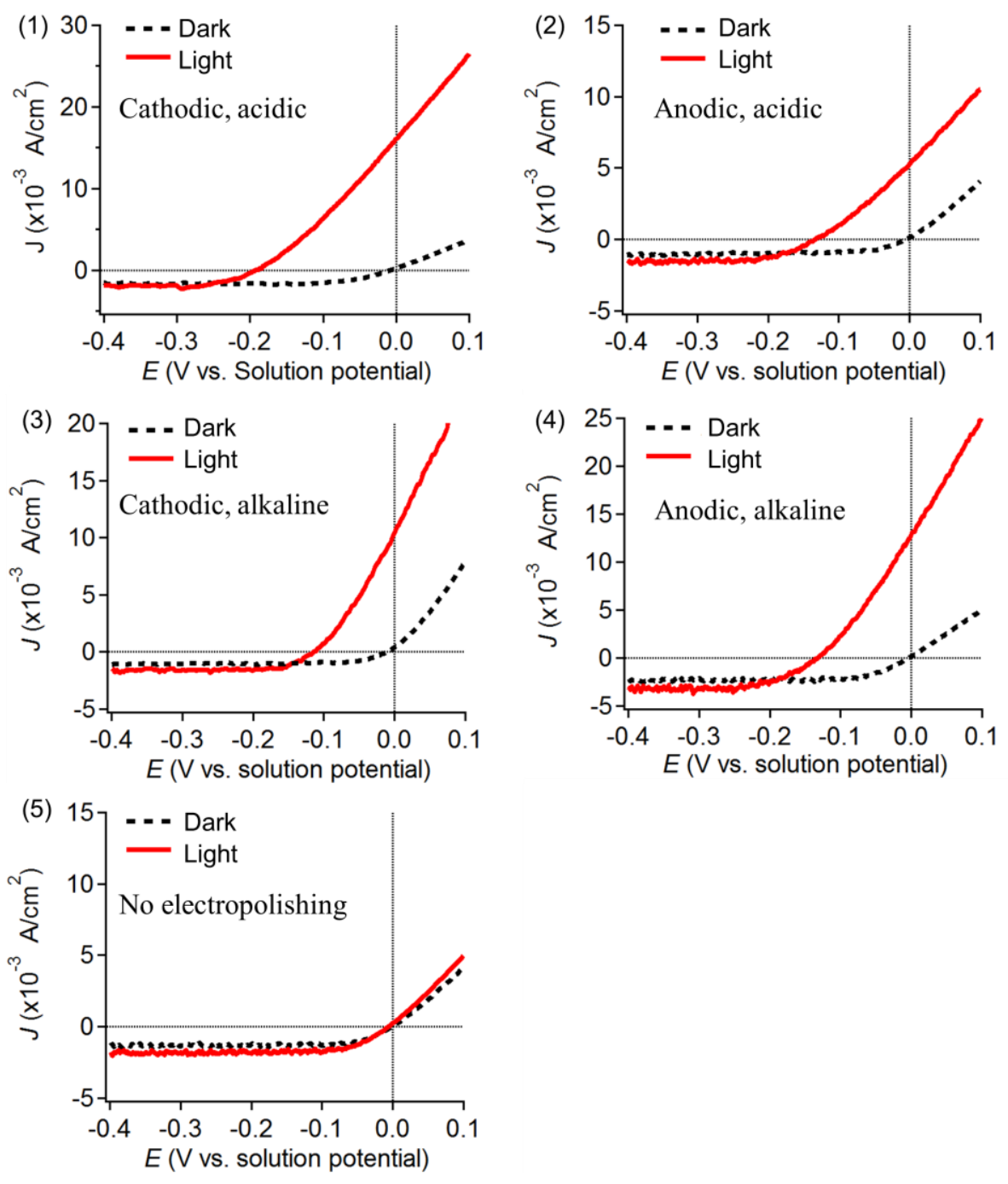

Figure VI-1. Representative $J-E$ data for $\mathrm{FeS}_{2} / \mathrm{I}^{-}, \mathrm{I}_{3}{ }^{-}$half cell after: (1) cathodically polarized in acidic media; (2) anodically polarized in acidic media; (3) cathodically polarized in alkaline media; (4) anodically polarized in alkaline media; and (5) no pretreatment. (Light intensity: $0.5 \mathrm{~W} \mathrm{~cm}^{-2}$ ) 
Table 10. Photovoltage and short-circuit current under illumination $\left(0.5 \mathrm{~W} \mathrm{~cm}^{-2}\right)$ after different surface treatments.

\begin{tabular}{cccc}
\hline Electrolyte & Bias & $V_{\mathrm{ph}}(\mathrm{mV})$ & $J_{\mathrm{sc}}\left(\mathrm{mA} \mathrm{cm}^{-2}\right)$ \\
\hline Acidic & Cathodic & 195 & 15.7 \\
Acidic & Anodic & 133 & 5.32 \\
Basic & Cathodic & 114 & 9.00 \\
Basic & Anodic & 150 & 12.4 \\
$/$ & $/$ & 5 & 0.10 \\
\hline
\end{tabular}

\section{2) Surface-properties of the electrode}

The polished $\mathrm{FeS}_{2}$ has mirror-like finish and metallic luster. ${ }^{124}$ The electrochemical treatment, under all four conditions, resulted in observable changes to the appearance of $\mathrm{FeS}_{2}$ electrode. Pits and scratches can easily be observed by naked eyes. In particular, red rust was formed on the surface of electrode during anodic polarization in $\mathrm{KOH}$ electrolyte, those species were removed by rinsing electrode with $\mathrm{DI} \mathrm{H}_{2} \mathrm{O}$ before further surface characterization.

The SEM images of $\mathrm{FeS}_{2}$ surfaces after electrochemical modifications in all four cases are shown in Figure VI-2. It is appeared that the dissolution of $\mathrm{FeS}_{2}$ started at certain "active sites" on the surfaces. These sites are ascribed to local impurities in the sample (e.g. $\mathrm{Si}, \mathrm{Al}, \mathrm{Mg}$ and etc.) and scratches caused by mechanical polishing. In addition, the surfaces after electropolishing in acidic electrolyte showed needle-like features arranged in the same direction, while the one after anodic etching in alkaline 
electrolyte showed diamond shape features. In all cases, the stoichiometry of polarized electrode surface was close to $\mathrm{FeS}_{2}$ (Figure VI-3 (4)).

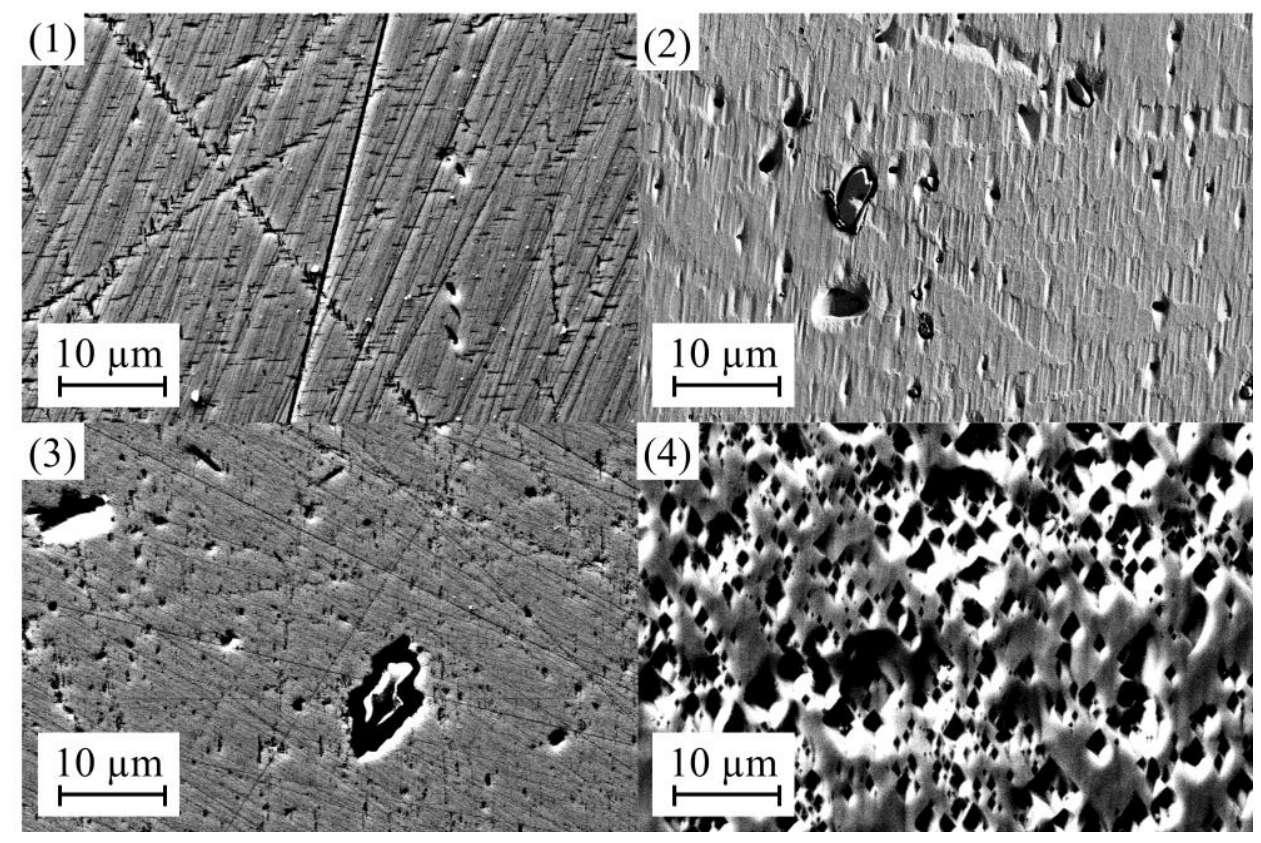

Figure VI-2. SEM images of pyrite electrodes after: (1) cathodically polarized in acidic media; (2) anodically polarized in acidic media; (3) cathodically polarized in alkaline media; (4) anodically polarized in alkaline media.

Electron backscatter diffraction (EBSD) was employed to study the surface crystal structure. In contrast to the blurred Kikuchi patterns of polished slides, some clearer Kikuchi patterns can be obtained and indexed as pyrite after polarization in relatively smooth area (Figure VI-3 (2) and (3)). It has to be mentioned that in the rough area, the acquired Kikuchi patterns were mostly shadowed, and thus cannot be solved 
either. For those Kikuchi patterns that can be solved, no other phases (e.g. sulfurdeficient impurities, iron oxide) were indexed.

(1) After polishing

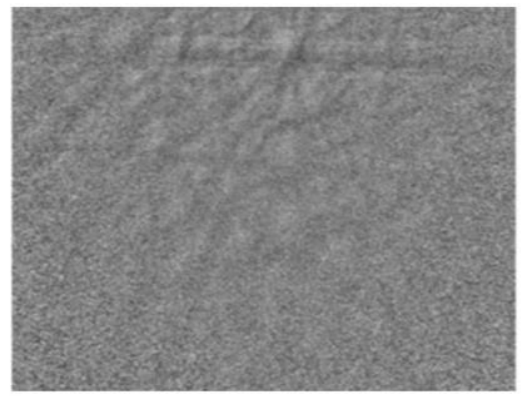

(3) Indexed patterns for (2)

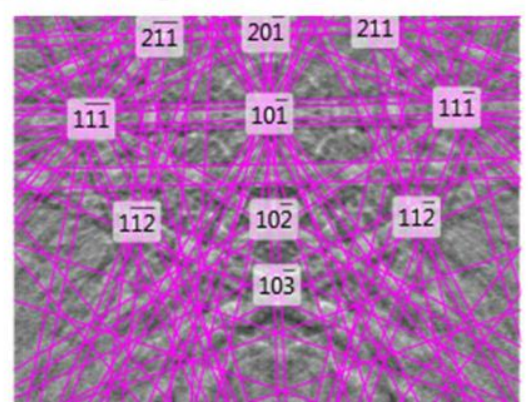

(2) After cathodic polarization in acid

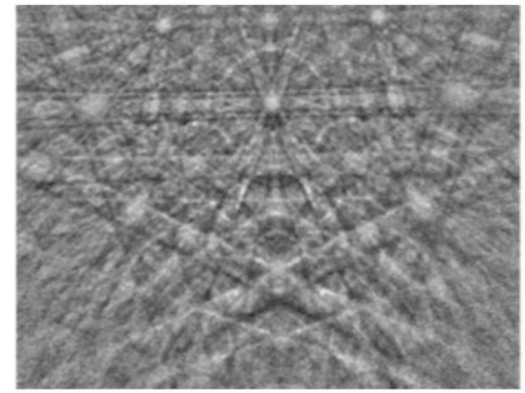

(4) EDX spectrum for (2)

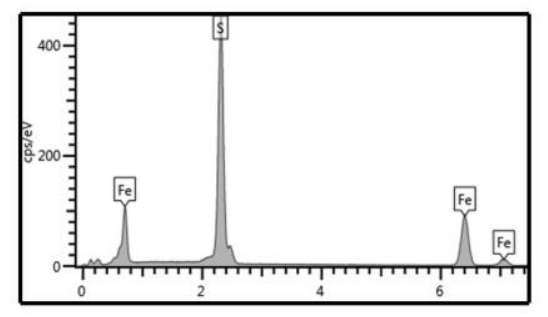

Figure VI-3. Kikuchi patterns of pyrite slide after (1) polishing; and (2) cathodic polarization in acidic media. (2) was automatically solved by software as shown in (3). (4) is the EDX spectrum for (2).

\section{C) Discussion}

Previous studies have shown that mechanical polishing can severely damage the pyrite surface and result in a metal-like response; ${ }^{37,44}$ which is in agreement with the extremely low photovoltage observed in this study. It has been previously hypothesized 
that the cathodic etching in acidic media restored the surfaces that are destroyed through the polishing. ${ }^{7,44}$ The main electrochemical reactions were described as:

$$
\begin{array}{lr}
\mathrm{FeS}_{2}+4 \mathrm{H}^{+}+2 e^{-} \rightarrow \mathrm{Fe}^{2+}+2 \mathrm{H}_{2} \mathrm{~S} & \mathrm{VI}-1 \\
2 \mathrm{H}^{+}+2 e^{-} \rightarrow \mathrm{H}_{2} & \text { VI-2 }
\end{array}
$$

The generated $\mathrm{H}_{2}$, in turn, passivates the sulfur-deficient defects by forming FeSH. It has also been suggested that this $\mathrm{H}_{2}$ evaluation process is orientation dependent. ${ }^{13}$ The new (100)-surfaces produced by etching are kinetically and sterically more favored than (111)-surfaces for the penetration of hydrogen. As a result, the dark current density of on initial (111)-surfaces gradually decreased during electrochemical treatment.

In this study, electrochemical treatments were shown to remove impurities and amorphous surface layer result from mechanical polishing. The enhancement of photoactivity indicated that surface stoichiometry and preferred surface structure also play a role in photoelectrochemistry of $\mathrm{FeS}_{2}$.

However, the influence of hydrogen penetration is still undetermined. Hydrogen evolution is not expected under conditions other than cathodic polarization in an acidic electrolyte. Therefore observed photoresponse in the other three cases cannot be contributed to hydrogen diffusion.

To investigate the exact functions of electrochemical pre-treatment on $\mathrm{FeS}_{2}$ surface, possible future work can be designed as:

i. Electrochemically polarize pyrite surface in strict anhydrous and anoxic conditions. 
ii. Investigate the influence of electrochemical treatments on $\mathrm{FeS}_{2}$ photoelectochemistry in non-aqueous and anoxic electrolyte with non-coordinating redox species.

iii. Fully characterize $\mathrm{FeS}_{2}$ surface after etching using a variety spectroscopy methods.

\section{D) Conclusions}

In this chapter, we reported the photoelectrochemical behavior of a $\mathrm{FeS}_{2} / \mathrm{I}^{-}, \mathrm{I}_{3}{ }^{-}$half cell as a function of electrochemical treatments. We demonstrated that the hydrogen penetration is not the only reason for the improvement in photoactivity of $\mathrm{FeS}_{2}$ after electrochemical pretreatments. We also linked surface stoichiometry and surface crystal structure to $\mathrm{FeS}_{2}$ photoelectrochemistry.

Future experiments can be focus on non-aqueous etching of $\mathrm{FeS}_{2}$ electrode and their influence on photoelectrochemical properties of pyrite/electrolyte junctions under anhydrous and anoxic condition with non-coordinating redox species. 


\section{REFERENCES}

1. L. Sousa, Energy Vision 2050 - part I, The Oil Drum: Europe (2008).

2. M. A. Green, Solar cells: operating principles, technology and system applications, Prentice-Hall, Upper, Saddle River, NJ (1982).

3. H. Kiess and W. Rehwald, On the ultimate efficiency of solar-cells, Sol. Energy Mater. Sol. Cells, 38, 45-55 (1995).

4. T. B. Schlömer S., L. Fulton, E. Hertwich, A. McKinnon, D. Perczyk, J. Roy, R. Schaeffer, R. Sims, P. Smith, and R. Wiser, Annex III: Technology-specific cost and performance parameters. In: climate change 2014: mitigation of climate change. Contribution of working group III to the fifth assessment report of the intergovernmental panel on climate change. [O. Edenhofer, R. Pichs-Madruga, Y. Sokona, E. Farahani, S. Kadner, K. Seyboth, A. Adler, I. Baum, S. Brunner, P. Eickemeier, B. Kriemann, J. Savolainen, S. Schlömer, C. von Stechow, T. Zwickel and J.C. Minx (eds.)]. Cambridge University Press, Cambridge, United Kingdom and New York, NY, USA (2014).

5. A. Shah, P. Torres, R. Tscharner, N. Wyrsch and H. Keppner, Photovoltaic technology: The case for thin-film solar cells, Science, 285, 692-698 (1999).

6. B. E. Layton, A comparison of energy densities of prevalent energy sources in units of joules per cubic meter, Int. J. Green Energy, 5, 438-455 (2008).

7. A. Ennaoui, S. Fiechter, C. Pettenkofer, N. Alonsovante, K. Buker, M. Bronold, C. Hopfner and H. Tributsch, Iron disulfide for solar-energy conversion, Sol. Energy Mater. Sol. Cells, 29, 289-370 (1993). 
8. R. E. Blankenship, D. M. Tiede, J. Barber, G. W. Brudvig, G. Fleming, M. Ghirardi, M. R. Gunner, W. Junge, D. M. Kramer, A. Melis, T. A. Moore, C. C. Moser, D. G. Nocera, A. J. Nozik, D. R. Ort, W. W. Parson, R. C. Prince and R. T. Sayre, Comparing photosynthetic and photovoltaic efficiencies and recognizing the potential for improvement, Science, 332, 805-809 (2011).

9. L. El Chaar, L. A. Lamont and N. El Zein, Review of photovoltaic technologies, Renewable Sustainable Energy Rev., 15, 2165-2175 (2011).

10. C. H. Henry, Limiting efficiencies of ideal single and multiple energy-gap terrestrial solar-cells, J. Appl. Phys., 51, 4494-4500 (1980).

11. T. Unold, H. W.Schock, Nonconventional (non-silicon-based) photovoltaic materials, Annu. Rev. Mater. Res., 41, 297-321 (2011).

12. C. Wadia, A. P. Alivisatos and D. M. Kammen, Materials availability expands the opportunity for large-scale photovoltaics deployment, Environ. Sci. Technol., 43, 20722077 (2009).

13. N. Alonsovante, G. Chatzitheodorou, S. Fiechter, N. Mgoduka, I. Poulios and H. Tributsch, Interfacial behavior of hydrogen-treated sulfur deficient pyrite $\left(\mathrm{FeS}_{2-\mathrm{X}}\right)$, Sol. Energy Mater., 18, 9-21 (1988).

14. M. S. Schmokel, L. Bjerg, S. Cenedese, M. R. V. Jorgensen, Y. S. Chen, J. Overgaard and B. B. Iversen, Atomic properties and chemical bonding in the pyrite and marcasite polymorphs of $\mathrm{FeS}_{2}$ : A combined experimental and theoretical electron density study, Chem. Sci., 5, 1408-1421 (2014). 
15. D. W. Bullett, Electronic-structure of 3d-pyrite-type and marcasite-type sulfides, J. Phys. C: Solid State Phys., 15, 6163-6174 (1982).

16. M. W. Chase, JANAF Thermochemical Tables (1986).

17. H. Ohfuji, A. P. Boyle, D. J. Prior and D. Rickard, Structure of framboidal pyrite: An electron backscatter diffraction study, Am. Mineral., 90, 1693-1704 (2005).

18. P. P. Altermatt, T. Kiesewetter, K. Ellmer and H. Tributsch, Specifying targets of future research in photovoltaic devices containing pyrite $\left(\mathrm{FeS}_{2}\right)$ by numerical modelling, Sol. Energy Mater. Sol. Cells, 71, 181-195 (2002).

19. A. Ennaoui, S. Fiechter, H. Goslowsky and H. Tributsch, Photoactive synthetic polycrystalline pyrite $\left(\mathrm{FeS}_{2}\right)$, J. Electrochem. Soc., 132, 1579-1582 (1985).

20. A. Ennaoui, S. Fiechter, W. Jaegermann and H. Tributsch, Photoelectrochemistry of highly quantum efficient single-crystalline n-FeS 2 (Pyrite), J. Electrochem. Soc., 133, 97-106 (1986).

21. L. P. Yu, S. Lany, R. Kykyneshi, V. Jieratum, R. Ravichandran, B. Pelatt, E. Altschul, H. A. S. Platt, J. F. Wager, D. A. Keszler and A. Zunger, Iron chalcogenide photovoltaic absorbers, Adv. Energy Mater., 1, 748-753 (2011).

22. J. Puthussery, S. Seefeld, N. Berry, M. Gibbs and M. Law, Colloidal iron pyrite $\left(\mathrm{FeS}_{2}\right)$ nanocrystal inks for thin-film photovoltaics, J. Am. Chem. Soc., 133, 716-719 (2011).

23. I. J. Ferrer, D. M. Nevskaia, C. Delasheras and C. Sanchez, About the band-gap nature of $\mathrm{FeS}_{2}$ as determined from optical and photoelectrochemical measurements, Solid State Commun., 74, 913-916 (1990). 
24. J. P. Wilcoxon, P. P. Newcomer and G. A. Samara, Strong quantum confinement effects in semiconductors: $\mathrm{FeS}_{2}$ nanoclusters, Solid State Commun., 98, 581-585 (1996).

25. G. Smestad, A. Ennaoui, S. Fiechter, H. Tributsch, W. K. Hofmann, M. Birkholz and W. Kautek, Photoactive thin-film semiconducting iron pyrite prepared by sulfurization of iron-oxides, Sol. Energy Mater., 20, 149-165 (1990).

26. A. Ennaoui, S. Fiechter, C. Pettenkofer, N. Alonsovante, K. Buker, M. Bronold, C. Hopfner and H. Tributsch, Iron disulfide for solar-energy conversion, Sol. Energy Mater.Sol. Cells, 29, 289-370 (1993).

27. A. Kirkeminde, R. Scott and S. Q. Ren, All inorganic iron pyrite nanoheterojunction solar cells, Nanoscale, 4, 7649-7654 (2012).

28. V. Antonucci, A. S. Arico, N. Giordano, P. L. Antonucci, U. Russo, D. L. Cocke and F. Crea, Photoactive screen-printed pyrite anodes for electrochemical photovoltaic cells, Sol. Cells, 31, 119-141 (1991).

29. A. Ennaoui, S. Fiechter, H. Tributsch, M. Giersig, R. Vogel and H. Weller, Photoelectrochemical energy-conversion obtained with ultrathin organo-metallicchemical-vapor-deposition layer of $\mathrm{FeS}_{2}$ (pyrite) on $\mathrm{TiO}_{2}$, J. Electrochem. Soc., 139, 2514-2518 (1992).

30. W. Shockley and H. J. Queisser, Detailed balance limit of efficiency of p-n junction solar cells, J. Appl. Phys., 32, 510-\& (1961).

31. A. Polman and H. A. Atwater, Photonic design principles for ultrahigh-efficiency photovoltaics, Nat. Mater., 11, 174-177 (2012). 
32. J. Hu, Y. N. Zhang, M. Law and R. Q. Wu, First-principles studies of the electronic properties of native and substitutional anionic defects in bulk iron pyrite, Phys. Rev. B, 85 (2012).

33. R. S. Sun, M. K. Y. Chan, S. Y. Kang and G. Ceder, Intrinsic stoichiometry and oxygen-induced p-type conductivity of pyrite $\mathrm{FeS}_{2}$, Phys. Rev. B, 84 (2011).

34. N. Berry, M. Cheng, C. L. Perkins, M. Limpinsel, J. C. Hemminger and M. Law, Atmospheric-Pressure Chemical Vapor Deposition of Iron Pyrite Thin Films, Adv. Energy Mater., 2, 1124-1135 (2012).

35. M. Birkholz, S. Fiechter, A. Hartmann and H. Tributsch, Sulfur deficiency in iron pyrite $\left(\mathrm{FeS}_{2-\mathrm{x}}\right)$ and its consequences for band-structure models, Phys. Rev. B, 43, 1192611936 (1991).

36. M. Bronold, C. Pettenkofer and W. Jaegermann, Surface photovoltage measurements on pyrite (100) cleavage planes-evidence for electronic bulk defects, $J$. Appl. Phys., 76, 5800-5808 (1994).

37. M. Caban-Acevedo, N. S. Kaiser, C. R. English, D. Liang, B. J. Thompson, H. E. Chen, K. J. Czech, J. C. Wright, R. J. Hamers and S. Jin, Ionization of high-density deep donor defect states explains the low photovoltage of iron pyrite single crystals, J. Am. Chem. Soc., 136, 17163-17179 (2014).

38. M. Bronold, Y. Tomm and W. Jaegermann, Surface-states on cubic d-band semiconductor pyrite $\left(\mathrm{FeS}_{2}\right)$, Surf. Sci., 314, L931-L936 (1994).

39. R. Murphy and D. R. Strongin, Surface reactivity of pyrite and related sulfides, Surf. Sci. Rep., 64, 1-45 (2009). 
40. Y. N. Zhang, J. Hu, M. Law and R. Q. Wu, Effect of surface stoichiometry on the band gap of the pyrite $\mathrm{FeS}_{2}$ (100) surface, Phys. Rev. B, 85 (2012).

41. A. M. A. El Halim, S. Fiechter and H. Tributsch, Control of interfacial barriers in n-type $\mathrm{FeS}_{2}$ (pyrite) by electrodepositing metals $(\mathrm{Co}, \mathrm{Cu})$ forming isostructural disulfides, Electrochim. Acta, 47, 2615-2623 (2002).

42. I. J. Ferrer and C. Sanchez, Photoelectrochemical response and optical-absorption of pyrite $\left(\mathrm{FeS}_{2}\right)$ natural single-crystals, Solid State Commun., 81, 371-374 (1992).

43. A. J. Bard, A. B. Bocarsly, F. R. F. Fan, E. G. Walton and M. S. Wrighton, The concept of fermi level pinning at semiconductor-liquid junctions - consequences for energy-conversion efficiency and selection of useful solution redox couples in solar devices, J. Am. Chem. Soc., 102, 3671-3677 (1980).

44. K. Buker, N. Alonsovante, R. Scheer and H. Tributsch, Influence of electrochemical activation and surface orientation on the photoresponse of singlecrystalline pyrite electrolyte and pyrite metal junctions, Ber. Bunsen-Ges. Phys. Chem., 98, 674-682 (1994).

45. D. Wei and K. OsseoAsare, Semiconductor electrochemistry of particulate pyrite: Dissolution via hole and electron pathways, J. Electrochem. Soc., 143, 3192-3198 (1996). 46. S. B. Lalvani, B. A. Deneve and A. Weston, Passivation of pyrite due to surfacetreatment, Fuel, 69, 1567-1569 (1990).

47. X. P. Li, N. A. Vante and H. Tributsch, Involvement of coordination chemistry during electron-transfer in the stabilization of the pyrite $\left(\mathrm{FeS}_{2}\right)$, J. Electroanal. Chem., 242, 255-264 (1988). 
48. B. Schubert and H. Tributsch, Photoinduced electron-transfer by coordination chemical pathways across pyrite electrolyte interfaces, Inorg. Chem., 29, 5041-5046 (1990).

49. K. Sasaki, M. Tsunekawa, K. Hasebe and H. Konno, Effect of anionic ligands on the reactivity of pyrite with Fe(III) ions in acid-solutions, Colloids Surf., A, 101, 39-49 (1995).

50. K. Buker, N. AlonsoVante and H. Tributsch, Photoelectrochemical investigations of complex formation phenomena on oriented n-pyrite $\left(\mathrm{FeS}_{2}\right)$ crystal surfaces, Ber. Bunsen-Ges. Phys. Chem, 100, 1808-1813 (1996).

51. M. J. Scaini, G. M. Bancroft, J. W. Lorimer and L. M. Maddox, The interaction of aqueous silver species with sulfur-containing minerals as studied by XPS, AES, SEM and electrochemistry, Geochim. Cosmochim. Acta, 59, 2733-2747 (1995).

52. P. Wersin, M. F. Hochella, P. Persson, G. Redden, J. O. Leckie and D. W. Harris, Interaction between aqueous uranium(VI) and sulfide minerals-spectroscopic evidence for sorption and reduction, Geochim. Cosmochim. Acta, 58, 2829-2843 (1994).

53. R. De Marco, S. Bailey, Z. T. Jiang, J. Morton and R. Chester, An in situ chronoamperometry/synchrotron radiation grazing incidence X-ray diffraction study of the electrochemical oxidation of pyrite in chloride media, Electrochem. Commun., 8, 1661-1664 (2006).

54. Y. F. Cai, Y. G. Pan, J. Y. Xue and G. Z. Su, Surficial phase-identification and structural profiles from weathered natural pyrites: A grazing-incidence X-ray diffraction study, Appl. Surf. Sci., 255, 4066-4073 (2009). 
55. Y. F. Cai, Y. G. Pan and J. Y. Xue, Grazing incidence X-ray diffraction study of products formed on (100) crystal face of pyrite, Geochim. Cosmochim. Acta, 70, A79A79 (2006).

56. J. R. Mycroft, G. M. Bancroft, N. S. McIntyre, J. W. Lorimer and I. R. Hill, Detection of sulfur and polysulfieds on electrochemically oxidized pyrite surfaces by Xray photoelectron-spectroscopy and Raman-spectroscopy, J. Electroanal. Chem., 292, 139-152 (1990).

57. P. R. Holmes and F. K. Crundwell, The kinetics of the oxidation of pyrite by ferric ions and dissolved oxygen: An electrochemical study, Geochim. Cosmochim. Acta, 64, 263-274 (2000).

58. L. A. J. Garvie and P. R. Buseck, Unoccupied states of pyrite probed by electron energy-loss spectroscopy (EELS), Am. Mineral., 89, 485-491 (2004).

59. J. Shamshuddin, S. Muhrizal, I. Fauziah and E. Van Ranst, A laboratory study of pyrite oxidation in acid sulfate soils, Commun. Soil. Sci. Plan., 35, 117-129 (2004).

60. J. R. Mycroft, G. M. Bancroft, N. S. McIntyre and J. W. Lorimer, Spontanous deposition of gold on pyrite from solutions containing $\mathrm{Au}(\mathrm{III})$ and $\mathrm{Au}(\mathrm{I})$ chlorides: a surface study, Geochim. Cosmochim. Acta, 59, 3351-3365 (1995).

61. A. Ennaoui, S. Fiechter, H. Tributsch, M. Giersig, R. Vogel and H. Weller, Photoelectrochemical energy-conversion obtained with ultrathin organo-metallicchemical-vapor-deposition layer of $\mathrm{FeS}_{2}$ (pyrite) on $\mathrm{TiO}_{2}$, J. Electroanal. Chem., 139, 2514-2518 (1992). 
62. Y. S. Yen and J. S. Wong, Infrared reflectance properties of surface thin-films, J. Phys. Chem., 93, 7208-7216 (1989).

63. M. J. Borda, D. R. Strongin and M. A. Schoonen, A vibrational spectroscopic study of the oxidation of pyrite by molecular oxygen, Geochim. Cosmochim. Acta, 68, 1807-1813 (2004).

64. X. Zhang, M. J. Borda, M. A. A. Schoonen and D. R. Strongin, Adsorption of phospholipids on pyrite and their effect on surface oxidation, Langmuir, 19, 8787-8792 (2003).

65. C. R. Usher, C. A. Cleveland, D. R. Strongin and M. A. Schoonen, Origin of oxygen in sulfate during pyrite oxidation with water and dissolved oxygen: An in situ horizontal attenuated total reflectance infrared spectroscopy isotope study, Environ. Sci. Technol., 38, 5604-5606 (2004).

66. S. W. Lehner, N. Newman, M. van Schilfgaarde, S. Bandyopadhyay, K. Savage and P. R. Buseck, Defect energy levels and electronic behavior of Ni-, Co-, and As-doped synthetic pyrite $\left(\mathrm{FeS}_{2}\right)$, J. Appl. Phys., 111 (2012).

67. L. E. O'Leary, E. Johansson, B. S. Brunschwig and N. S. Lewis, Synthesis and Characterization of Mixed Methyl/Allyl Monolayers on Si(111), J. Phys. Chem. B, 114, 14298-14302 (2010).

68. E. Johansson, P. T. Hurley, B. S. Brunschwig and N. S. Lewis, Infrared vibrational spectroscopy of isotopically labeled ethyl-terminated $\mathrm{Si}(111)$ surfaces prepared using a two-step chlorination/alkylation procedure, J. Phys. Chem. C, 113, $15239-15245$ (2009). 
69. M. Milosevic, V. Milosevic and S. L. Berets, Grazing angle attenuated total reflection spectroscopy: Fields at the interface and source of the enhancement, Appl. Chem., 61, 530-536 (2007).

70. V. P. Evangelou, A. K. Seta and A. Holt, Potential role of bicarbonate during pyrite oxidation, Environ. Sci. Technol., 32, 2084-2091 (1998).

71. G. H. Kelsall, Q. Yin, D. J. Vaughan, K. E. R. England and N. P. Brandon, Electrochemical oxidation of pyrite $\left(\mathrm{FeS}_{2}\right)$ in aqueous electrolytes, J. Electroanal. Chem., 471, 116-125 (1999).

72. H. Brunner, U. Mayer and H. Hoffmann, External reflection infrared spectroscopy of anisotropic adsorbate layers on dielectric substrates, Appl. Spectrosc., 51, 209-217 (1997).

73. W. N. Hansen, Electric fields produced by propagation of plane coherent electromagnetic radiation in a stratified medium, J. Opt. Soc. Am., 58, 380-\& (1968).

74. P. Yeh, Optics of anisotropic layered media -a new 4X4 matrix algebra, Surf. Sci., 96, 41-53 (1980).

75. A. N. Parikh and D. L. Allara, Quantitative-determination of molecular-structure in multilayered thin-films of biaxial and lower symmertry from photon spectroscopies: reflection infrared vibrational spectroscopy, J. Chem. Phys., 96, $927-945$ (1992).

76. J. A. Mielczarski, External reflection infrared-spectroscopy at metallic, semiconductor, and nonmetallic substrates: monolayer films J. Phys. Chem., 97, 26492663 (1993). 
77. S. K. Ghosh, S. Nath, S. Kundu, K. Esumi and T. Pal, Solvent and ligand effects on the localized surface plasmon resonance (LSPR) of gold colloids, J. Phy. Chem. B, 108, 13963-13971 (2004).

78. S. A. Putnam, D. G. Cahill, P. V. Braun, Z. B. Ge and R. G. Shimmin, Thermal conductivity of nanoparticle suspensions, J. Appl. Phys., 99 (2006).

79. E. D. Palik, Handbook of Optical Constants of Solids, Academic Press,San Diego (1998).

80. C. M. Eggleston, J. J. Ehrhardt and W. Stumm, Surface structural controls on pyrite oxidation kinetics: An XPS-UPS, STM, and modeling study, Am. Mineral., 81, 1036-1056 (1996).

81. S. Chaturvedi, R. Katz, J. Guevremont, M. A. A. Schoonen and D. R. Strongin, XPS and LEED study of a single-crystal surface of pyrite, Am. Miner., 81, 261-264 (1996).

82. H. W. Nesbitt and I. J. Muir, X-ray photoelectron spectroscopic study of a pristine pyrite surface reacted with water-vapor and air, Geochim. Cosmochim. Acta, 58, 46674679 (1994).

83. R. Morrish, R. Silverstein and C. A. Wolden, Synthesis of Stoichiometric FeS 2 through Plasma-Assisted Sulfurization of $\mathrm{Fe}_{2} \mathrm{O}_{3}$ Nanorods, J. Am. Chem. Soc., 134, 17854-17857 (2012).

84. A. G. Schaufuss, H. W. Nesbitt, I. Kartio, K. Laajalehto, G. M. Bancroft and R. Szargan, Reactivity of surface chemical states on fractured pyrite, Surf. Sci., 411, 321328 (1998). 
85. J. A. Leiro, S. S. Mattila and K. Laajalehto, XPS study of the sulphur $2 p$ spectra of pyrite, Surf. Sci., 547, 157-161 (2003).

86. J. M. Guevremont, D. R. Strongin and M. A. A. Schoonen, Effects of surface imperfections on the binding of $\mathrm{CH}_{3} \mathrm{OH}$ and $\mathrm{H}_{2} \mathrm{O}$ on $\mathrm{FeS}_{2}(100)$ : using adsorbed $\mathrm{Xe}$ as a probe of mineral surface structure, Surf. Sci., 391, 109-124 (1997).

87. H. J. Himmel, M. Kaschke, P. Harder and C. Woll, Adsorption of organic monolayers on pyrite $\left(\mathrm{FeS}_{2}\right)(100)$, Thin Solid Films, 284, 275-280 (1996).

88. C. R. Usher, K. W. Paul, J. Narayansamy, J. D. Kubicki, D. L. Sparks, M. A. A. Schoonen and D. R. Strongin, Mechanistic aspects of pyrite oxidation in an oxidizing gaseous environment: An in situ HATR-IR isotope study, Environ. Sci. Technol., 39, 7576-7584 (2005).

89. J. S. Wong and Y. S. Yen, Intriguing absorption-band behavior of IR reflectance spectra of silicon dioxide on silicon, Appl. Spectrosc., 42, 598-604 (1988).

90. D. W. Berreman, Infrared absorption at longitudinal optic frequency in cubic crystal films, Phys. Rev., 130, 2193-\& (1963).

91. E. G. Ehlers and J. D. Birle, Electropolishing of pyrite, Am. Mineral., 49, 800-\& (1964).

92. K. K. Mishra and K. Osseoasare, Photodissolution of coal pyrite, Fuel, 66, 1161$1162(1987)$.

93. C. G. Liu, C. Pettenkofer and H. Tributsch, Enhancement of photoactivity in pyrite $\left(\mathrm{FeS}_{2}\right)$ interfaces by photoelectrochemical processes, Surf. Sci., 204, 537-554 (1988). 
94. E. Libowitzky, Anisotropic pyrite - a polishing effect, Phys. Chem. Miner., 21, 97-103 (1994).

95. W. A. West and A. W. C. Menzies, The vapor pressures of sulfur between $100^{\circ}$ and $550^{\circ}$ with related thermal data, J. Phys. Chem., 33, 1880-1892 (1929).

96. P. Salvador, D. Tafalla, H. Tributsch and H. Wetzel, Reaction-mechanisms at the n-FeS $2 / \mathrm{I}$ interface - an electrolyte electroreflectance study, J. Electrochem. Soc., 138, 3361-3369 (1991).

97. K. Buker, N. AlonsoVante and H. Tributsch, Photoelectrochemical investigations of complex formation phenomena on oriented n-pyrite $\left(\mathrm{FeS}_{2}\right)$ crystal surfaces, Ber. Bunsen-Ges. Phys. Chem., 100, 1808-1813 (1996).

98. A. Ennaoui and H. Tributsch, Light-induced electron-transfer and photoelectrocatalysis of chlorine evolution at $\mathrm{FeS}_{2}$ electrodes, J. Electroanal. Chem., 204, 185-195 (1986).

99. K. K. Mishra and K. Osseoasare, Aspects of the interfacial electrochemistry of semiconductor pyrite $\left(\mathrm{FeS}_{2}\right)$, J. Electrochem. Soc., 135, 2502-2509 (1988).

100. C. Chatfield, Statistics for technology, Penguin Books Inc., Baltimore, USA (1970).

101. A. J. Bard and L. R. Faulkner, Electrochemical Methodes Fundamental and Applications, John Wiley \& Sons, Inc., New York (2001).

102. C. G. Liu, C. Pettenkofer and H. Tributsch, Enhancement of photoactivity in pyrite $\left(\mathrm{FeS}_{2}\right)$ interfaces by photoelectrochemical processes, Surf. Sci., 204, 537-554 (1988). 
103. M. L. Rosenbluth and N. S. Lewis, Ideal behavior of the open circuit voltage of semiconductor liquid junctions, J. Phys. Chem., 93, 3735-3740 (1989).

104. D. Mao, K. J. Kim and A. J. Frank, Open-circuit photovoltage and charge recombination at semiconductor liquid interfaces, J. Electrochem. Soc. , 141, 1231-1236 (1994).

105. M. J. Borda, A. R. Elsetinow, D. R. Strongin and M. A. Schoonen, A mechanism for the production of hydroxyl radical at surface defect sites on pyrite, Geochim. Cosmochim. Acta, 67, 935-939 (2003).

106. D. Wei and K. OsseoAsare, Semiconductor electrochemistry of particulate pyrite - Mechanisms and products of dissolution, J. Electrochem. Soc., 144, 546-553 (1997).

107. R. T. Lowson, Aqueous oxidation of pyrite by molecular-oxygen, Chem. Rev., 82, 461-497 (1982).

108. Q. Tong and E. Johansson, Photoelectrochemical Behavior of $\mathrm{FeS}_{2}$ in Aqueous and Nonaqeuous I'// ${ }_{3}^{-}$Electrolytes, J. Electrochem. Soc., 161, H950-H954 (2014).

109. W. L. F. Armarego and C. L. L. Chai, Purification of laboratory chemicals, Butterworth-Heinemann (2003).

110. J. A. Haber and N. S. Lewis, Infrared and X-ray photoelectron spectroscopic studies of the reactions of hydrogen-terminated crystalline $\mathrm{Si}(111)$ and $\mathrm{Si}(100)$ surfaces with $\mathrm{Br}_{2}, \mathrm{I}_{2}$, and ferrocenium in alcohol solvents, J. Phys. Chem. B, 106, 3639-3656 (2002).

111. D. S. Briggs and M. P. Seah, Practical surface analysis: Auger and X-ray photoelectron spectroscopy, Wiley: New York (1990). 
112. K. B. Yatsimirskii, V. V. Nemoshkalenko, Y. P. Nazarenko, V. G. Aleshin, V. V. Zhilinskaya and N. A. Tomashevsky, Use of x-ray photoelectron and Mossbauer spectroscopies in study of iron pentacyanide complexes, J. Electron. Spectrosc. Relat. Phenom., 10, 239-245 (1977).

113. H. Konno, K. Sasaki, M. Tsunekawa, T. Takamori and R. Furuichi, X-ray photoelectron spectroscopic analysis of surface products on pyrite formed by bacterial leaching, Bunseki Kagaku, 40, 609-616 (1991).

114. B. M. Biwer and S. L. Bernasek, Electron spectroscopic study of the iron surface and its interaction with oxygen and nitrogen, J. Electron Spectrosc. Relat. Phemon., 40, 339-351 (1986).

115. J. A. Connor, M. B. Hall, I. H. Hillier, W. N. Meredith, M. Barber and Q. Herd, High-energy photoelectron-spectroscopy of transition-metal complexes .3. Direct measurement and interpretation of core level shifts between free and complexed co, and bonding in some substituted manganese pentacarbonyls, J. Chem. Soc., Faraday Trans., 69, 1677-1684 (1973).

116. M. Barber, J. A. Connor, M. F. Guest, M. B. Hall, I. H. Hillier and W. N. Meredith, High-energy photoelectron spectroscopy of transition-metal complexes .1. Bonding in substituted and unsubstituted first row carbonyls, Faraday Discuss., 54, 219$226(1972)$.

117. N. Hellgren, M. P. Johansson, E. Broitman, L. Hultman and J. E. Sundgren, Role of nitrogen in the formation of hard and elastic $\mathrm{CNx}$ thin films by reactive magnetron sputtering, Phys. Rev. B, 59, 5162-5169 (1999). 
118. O. Maida, A. Asano, M. Takahashi, H. Iwasa and H. Kobayashi, Experimental and theoretical studies of $\mathrm{Si}-\mathrm{CN}$ bonds to eliminate interface states at $\mathrm{Si} / \mathrm{SiO}_{2}$ interface, Surf. Sci., 542, 244-252 (2003).

119. M. Datta and A. Datta, In situ FTIR and XPS studies of the hexacyanoferrate redox system, J. Phys. Chem., 94, 8203-8207 (1990).

120. A. I. Melato, L. M. Abrantes and A. M. B. do Rego, $\mathrm{Fe}(\mathrm{CN})_{6}{ }^{3-}$ incorporation on Poly(3,4-ethylenedioxythiophene) films: Preparation and X-ray Photoelectron Spectroscopy characterization of the modified electrodes, Thin Solid Films, 518, 19471952 (2010).

121. C. L. Levoguer and R. M. Nix, Adsorption and decomposition of HCN on a polycrystalline Pt foil studied by TPD, MBRS, XPS and FT-RAIRS, J. Chem. Soc., Faraday Trans., 92, 4799-4807 (1996).

122. F. Honda and K. Hirokawa, On the Chemical States of Nitrogen on Iron Surfaces Reacted with Ammonia and Sodium Cyanide, Studied by X-Ray Photoelectron Spectroscopy(Chemistry), Science reports of the Research Institutes, Tohoku University. Ser. A, Physics, chemistry and metallurgy, 27, 82 (1979).

123. A. Lisowska-Oleksiak, A. P. Nowak, M. Wilamowska, M. Sikora, W. Szczerba and C. Kapusta, Ex situ XANES, XPS and Raman studies of poly(3,4ethylenedioxythiophene) modified by iron hexacyanoferrate, Synth. Met., 160, 1234-1240 (2010). 
124. Q. Tong, E. R. Young and E. Johansson, Infrared Reflection-Absorption Spectroscopy of an Isotropic Adsorbate Layer on Pyrite, J. Phys. Chem. C, 117, 2598225990 (2013). 


\title{
APPENDICES
}

\section{Appendix A. Copyright information}

1) Permission for Tong, Q.; Young, R. E.; Johansson, E. J. Phys. Chem. C. 2013,

$117,25982-25990:$

\section{http://pubs.acs.org/userimages/ContentEditor/1218205107465/dissertation.pdf}

\section{American Chemical Society's Policy on Theses and Dissertations}

\author{
If your university requires you to obtain permission, you must use the RightsLink permission system. \\ See RightsLink instructions at http://pubs.acs.org/page/copvright/permissions.html.
}

This is regarding request for permission to include your paper(s) or portions of text from your paper(s) in your thesis. Permission is now automatically granted; please pay special attention to the implications paragraph below. The Copyright Subcommittee of the Joint Board/Council Committees on Publications approved the following:

Copyright permission for published and submitted material from theses and dissertations

ACS extends blanket permission to students to include in their theses and dissertations their own articles, or portions thereof, that have been published in ACS journals or submitted to ACS journals for publication, provided that the ACS copyright credit line is noted on the appropriate page(s).

Publishing implications of electronic publication of theses and dissertation material Students and their mentors should be aware that posting of theses and dissertation material on the Web prior to submission of material from that thesis or dissertation to an ACS journal may affect publication in that journal. Whether Web posting is considered prior publication may be evaluated on a case-by-case basis by the journal's editor. If an ACS journal editor considers Web posting to be "prior publication", the paper will not be accepted for publication in that journal. If you intend to submit your unpublished paper to ACS for publication, check with the appropriate editor prior to posting your manuscript electronically.

Reuse/Republication of the Entire Work in Theses or Collections: Authors may reuse all or part of the Submitted, Accepted or Published Work in a thesis or dissertation that the author writes and is required to submit to satisfy the criteria of degree-granting institutions. Such reuse is permitted subject to the ACS' "Ethical Guidelines to Publication of Chemical Research" (http://pubs.acs.org/page/policy/ethics/index.html); the author should secure written confirmation (via letter or email) from the respective ACS journal editor(s) to avoid potential conflicts with journal prior publication*/embargo policies. Appropriate citation of the Published Work must be made. If the thesis or dissertation to be published is in electronic format, a direct link to the Published Work must also be included using the ACS Articles on Request author-directed link - see http://pubs.acs.org/page/policy/articlesonrequest/index.html 


\section{Request for Permission to Reproduce or Re-Publish ECS Material}

Please fax this form to: The Electrochemical Society (ECS), Attn: Permissions Requests, 1.609.730.0629. You may also e-mail your request to: copyright@electrochem.org. Include all the information as required on this form. Please allow 3-7 days for your request to be processed.

I am preparing a (choose one): $\Gamma$ paper $\Gamma$ chapter $\Gamma$ book $\Gamma$ thesis entitled:

Surface and electro-chemistry of iron pyrite

to be published by:

in an upcoming publication entitled:

I request permission to use the following material in the publication noted above, and request nonexclusive rights for all subsequent editions and in all foreign language translations for distribution throughout the world.

Description of material to be used-Indicate what material you wish to use (figures, tables, text, etc.) and give the full bibliographic reference for the source publication. You may attach a separate list, organized by ECS title.

Full article of "Tong, Q.; Johansson, E. Photoelectrochemical behavior of FeS2 in Aqueous and Nonaqueous I-/13- electrolytes, J. Electrochem. Soc. 2014, 161, H950-H954"

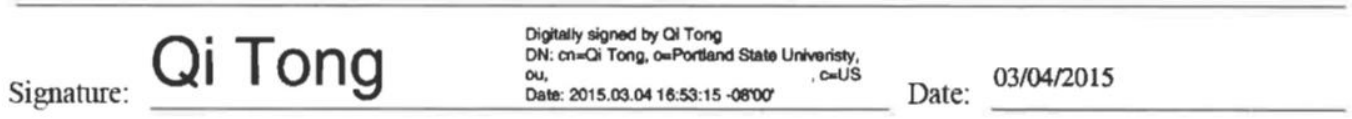

Name: Qi Tong

Address:

Telephone: Fax:

E-mail: qtong@pdx.edu

Permission is granted to include the above-referenced paper in a dissertation, provided that permission is obtained from all of the individual authors. In the dissertation, please acknowledge the authors and the citation given above, and include the words: "Reproduced by permission of ECS - The Electrochemical Society."

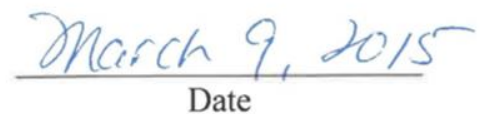

Date

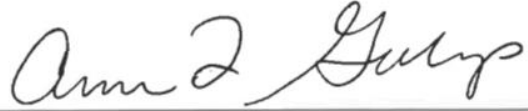

Ann F. Goedkoop, Publications Production Director 


\section{Appendix B. List of publications and presentations}

1. Tong, Q.; Johansson, E. Photoelectrochemical behavior of $\mathrm{FeS}_{2}$ in aqueous and nonaqueous $I^{-} / I_{3}{ }^{-}$electrolytes, J. Electrochem. Soc. 2014, 161, H950-H954

2. Tong, Q.; Young, R. E.; Johansson, E. Infrared reflection-absorption spectroscopy of an isotropic adsorbate layer on pyrite J. Phys. Chem. C. 2013, 117, 2598225990

3. Tong, Q.; Wang, X.; Wang, H.; Yan, M. Fabrication of glyconanoparticle microarrays Anal. Chem. 2012, 84, 3049-3052.

4. Wang, H.; Tong, Q.; Yan, M. Antifouling surfaces for proteins labeled with dyedoped silica nanoparticles Anal. Chem. 2013, 85, 23-27.

5. Kubo, T.; Wang, X.; Tong, Q.; Yan, M. Polymer-based photocoupling agent for the efficient immobilization of nanomaterials and small molecules Langmuir 2011, $27,9372-9378$

6. Wang, H.; Li, L.; Tong, Q.; Yan, M. Evaluation of photochemically immobilized poly(2-ethyl-2-oxazoline) thin films as protein-resistant surfaces ACS Applied Materials \& Interfaces 2011, 3, 3463-3471

7. Tong, Q.; Young, R. E.; Johansson, E. Influence of surface passivation on the photoresponse of iron pyrite in a non-aqueous electrolyte with non-coordinating redox couple (Manuscript in preparation) 
8. Young, R. E.; Tong, Q. and Johansson, E., Surface and electrochemistry of natural and synthetic pyrite Poster Presentation at 68th ACS Northwest Regional Meeting (NORM), 2013, Corvallis, Oregon

9. Tong, Q. and Johansson E. , The correlation between surface and near-surface chemistry of $\mathrm{FeS}_{2}$ and the photoelectrochemistry of $\mathrm{FeS}_{2}$ /liquid half-cells Poster Presentation at 248th American Chemical Society National Meeting \& Exposition, 2014, San Francisco, California

10. Tong, Q.; Young, R. E.; and Johansson E., Influence of surface treatments on the photoresponse of iron pyrite in a non-aqueous electrolyte with non-coordinating redox couples Poster presentation at 2015 MRS Spring Meeting \& Exhibit, 2015, San Francisco, California 